\author{
Universidade de São Paulo \\ Instituto de Física
}

\title{
Fotocolheita em Interface Híbrida de Molécula Orgânica e Óxido de Titânio
}

\author{
Leonardo Matheus Marion Jorge
}

Orientadora: Profa. Dra. Marília Junqueira Caldas

Tese de Doutorado apresentada ao Instituto de Física para a obtenção do título de Doutor em Ciências

Comissão examinadora:

1. Profa. Dra. Marília Junqueira Caldas (Orientadora - DFMT-IFUSP)

2. Prof. Dr. Antonio Martins Figueiredo Neto (DFEP-IFUSP)

3. Prof. Dr. Henrique Eisi Toma (IQUSP)

4. Prof. Dr. Luis Gregório Godoy de Vasconcellos Dias da Silva (DFMT-IFUSP)

5. Prof. Dr. Marlus Koehler (UFPR)

São Paulo

2013 


\section{FICHA CATALOGRÁFICA \\ Preparada pelo Serviço de Biblioteca e Informação \\ do Instituto de Física da Universidade de São Paulo}

Jorge, Leonardo Matheus Marion

Fotocolheita em interface híbrida de molécula orgânica e óxido de titânio. - São Paulo, 2013

Tese (Doutorado) - Universidade de São Paulo.

Instituto de Física. Depto. de Física dos Materiais e Mecânica.

Orientadora: Profa. Dra. Marília Junqueira Caldas Área de Concentração: Física

Unitermos: 1. Física computacional; 2. Física da matéria condensada; 3. Nanopartículas; 4. Superfície física.

$\mathrm{USP} / \mathrm{IF} / \mathrm{SBI}-040 / 2013$ 
Aos meus pais, que me deixaram sonhar. A Elisa, com quem quero realizar estes sonhos. 



\section{Agradecimentos}

Agradeço primeiramente à Profa. Dra. Marília Junqueira Caldas, cuja orientação começou já em uma conversa no início de 2003 quando pedi sua opinião sobre o Curso de Ciências Moleculares, e segui desde então.

Agradeço muito à minha família, principalmente a meus avós que tanto me apoiam.

Agradeço também aos colegas do grupo Nanomol, compartilhando os problemas e as soluções que sempre aparecem.

Também agradeço à Profa. Dra. Alice Ruini, e a todos os estudantes e pesquisadores italianos que me acolheram em meu período por lá.

A lista de amigos que tem a minha gratidão é extensa, e invariavelmente não conseguiria citar todos, mas em especial agradeço a Elton, Rebeca, "Uêba", Daniel, "Chico", "Gaia" e Seiti pelas farras gastronômicas e jogatinas, a Gustavo, Sahba e Nathalia por sempre estarem por perto, e a Filipe e Philippe pelas conversas de sala necessárias para me manter são.

E um agradecimento especial para a Sandra, pois sem a ajuda dela o tempo disponível para fazer pesquisa seria muito menor.

Agradeço à FAPESP pelo apoio financeiro. 



\section{Resumo}

É crescente o interesse, dentre os diversos tipos de dispositivos fotovoltaicos, nas células solares com corantes (dye-sensitized solar cell, DSCC). Isto é devido não só aos menores custos de produção (química molhada), mas também ao grande número de combinações orgânico/semicondutor que podem ser utilizadas, buscando as propriedades de interesse de cada dispositivo. Em uma DSSC a absorção de luz é realizada pelo material orgânico, que injeta o elétron no semicondutor para sua extração como corrente. A neutralidade da molécula é recuperada através de um eletrólito transportador de carga a partir do outro terminal.

Este problema é de difícil investigação experimental, devido ao grande número de variáveis envolvidas, já que qualquer defeito ou mudança na deposição pode alterar o processo de transferência de carga. Da mesma forma, também o estudo teórico apresenta grande dificuldade, sendo necessária a adoção de modelos simplificados para o estudo, buscando um entendimento mais profundo dos processos que ocorrem durante a absorção de luz.

Neste trabalho investigamos uma combinação de materiais de alta relevância, ácido retinóico sobre óxido de titânio na fase anatase, a mais importante para nanoestruturas. Realizamos uma investigação detalhada da aplicabilidade de diferentes metodologias ao problema, focalizando as características eletrônicas e óticas, e buscando evidências de transferência de carga. Para tal, analisamos modelos simples (materiais isolados, e outros sistemas diferentes de mesmas características), utilizando métodos vindos de diferentes postulações iniciais, como Hartree-Fock e Funcional da Densidade, e também partindo tanto de implementações $a b$ initio (primeiros princípios) como de formulações semi-empíricas. Por fim, escolhida uma metodologia ideal, estudamos sistemas mais realistas de interfaces orgânico/óxido.

Nossos resultados indicam a influência das dimensões nanoscópicas da matriz inorgânica nas propriedades de fotocolheita, assim como a grande importância da ligação covalente, presente na montagem quimissorvida molécula/superfície, que altera as propriedades óticas de ambos os componentes. 


\section{Abstract}

There is growing interest, among the many types of photovoltaic devices, in dye-sensitized solar cells (DSSC). The reasons for that are not only the lower costs of production (wet chemistry), but also the large number of organic/semiconductor combinations that can be made, depending on the properties that are interesting for each device. On a DSSC the light absorption occurs in the organic material, from which the electron is transferred to the semiconductor for current generation. The molecule regains its neutrality through an electrolyte that carries charge from the opposing terminal.

The experimental investigation of this problem is very difficult, due to the large number of variables involved, as any defect or change on the deposition can affect the charge transfer process. Similarly, the theoretical study is also difficult, making necessary the use of simplified models for the system to gain deeper understanding of the processes of light absorption.

In this work we have studied a combination of large relevancy, retinoic acid over titanium oxide, at the anatase phase, the most important for nanostrucutres. We have thoroughly investigated the applicability of several methodologies, focusing at electronic and optical characteristics, and searching for evidences of charge transfer. For this we analyzed simple models (isolated materials, and other systems that share the same characteristics), using methodologies from different starting theories, as Hartree-Fock and Density Functional Theory, and also applying both $a b$ initio and semi-empirical approaches. Once chosen the best methodology, we studied a more realistic system, true organic/oxide interfaces.

Our results show the influence of the nanoscopic dimensions of the inorganic substrate on the properties of the photoharvest, and also the fundamental role played by the covalent bond that exists on the chemisorbed deposition of molecule/surface, that alters the optical properties of both components. 


\section{Sumário}

\begin{tabular}{lll}
\hline Agradecimentos & v
\end{tabular}

Resumo vii

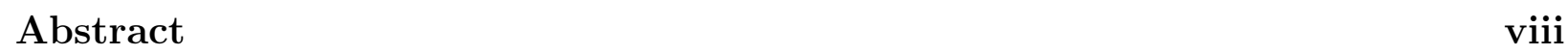

\begin{tabular}{lll}
\hline & Introdução & 1
\end{tabular}

$\begin{array}{lll}2 & \text { Métodos de campo médio para estrutura eletrônica } & 7\end{array}$

2.1 Teoria . . . . . . . . . . . . . . . . . . . . . . . . 7

2.1 () Método de Hartree-Fock . . . . . . . . . . . . . . . . . 7

2.12 Teoria do Funcional da Densidade . . . . . . . . . . . . . . . . . . . 14

2.1 .3 DFT generalizada . . . . . . . . . . . . . . . . . . . . . . . 21

2.2 Implementaçoes principais . . . . . . . . . . . . . . . . . . . . . 24

2.2 .1 Combinação Linear de Orbitais Atômicos . . . . . . . . . . . . . . . . 25

2.2 .2 Métodos Semi-empíricos . . . . . . . . . . . . . . . . . . . . . 27

2.2 .3 Ondas Planas . . . . . . . . . . . . . . . . . . . . . 30

2.2 .4 Aproximação de Pseudopotenciais . . . . . . . . . . . . . . . . . . . 31

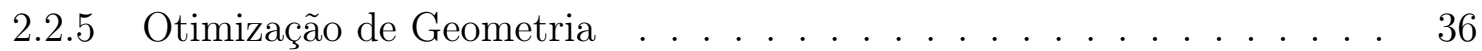

2.2 .6 Método LDA-1/2 $\ldots \ldots \ldots \ldots \ldots$

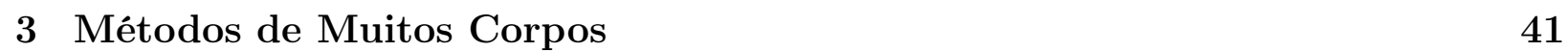

3.1 Estado Fundamental: Teoria de Perturbação . . . . . . . . . . . . . . . . . . 41

3.2 Excitações Duplas Neutras: Interação de Configuraçóes . . . . . . . . . . . . 44

3.2 .1 A Parametrização MSINDO . . . . . . . . . . . . . . . . . . . 47

3.3 Excitações de Uma Partícula: Aproximação GW . . . . . . . . . . . . . . . . . 49 
$\begin{array}{lll}4 \text { Resultados } & 59\end{array}$

4.1 Propriedades Estruturais . . . . . . . . . . . . . . . . . . . . . . . . . . . 59

4.1 Sistemas isolados . . . . . . . . . . . . . . . . . . . . . . 59

4.1 .2 Montagem Superfície-Ácido Retinóico . . . . . . . . . . . . . . . 63

4.2 Propriedades Eletrônicas: Nanoestruturas e o efeito de confinamento . . . . . 66

4.3 Propriedades Eletrônicas: Problemas no Tratamento DF"T para Sistemas Híbridos . . . . . . . . . . . . . . . . . . . . 67

4.4 Propriedades Eletrônicas e Óticas . . . . . . . . . . . . . . . . . . . 70

4.4 .1 Moléculas . . . . . . . . . . . . . . . . . . . . . 70

$4.4 .2 \mathrm{TiO}_{2} \ldots \ldots \ldots \ldots \ldots$

4.4 .3 Tiofeno sobre $\mathrm{TiO}_{2} \ldots \ldots \ldots \ldots \ldots \ldots$. . . . . . . . . . . . . . . 78

4.4 .4 Ácido Retinóico sobre $\mathrm{TiO}_{2}$. . . . . . . . . . . . . . . . . . 83

$\begin{array}{lrr}5 \text { Conclusöes } & 87\end{array}$

$\begin{array}{lr}\text { Referências } & 89\end{array}$ 


\section{Capítulo 1}

\section{Introdução}

A busca por fontes de energia limpa e renovável se torna cada vez mais importante no mundo moderno, já que o consumo cresce de forma cada vez mais rápida. No Brasil as hidrelétricas representam $70 \%$ da eletricidade gerada[M], mas ao redor do mundo as fontes fósseis representam mais de $80 \%$ da geração de energia elétrica[2].

Uma opção de energia renovável é a energia solar, que apresenta baixos custos ambientais. Sua aplicação, porém, ainda é cara, pois é baseada em Silício, e depende de uma fabricação precisa e em sala-limpa[3, 4, 5], além do desempenho apenas satisfatório na conversão de energia em larga escala (em escala laboratorial já se consegue uma eficiência de mais de 40\%[6], mas para um feixe concentrado equivalente a 947 sóis). Outro problema das células convencionais de Silício é o alto energy payback time, que é o tempo necessário para que o dispositivo gere energia equivalente àquela gasta em sua fabricação, de 1 a 4 anos[7].

Um passo na direção de reduzir os custos de células solares está na tentativa de montar, em outra arquitetura, materiais distintos, orgânicos e inorgânicos, que em princípio podem ser desordenados: são as células solares sensibilizadas por corante (DSSC, do inglês dye sensitized solar cell, também chamadas Células de Grätzel em homenagem ao seu idealizador) [8, 9, 10]. Em uma DSSC temos um óxido (em geral dióxido de titânio) como anodo, sobre o qual é montado o corante (molécula orgânica foto-ativa). Ambos os materiais estão mergulhados em um eletrólito que fecha o circuito, carregando os elétrons do cátodo (em geral de platina) de volta à molécula. Comparativamente com as células solares tradicionais de silício, em que o mesmo material serve como condutor e gerador de foto-elétrons, aqui estas funções são dissociadas, e podemos buscar materiais que melhor desempenham 
cada uma separadamente.

As células solares com corante apresentam menor custo de produção, tanto pelos custos dos materiais constituintes quanto pelo próprio processo de produção, que dá-se como química molhada, não necessitando de ambientes super-limpos. Apesar de apresentarem eficiência inferior aos modelos puramente de semicondutores tradicionais, devido ao baixo custo, resistência mecânica, e leveza, são ótimas opções para se colocar sobre telhados, por exemplo. Devido a sua produção simplificada, espera-se também que em pouco tempo atinja-se um energy payback time da ordem de dias[7]. O uso de eletrólitos líquidos, porém, traz alguns problemas relacionados à vedação e estabilidade térmica.

De forma a maximizar a superfície exposta para deposição do corante, em geral se utiliza uma deposição de nanopartículas do óxido, formando um material mesoporoso. As nanopar-

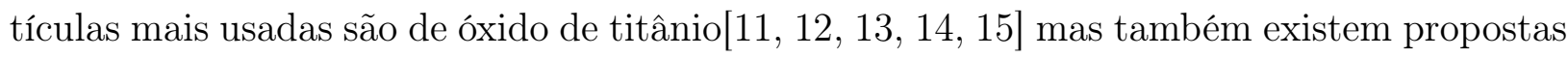
para partículas de óxido de zinco ou sulfeto cádmio [16].

O óxido de titânio é encontrado na natureza no minério Ilmenita, em rochas ou como areia (segunda areia mineral mais abundante), mas principalmente sintetizado quimicamente. É utilizado como pigmento branco, representando $70 \%$ da produção mundial de pigmentos, e aproximadamente 4,6 milhões de toneladas são consumidos mundialmente por ano. Seu uso como pigmento é tão interessante devido ao seu alto brilho e índice de refração, sendo conhecido como "branco puro", sendo utilizado não só em tintas, mas também pastas de dente, protetor solar, papéis e alimentos (por exemplo, como branqueador para leite desnatado) [17].

A fase mais estável do dióxido de titânio é a rutila; em nanoescala, porém, a fase anatase torna-se mais estável[[18], e portanto é a fase que apresenta maior interesse tecnológico em nanociência[[1.9]. Dentre as superfícies presentes em uma nanopartícula (figura LI), a mais estável[201, 21] (e assim, a mais extensa) é a superfície (101). Há indicações de que nesta face se concentram os foto-elétrons, criados pela absorção de luz, enquanto os "buracos" se acumulam na face (001) [22].

A escolha do corante é também importante: carotenóides são os pigmentos naturais mais abundantes na natureza, em paralelo com as clorofilas, e complexos carotenóide-clorofila são de fato responsáveis pela colheita de luz solar na maior parte dos organismos aptos à fotossíntese. Além disso, carotenóides (como o $\beta$-Caroteno, figura ए2) são também responsáveis por mecanismos de desativação de radicais reativos, e outros canais de fotoproteção, envolvendo de alguma forma o transporte eletrônico de um ponto a outro do complexo molecular[23]. Essas duas características encorajaram pesquisadores a trabalhar no desenho e realização 


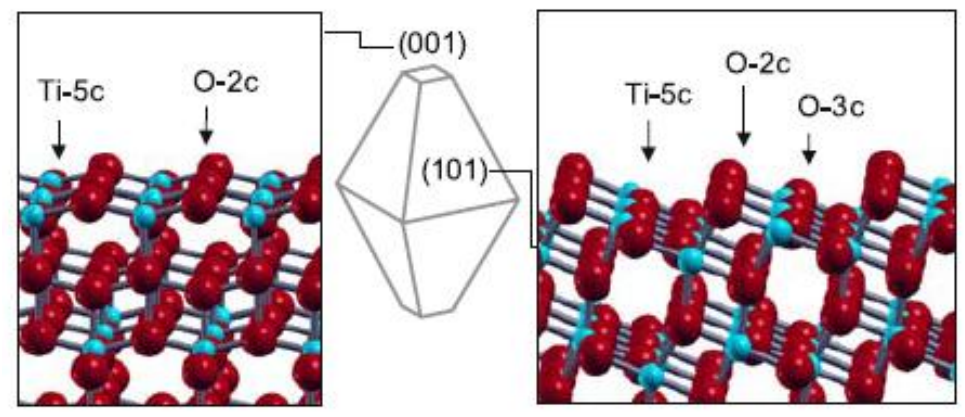

Figura 1.1: Construção de uma nanopartícula de $\mathrm{TiO}_{2}$ indicando as superfícies presentes. Retirado de[20]].

de células eletroquímicas fotovoltaicas (do tipo Grätzel) utilizando complexos envolvendo carotenóides, acoplados por exemplo a porfirinas[24].

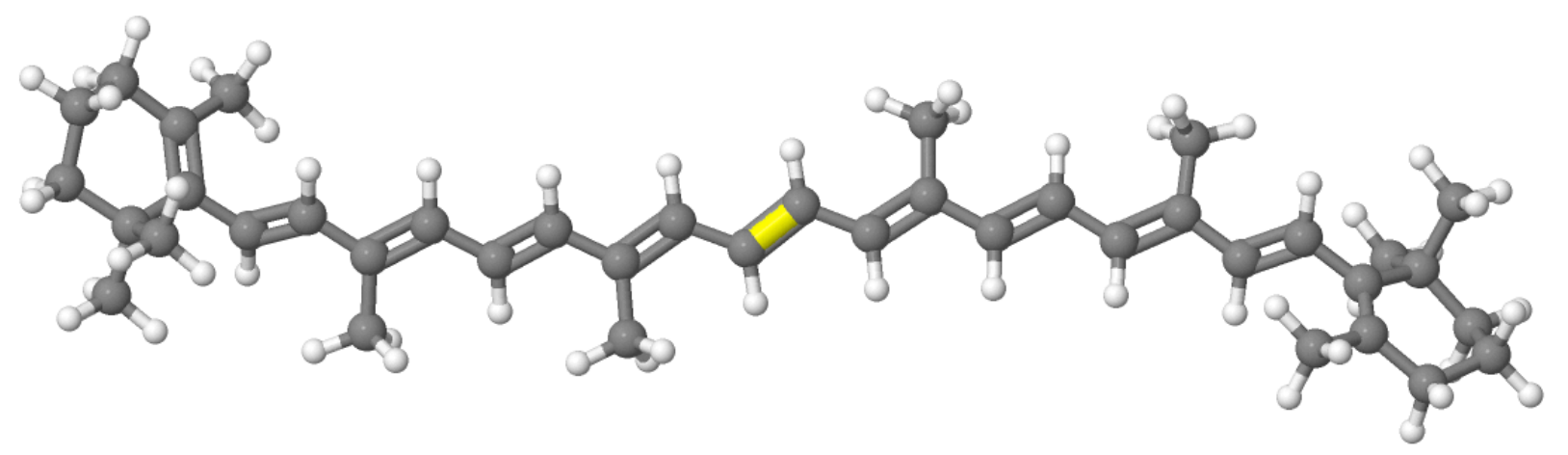

Figura 1.2: Estrutura do $\beta$-Caroteno, em destaque a ligação que dá a simetria de inversão da molécula.

Recentemente, outros derivados de carotenos, como os ácidos retinóicos, foram sintetizados para inserção em células de Grätzel. Nesse caso, a inovação é a complexação com nanopartículas semicondutoras, pois foi proposto[1T] que a fotocolheita em complexos híbridos de ácido all-trans-retinóico (ATRA, figura [.3) e $\mathrm{TiO}_{2}$ produz o cation ATRA ${ }^{+}$, o que indicaria a transferência eletrônica ATRA $\rightarrow \mathrm{TiO}_{2}$. Assim, a partir da colheita de luz pela molécula orgânica, as nanopartículas atuariam como substrato receptor de elétrons. Parte-se do pressuposto que o fotoreceptor adere à superfície da nanopartícula, aparentemente por uma ligação covalente através da cauda carboxílica. O estado de carga ou ionicidade do híbrido resultante no estado fundamental (figura 4.4) ainda é motivo de pesquisa e controvérsia[[2].

Neste trabalho buscamos a investigação de propriedades estruturais, eletrônicas e óti- 


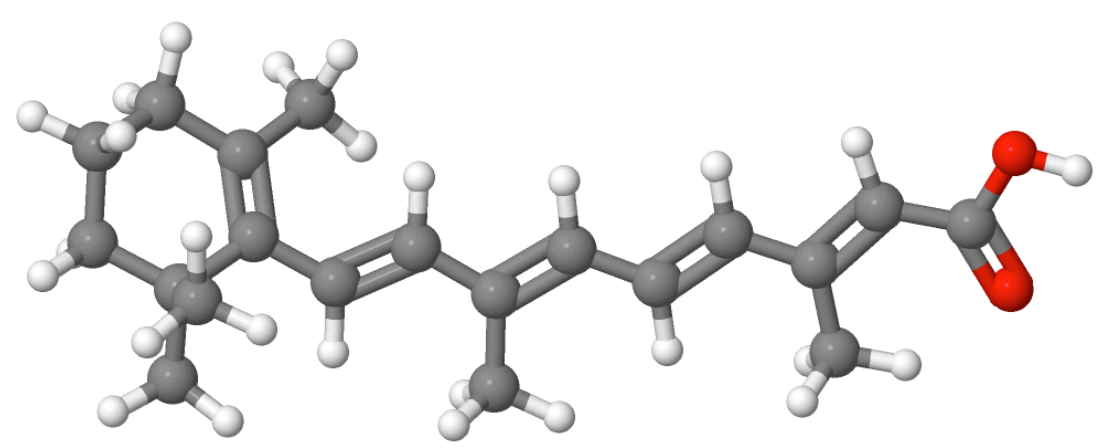

Figura 1.3: Estrutura do ácido all-trans-retinóico.

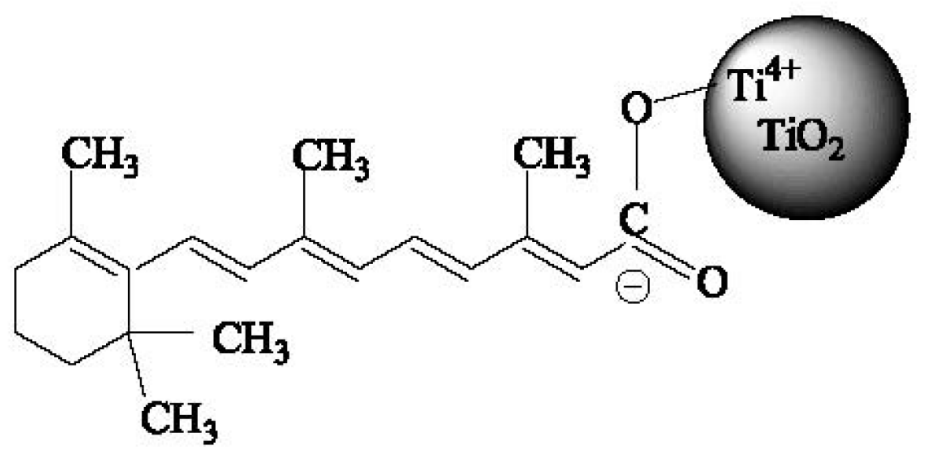

Figura 1.4: Proposta de quimissorção do ácido retinóico em nanopartícula de $\mathrm{TiO}_{2}$, de acordo com [14].

cas de montagens de ácidos retinóicos sobre filmes nanométricos de $\mathrm{TiO}_{2}$. A dinâmica de excitação em carotenóides, livres ou em solução, já é bastante estudada do ponto de vista experimental, dada a sua importância para a fotossíntese, entretanto ainda existem muitos pontos não elucidados[23]. Já o estudo teórico é mais recente, dada a complexidade do sistema, e tem sido abordado[25] por técnicas de uso corrente em química quântica, e sempre para as moléculas isoladas [26, 27] com inferências quanto à dinâmica em complexos moleculares [28, [2.9].

O estudo completo de um sistema fotoreceptor/semicondutor, porém, demanda análise totalmente diferente. Alguns trabalhos da literatura[30, 31, 32] que tentaram abordar este problema optaram por simular o material semicondutor através de um aglomerado de pouquíssimos átomos, longe de se equiparar a uma nanopartícula. O estudo de sistemas da ordem de grandeza dos reais, porém, é impraticável computacionalmente, e por isso adota- 
mos o uso da periodicidade (filmes 2D) para a descrição do nosso sistema. Não queremos implicar com isto que o sistema real seja por si periódico, mas sim que, na escala de estudo (cerca de $10 \AA ̊$ lateralmente), a descrição periódica é mais adequada que "clusters" compostos por poucas unidades químicas de $\mathrm{TiO}_{2}$.

Nosso estudo deu-se em duas etapas, em que iniciamos pela descrição dos sistemas componentes de forma individual, varrendo um amplo conjunto metodológico para verificar a adequação de cada um ao problema, e apenas então iniciamos o estudo da montagem molécula-óxido. Para a obtenção das geometrias atômicas utilizamos minimização de energia em cálculos de Teoria do Funcional da Densidade (Density Functional Theory, DFT), na Aproximação da Densidade Local (Local Density Approximation, LDA).

A metodologia do estado-da-arte em estrutura eletrônica para obtenção de estados excitados, como nos interessa aqui, parte da teoria de perturbação de muitos corpos aplicável ao ponto de partida da DFT. Faz uso de expansões em termos de funções de Green e é conhecida diretamente como GW. Sua aplicação para sistemas com número grande de átomos, ou sistemas mais complexos, demanda um alto poder computacional e é por vezes proibitivo. Deste modo, o uso de metodologias mais simples faz-se necessário, e adotamos como padrão, para verificar a qualidade de tais metodologias, os resultados GW para os sistemas simples.

Por exemplo, cálculos DFT sabidamente subestimam os gaps de energia, uma das propriedades mais importantes da estrutura eletrônica para o cálculo futuro de propriedades óticas do sistema. Testamos diversas propostas de melhorar a descrição, como o uso de funcionais híbridos ou a metodologia LDA-1/2, mas nenhuma foi capaz de descrever satisfatoriamente ambos os sistemas orgânico e óxido separadamente, impedindo então a sua adoção para o sistema completo.

A abordagem que escolhemos foi através da teoria Hartree-Fock em metodologia semiempírica parametrizada MSINDO. Esta metodologia já havia sido aplicada para sistemas semelhantes de adsorção de moléculas pequenas a superfícies de $\mathrm{TiO}_{2}$ [33, 34], e destaca-se das demais metodologias semi-empíricas por possibilitar o estudo de sistemas periódicos. Nesse caso, as propriedades óticas foram obtidas em cálculo de Interação de Configurações (Configuration Interaction, CI), o que nos permite também obter informações sobre transferência de carga.

Obtivemos muito boa qualidade para os resultados de sistemas simples, incluindo ainda um segundo modelo orgânico/óxido de interesse também para fotocolheita (tiofeno sobre dióxido de titânio) em células fotovoltaicas[35].

A seguir, descrevemos as metodologias utilizadas em certo detalhe, separadas de acordo 
com o formalismo teórico em que estão baseadas. Em seguida apresentamos nossos resultados, começando pela análise metodológica dos sistemas isolados e então prosseguindo para a análise das propriedades eletrônicas e óticas das montagens orgânico/óxido, e por fim apresentamos nossas conclusões. 


\section{Capítulo 2}

\section{Métodos de campo médio para estrutura eletrônica}

A aproximação de campo médio é a aproximação principal dos métodos Hartree-Fock e da implementação de Kohn-Sham da Teoria do Funcional da Densidade, metodologias que formam a base da pesquisa em estrutura eletrônica. Nesta aproximação um elétron não interage especificamente com cada um dos outros, mas sim com um campo médio criado pelos demais elétrons, e com isso o problema original de $\mathrm{N}$ partículas recai em uma forma mais simples de N problemas de uma partícula. Neste contexto consegue-se uma boa descrição de propriedades do estado fundamental, em especial da geometria de variados tipos de sistemas.

Esta aproximação sabidamente apresenta problemas quando estudamos propriedades relacionadas a estados excitados, como o gap fundamental de energias de semicondutores e isolantes; devido ao custo computacional extremamente reduzido, em relação aos métodos de muitos corpos, existem diversas tentativas de melhorar a descrição destas propriedades, sem deixar a aproximação de campo médio. Descrevemos brevemente os pontos relevantes abaixo destas metodologias, e na sessão seguinte alguns detalhes de suas implementações.

\section{$2.1 \quad$ Teoria}

\subsubsection{O Método de Hartree-Fock}

O método de Hartee-Fock foi um dos primeiros métodos de estrutura eletrônica a se estabelecer. Apesar de sua implementação para sistemas cristalinos não ser tão comum, no 
estudo de sistemas moleculares é um método de grande aplicabilidade, principalmente com o uso de bases locais analíticas.

O objetivo final é resolver o problema de muitos elétrons sob ação de um potencial externo, ou seja, obter a função de onda total que represente o sistema, dado um Hamiltoniano de interação entre as partículas.

A idéia original de Hartree[36] é decompor a função de onda total do sistema de N partículas em um produto de funções de uma partícula. Como o Hamiltoniano resultante apresenta dependência com a função de onda, foi proposto também que o problema fosse resolvido de forma iterativa, ou seja, que a partir de uma função de onda inicial fosse criado um Hamiltoniano, que ao ser resolvido nos forneceria uma nova função de onda. Com esta nova função de onda inicia-se um novo ciclo, até que a mudança na energia total do sistema seja menor que um critério de convergência. Esta forma de resolução do problema se denomina autoconsistente, pois o ciclo só é interrompido quando a diferença entre a função de onda de entrada e de saída é muito pequena, abaixo de um critério pré-definido.

Consideremos a função de onda de um elétron

$$
\begin{aligned}
\psi_{\kappa}^{\mu} & =\psi_{\kappa}\left(x^{\mu}, y^{\mu}, z^{\mu}, s^{\mu}\right) \\
& =\varphi_{\kappa}\left(x^{\mu}, y^{\mu}, z^{\mu}\right) \eta_{\kappa}\left(s^{\mu}\right)=\varphi_{\kappa}^{\mu} \eta_{\kappa}^{\mu}
\end{aligned}
$$

onde $\mu$ se refere ao elétron, $\kappa$ à função de onda espacial, e é incluído o spin

$$
\eta_{\kappa}^{\mu}=\left\{\begin{array}{c}
\alpha^{\mu} \\
\beta^{\mu}
\end{array}\right.
$$

em que supomos que o campo externo a que está sujeito o elétron não acopla espaço-spin.

A aproximação proposta por Hartree considera a função de onda total de um sistema de $\mathrm{N}$ elétrons como composta de um produto de $\mathrm{N}$ funções de onda de um elétron, ou seja, os elétrons são independentes, não há nenhuma correlação entre eles. A proposta de Fock[37] foi a antissimetrização do produto das funções de onda de um elétron. Com ela, ainda não é incorporada a correlação eletrônica espacial, porém ao adotar uma combinação antissimétrica destes produtos garantimos que o sistema respeite a estatística de FermiDirac perante a troca entre dois elétrons. Essa combinação antissimétrica de N funções de 
um elétron fora já proposta por Slater, e é conhecida por Determinante de Slater:

$$
\Psi=\frac{1}{\sqrt{N !}}\left|\begin{array}{cccc}
\psi_{1}^{1} & \psi_{2}^{1} & \cdots & \psi_{N}^{1} \\
\psi_{1}^{2} & \psi_{2}^{2} & \cdots & \psi_{N}^{2} \\
\vdots & \vdots & \ddots & \vdots \\
\psi_{1}^{N} & \psi_{2}^{N} & \cdots & \psi_{N}^{N}
\end{array}\right|
$$

Para que este determinante seja não nulo, as funções $\psi_{\kappa}^{\mu}$ devem ser linearmente independentes. Podemos sempre admitir, sem perda de generalidade, que elas são também ortonormais entre si (já que sempre existe uma matriz de transformação que leva um conjunto linearmente independente a um conjunto ortonormal).

Como a função de onda total é normalizada, a energia do sistema é dada por:

$$
E=\langle\Psi|\mathcal{H}| \Psi\rangle
$$

onde $\mathcal{H}$ é o Hamiltoniano do sistema:

$$
\begin{array}{r}
\mathcal{H}=\sum_{\mu} \mathcal{H}^{\mu}+\frac{1}{2} \sum_{\mu \neq \nu} \mathcal{V}^{\mu \nu} \\
\mathcal{H}^{\mu}=\mathcal{T}^{\mu}+\mathcal{U}=-\frac{\hbar^{2}}{2 m} \nabla_{\mu}^{2}+\mathcal{U}
\end{array}
$$

com $\mathcal{H}^{\mu}$ sendo o hamiltoniano de uma partícula do $\mu$-ésimo elétron, composto pelo termo cinético $\mathcal{T}$ e pelo potencial externo $\mathcal{U}$, e $\mathcal{V}^{\mu \nu}$ a interação coulombiana entre os elétrons $\mu$ e $\nu$ (o fator $1 / 2$ surge devido à contagem dupla dos pares de elétrons).

Ao calcular a energia surgem dois termos, um que depende apenas das coordenadas de um elétron, e outro cujo cálculo depende das coordenadas de dois elétrons. Para o primeiro termo, com a substituição do determinante de Slater, e levando em conta a ortogonalidade dos MOs, temos

$$
\left\langle\Psi\left|\sum_{\mu} \mathcal{H}^{\mu}\right| \Psi\right\rangle=\sum_{i} H_{i}
$$

onde

$$
H_{i}=\bar{H}_{i}=\left\langle\psi_{i}^{\mu}\left|\mathcal{H}^{\mu}\right| \psi_{i}{ }^{\mu}\right\rangle
$$


Já para o segundo termo, a substituição da função antissimetrizada nos dá:

$$
\frac{1}{2}\left\langle\Psi\left|\sum_{\mu \neq \nu} \mathcal{V}^{\mu \nu}\right| \Psi\right\rangle=\frac{1}{2} \frac{1}{N !} \sum_{\mu \neq \nu}\left|\begin{array}{cccc}
\left\langle\psi_{1}^{1}\right| & \left\langle\psi_{2}^{1}\right| & \cdots & \left\langle\psi_{N}^{1}\right| \\
\left\langle\psi_{1}^{2}\right| & \left\langle\psi_{2}^{2}\right| & \cdots & \left\langle\psi_{N}^{2}\right| \\
\vdots & \vdots & \ddots & \vdots \\
\left\langle\psi_{1}^{N}\right| & \left\langle\psi_{2}^{N}\right| & \cdots & \left\langle\psi_{N}^{N}\right|
\end{array}\right| \mathcal{V}^{\mu \nu}\left|\begin{array}{cccc}
\left|\psi_{1}^{1}\right\rangle & \left|\psi_{2}^{1}\right\rangle & \cdots & \left|\psi_{N}^{1}\right\rangle \\
\left|\psi_{1}^{2}\right\rangle & \left|\psi_{2}^{2}\right\rangle & \cdots & \left|\psi_{N}^{2}\right\rangle \\
\vdots & \vdots & \ddots & \vdots \\
\left|\psi_{1}^{N}\right\rangle & \left|\psi_{2}^{N}\right\rangle & \cdots & \left|\psi_{N}^{N}\right\rangle
\end{array}\right|
$$

Para cada um dos $N$ ! termos do primeiro determinante deveríamos expandir o segundo determinante obtendo mais $N$ ! termos. Entretanto, como cada termo da interação depende apenas das coordenadas dos elétrons $\mu$ e $\nu$, e as funções de onda $\psi$ são ortonormais, todos os termos em que os demais elétrons estejam em orbitais diferentes automaticamente se anulam. Restam desta forma apenas os termos em que todos os elétrons estão ocupando os mesmos orbitais, ou os termos em que apenas os elétrons $\mu$ e $\nu$ trocam de orbitais, e que pela antissimetrização levam o sinal negativo:

$$
\frac{1}{2}\left\langle\Psi\left|\sum_{\mu \neq \nu} \mathcal{V}^{\mu \nu}\right| \Psi\right\rangle=\frac{1}{2} \sum_{i \neq j}\left\langle\psi_{i}^{\mu} \psi_{j}^{\nu}\left|\mathcal{V}^{\mu \nu}\right| \psi_{i}^{\mu} \psi_{j}^{\nu}\right\rangle-\left\langle\psi_{i}^{\mu} \psi_{j}^{\nu}\left|\mathcal{V}^{\mu \nu}\right| \psi_{j}^{\mu} \psi_{i}^{\nu}\right\rangle
$$

onde passamos da soma nos elétrons à soma nos orbitais.

Para simplificar a notação, utilizamos as seguintes definições:

$$
\begin{array}{r}
J_{i j}=J_{j i}=\bar{J}_{i j}=\bar{J}_{i j}=\left\langle\psi_{i}^{\mu} \psi_{j}^{\nu}\left|\mathcal{V}^{\mu \nu}\right| \psi_{i}^{\mu} \psi_{j}^{\nu}\right\rangle \\
K_{i j}=K_{j i}=\bar{K}_{i j}=\bar{K}_{i j}=\left\langle\psi_{i}^{\mu} \psi_{j}^{\nu}\left|\mathcal{V}^{\mu \nu}\right| \psi_{j}^{\mu} \psi_{i}^{\nu}\right\rangle
\end{array}
$$

respectivamente, para os chamados termos direto (ou coulombiano) $J$ e de troca $K$. No termo direto os orbitais à esquerda e à direita do operador possuem a mesma ocupação, ao passo que no termo de troca os orbitais de cada lado apresentam ocupação trocada. $J$ e $K$ podem também ser reescritos em termos dos operadores

$$
\begin{aligned}
& \mathcal{J}_{i}\left|\psi_{j}^{\mu}\right\rangle=\left\langle\psi_{i}^{\nu}\left|\mathcal{V}^{\mu \nu}\right| \psi_{i}^{\nu}\right\rangle\left|\psi_{j}^{\mu}\right\rangle \\
& \mathcal{K}_{i}\left|\psi_{j}^{\mu}\right\rangle=\left\langle\psi_{i}^{\nu}\left|\mathcal{V}^{\mu \nu}\right| \psi_{j}^{\nu}\right\rangle\left|\psi_{i}^{\mu}\right\rangle
\end{aligned}
$$


Chegamos assim à equação para a energia total do sistema:

$$
E=\sum_{i} H_{i}+\frac{1}{2} \sum_{i j}\left(J_{i j}-K_{i j}\right)
$$

Um fato interessante a se notar aqui é que os termos diagonais $i=j$ não precisam ser excluídos da somatória; eles se anulam naturalmente, já que $J_{i i}=K_{i i}$. Veremos adiante que isto não ocorre na DFT, dando origem ao problema da "autointeração" do elétron.

Esta equação para a energia, porém, ainda não nos indica como obter a função de onda do estado fundamental de nosso sistema. Para isto deve ser utilizado o Princípio Variacional, que diz que dado o funcional energia

$$
E[\Psi]=\langle\Psi|\mathcal{H}| \Psi\rangle
$$

então

- $E[\Psi] \geq E_{0}$, onde $E_{0}$ é a energia do estado fundamental to Hamiltoniano $\mathcal{H}$, e

- $E=E_{0}$ se e somente se $\Psi$ é a função de onda exata do estado fundamental.

Como $E_{0}$ é um ponto de mínimo do funcional $E[\Psi]$ quando $\Psi=\Psi_{0}$ é o estado fundamental, então

$$
\frac{\delta}{\delta \Psi} E\left[\Psi_{0}+\delta \Psi\right]-\sum_{i j} \varepsilon_{i j}\left(\left\langle\psi_{i}^{\mu} \mid \psi_{j}^{\mu}\right\rangle-\delta_{i j}\right)=0
$$

para pequenas variações $\delta \Psi$ ao redor do estado fundamental. A variável $\varepsilon$ é introduzida como um multiplicador de Lagrange de forma a garantir que os orbitais se mantenham ortonormais.

Utilizando cálculo de variações, pode-se reescrever a equação acima como:

$$
\mathcal{F}\left|\psi^{\mu}\right\rangle=\mathcal{H}^{\mu}\left|\psi^{\mu}\right\rangle+\sum_{j}\left(\mathcal{J}_{j}-\mathcal{K}_{j}\right)\left|\psi^{\mu}\right\rangle=\varepsilon\left|\psi^{\mu}\right\rangle
$$

$\mathrm{ou}$

$$
F_{i}=H_{i}+\sum_{j}\left(J_{i j}-K_{i j}\right)=\varepsilon_{i i}=\varepsilon_{i}
$$

conhecida como Equação de Hartree-Fock, na qual foi definido o operador de Fock $\mathcal{F}$. Esta equação, diferentemente da equação 2.14 , representa um problema de um elétron, e não mais 
de N elétrons, simplificando assim a sua resolução.

Este problema de auto-valores não apresenta solução única; os $\mathrm{N}$ menores auto-valores representam a energia de uma partícula dos estados ocupados, e a partir de suas funções $\psi$ pode-se obter então o determinante de Slater da função de onda total do estado fundamental do sistema. Já a energia total do sistema não é uma simples soma das energias de uma partícula $\varepsilon$, mas pode ser obtida através da equação

$$
E=\sum_{i} H_{i}+\frac{1}{2} \sum_{i j}\left(J_{i j}-K_{i j}\right)=\sum_{i} \varepsilon_{i}-\frac{1}{2} \sum_{i j}\left(J_{i j}-K_{i j}\right)
$$

A equação $2 . T 7$ porém não pode ser resolvida diretamente para $\psi$, já que o operador de Fock $\mathcal{F}$ depende de $\psi$ (e também de todos os demais orbitais ocupados do sistema). Desta forma a metodologia adotada é a da autoconsistência, que consiste na busca iterativa pela solução. Ela será descrita em mais detalhes na sessão [2.2.], quando adotamos uma base para a descrição das funções de onda.

É interessante notar que as energias $\varepsilon$ foram introduzidas simplesmente como multiplicadores de Lagrange. Sua interpretação, porém, é dotada de significado físico, através do Teorema de Koopmans[38], demonstrado a seguir.

Seja $\Psi_{0}$ a função de onda do estado fundamental, e $\Psi_{i}$ a função de onda do estado ionizado que teve o elétron do orbital $i$ removido, desconsiderando qualquer relaxação estrutural ou eletrônica. Sua energia total é dada (de acordo com a equação [2.14) por:

$$
\begin{aligned}
E\left(\Psi_{i}\right)= & \sum_{j \neq i} H_{j}+\frac{1}{2} \sum_{j \neq i} \sum_{k \neq i}\left(J_{j k}-K_{j k}\right) \\
= & \sum_{j} H_{j}+\frac{1}{2} \sum_{j} \sum_{k}\left(J_{j k}-K_{j k}\right) \\
& -H_{i}-\frac{1}{2}\left(\sum_{k}\left(J_{i k}-K_{i k}\right)+\sum_{j}\left(J_{j i}-K_{j i}\right)\right)-\frac{1}{2}\left(J_{i i}-K_{i i}\right)
\end{aligned}
$$

onde expandimos a dupla somatória em $j$ e $k$ diferentes de $i$ em duas somatórias distintas, e subtraimos o termo diagonal que é somado duas vezes.

Entretanto, como o termo diagonal se anula (conforme discutido acima sobre a autointeração), e $J$ e $K$ são simétricos, podemos então agrupar as duas somatórias simples em 
uma:

$$
E\left(\Psi_{i}\right)=E\left(\Psi_{0}\right)-\left(H_{i}+\sum_{j}\left(J_{i j}-K_{i j}\right)\right)
$$

e então, de acordo com a equação de Hartree-Fock, a energia necessária para ionizar um elétron do orbital $i$ é

$$
I_{i}=E\left(\Psi_{i}\right)-E\left(\Psi_{0}\right)=-F_{i}=-\varepsilon_{i}
$$

Ou seja, a energia de um orbital ocupado por uma partícula corresponde à energia necessária para sua remoção. No caso do orbital ocupado de mais alta energia (Highest Occupied Molecular Orbital, HOMO), a sua energia corresponderia ao potencial de ionização do sistema. Esta formulação admite que os demais orbitais não relaxam ou seja, não são afetados por esta remoção de um elétron do orbital $i$; claramente esta hipótese não é válida sempre, principalmente quando a remoção se faz em um orbital de baixa energia, mas é plenamente aceitável para aquele de mais alta energia HOMO, e mais razoável quanto mais delocalizada essa densidade orbital (pois espera-se uma relaxação menor dos demais elétrons com a retirada de um elétron delocalizado em relação à retirada de um elétron bem localizado). Assim, para o potencial de ionização IP de um sólido infinito, deveria ser bastante razoável, e mesmo para o IP de moléculas em geral. Se por outro lado efeitos de correlação são importantes, teremos uma correção que pode ser mais ou menos substancial e, neste caso, devemos passar a métodos que serão descritos mais à frente, como a teoria de Perturbação de Møller-Plesset, ou cálculos com Interação de Configurações incluindo excitações duplas.

Para energias de excitação de um elétron de um estado ocupado $i$ para um estado desocupado a uma abordagem semelhante pode ser realizada. Se $\Psi_{i}^{a}$ representa este sistema, um desenvolvimento semelhante ao descrito acima nos dá a chamada "correção de orbital virtual", e a energia correspondente a tal "excitação" pode ser escrita como

$$
E\left(\Psi_{i}^{a}\right)-E\left(\Psi_{0}\right)=\varepsilon_{a}-\varepsilon_{i}-\left(J_{a i}-K_{a i}\right)
$$

Esta associação de energias a cada determinante de Slater está na base da metodologia CI, que será descrita adiante. 


\subsubsection{Teoria do Funcional da Densidade}

A idéia de tratar o problema eletrônico a partir da densidade eletrônica teve início em 1927 com os modelos de Thomas[39] e Fermi[40], e posteriormente em 1951 por Slater[41] (método $X \alpha$ ), mas foi apenas em 1964 com o Teorema de Hohenberg e Kohn[42] que foi provado que utilizando diretamente a densidade (uma função de $\mathbb{R}^{3}$ ), e não, como no método de Hartree-Fock, a função de onda total de $\mathrm{N}$ partículas (uma função de $\mathbb{R}^{3 N}$ ), não há perda de informação referente ao estado fundamental do sistema, ou seja, que qualquer observável relativo ao estado fundamental pode ser obtido a partir da densidade.

Com o embasamento teórico definido, faltava apenas um modo eficiente e preciso de utilizar a densidade. Este método surgiu no ano seguinte, quando Kohn e Sham[43], propuseram uma aproximação que forma a base do que hoje se entende por Teoria do Funcional da Densidade de Kohn-Sham, DFT.

\subsubsection{Teorema de Hohenberg e Kohn}

O Teorema de Hohenberg e Kohn divide-se em duas partes: a primeira mostra que qualquer observável $\mathcal{O}$ pode ser escrito como um funcional da densidade do estado fundamental do sistema eletrônico; a segunda define um "Funcional Energia", que ao ser minimizado corresponde à energia desse estado.

Consideramos o Hamiltoniano independente do tempo dado por:

$$
\mathcal{H}=\mathcal{T}+\mathcal{U}+\mathcal{V}
$$

onde $\mathcal{V}$ é o termo de interação de duas partículas e tem uma forma fixa, e $\mathcal{U}$ é um potencial externo. Definimos então o conjunto $\mathfrak{U}$ como o conjunto de potenciais $\mathcal{U} \in \mathfrak{U}$ de tal forma o Hamiltoniano correspondente apresente como auto-estado um estado fundamental não degenerado de $\mathrm{N}$ fermions:

$$
\mathcal{H}|\Psi\rangle=E_{0}|\Psi\rangle
$$

Se agruparmos todos estes possíveis estados fundamentais no conjunto $\boldsymbol{\Psi}$, podemos então admitir que através da equação de Schrödinger acima existe uma função

$$
C: \mathfrak{U} \mapsto \Psi
$$


que relaciona um potencial $\mathcal{U} \in \mathfrak{U}$ a uma função $\Psi \in \Psi$.

Para cada estado fundamental contido em $\boldsymbol{\Psi}$, podemos calcular sua densidade:

$$
n(\boldsymbol{r})=\langle\Psi|(\boldsymbol{r})| \Psi\rangle=N \sum_{\alpha} \int \mathrm{d} x_{2} \cdots \int \mathrm{d} x_{N}\left|\Psi\left(\boldsymbol{r}_{\alpha}, x_{2}, \cdots, x_{N}\right)\right|^{2}
$$

estabelecendo assim uma segunda função

$$
D: \Psi \mapsto \mathfrak{N}
$$

que leva as funções de onda de estado fundamental nas suas densidades.

Para demonstrar a primeira afirmação do Teorema de Hohenberg-Kohn, basta-nos provar que as funções $C$ e $D$, definidas acima, são inversíveis, ou seja, que podemos escrever o potencial externo $\mathcal{U}$ como função da função de onda, e esta por sua vez como função da densidade. Isto é interessante pois, dada uma densidade de estado fundamental, poderíamos encontrar o seu respectivo Hamiltoniano e a partir deles encontrar as demais propriedades, como mostrado abaixo.

$$
\begin{array}{r}
(D \circ C): \mathfrak{U} \mapsto \mathfrak{N} \Rightarrow \quad(D \circ C)^{-1}: \mathfrak{N} \mapsto \mathfrak{U} \\
\langle\Psi|\mathcal{O}| \Psi\rangle=\langle\Psi[n]|\mathcal{O}| \Psi[n]\rangle=O[n]
\end{array}
$$

Para que a função $C$ seja inversível, dois potenciais cuja diferença não é uma constante não podem gerar um mesmo estado fundamental. Vamos supor por absurdo que isso é falso, ou seja, que dois potenciais diferentes geram um mesmo estado fundamental. Teríamos então:

$$
\begin{array}{r}
(\mathcal{T}+\mathcal{V}+\mathcal{U})|\Psi\rangle=E_{0}|\Psi\rangle \\
\left(\mathcal{T}+\mathcal{V}+\mathcal{U}^{\prime}\right)|\Psi\rangle=E_{0}^{\prime}|\Psi\rangle
\end{array}
$$

Subtraindo ambas equações obtemos:

$$
\left(\mathcal{U}-\mathcal{U}^{\prime}\right)|\Psi\rangle=\left(E_{0}-E_{0}^{\prime}\right)|\Psi\rangle
$$

que é equivalente a dizer que $u(\boldsymbol{r})=u^{\prime}(\boldsymbol{r})+$ cte, já que $\mathcal{U}$ e $\mathcal{U}^{\prime}$ são operadores multiplicativos. Mas isto contradiz a hipótese inicial que os operadores são diferentes, levando ao absurdo e 
concluindo a demonstração que $C$ é de fato inversível.

Para a função $D$, de forma análoga, temos que mostrar que duas funções de onda de estados fundamentais diferentes não geram uma mesma densidade. Temos, de acordo com o princípio variacional (também chamado princípio de Ritz), que:

$$
\begin{array}{lll}
E_{0}=\langle\Psi|\mathcal{H}| \Psi\rangle & <\left\langle\Psi^{\prime}|\mathcal{H}| \Psi^{\prime}\right\rangle \\
E_{0}^{\prime}=\left\langle\Psi^{\prime}\left|\mathcal{H}^{\prime}\right| \Psi^{\prime}\right\rangle & <\left\langle\Psi\left|\mathcal{H}^{\prime}\right| \Psi\right\rangle
\end{array}
$$

Mas podemos escrever também que:

$$
\left\langle\Psi^{\prime}|\mathcal{H}| \Psi^{\prime}\right\rangle=\left\langle\Psi^{\prime}\left|\mathcal{H}^{\prime}+\mathcal{U}-\mathcal{U}^{\prime}\right| \Psi^{\prime}\right\rangle=E_{0}^{\prime}+\int n^{\prime}(\boldsymbol{r})\left[u(\boldsymbol{r})-u^{\prime}(\boldsymbol{r})\right] \mathrm{d} \boldsymbol{r}
$$

e, equivalentemente:

$$
\left\langle\Psi\left|\mathcal{H}^{\prime}\right| \Psi\right\rangle=E_{0}+\int n(\boldsymbol{r})\left[u^{\prime}(\boldsymbol{r})-u(\boldsymbol{r})\right] \mathrm{d} \boldsymbol{r}
$$

Admitindo por absurdo que as duas funções de onda geram uma mesma densidade $n(\boldsymbol{r})=$ $n^{\prime}(\boldsymbol{r})$, somando as desigualdades [2.3:3,2:34 e substituíndo os termos acima, chegamos a

$$
E_{0}+E_{0}^{\prime}<E_{0}+E_{0}^{\prime}
$$

que é obviamente falsa, demonstrando assim a afirmação inicial. E com isso terminamos a demonstração da primeira parte do teorema.

Para a segunda parte, basta apenas definir o "Funcional Energia"

$$
E_{U_{0}}[n]:=\left\langle\Psi[n]\left|\mathcal{T}+\mathcal{V}+\mathcal{U}_{0}\right| \Psi[n]\right\rangle
$$

onde as funções $\Psi[n]$ sáo definidas pela função $D^{-1}$.

Pelo princípio de Ritz, temos que

$$
\min _{\Psi \in \Psi}\langle\Psi|H| \Psi\rangle=\left\langle\Psi^{0}|H| \Psi^{0}\right\rangle=E_{0}
$$

Mas através do teorema anterior, também é válido que:

$$
\min _{n \in \mathfrak{N}} E_{U_{0}}[n]=E_{U_{0}}\left[n_{0}\right]=E_{0} \quad, \quad n_{0}=\left\langle\Psi^{0}|(\boldsymbol{r})| \Psi^{0}\right\rangle
$$




\subsubsection{Equações de Kohn-Sham}

O Teorema de Hohenberg-Kohn mostra a validade de se usar a densidade como variável de cálculo, mas não mostra como fazê-lo, em especial por não conhecermos a forma funcional dos termos da Hamiltoniana. As equações de Kohn-Sham, porém, indicam um método no qual novamente, como no Hartree-Fock, substitui-se o problema de partículas interagentes por outro de partículas não interagentes submetidas a potencial efetivo, cuja solução é mais simples.

Seja um sistema interagente, de hamiltoniana $\mathcal{H}=\mathcal{T}+\mathcal{U}+\mathcal{V}$, com estado fundamental $\Psi$ (suposto não degenerado), e densidade $n(\boldsymbol{r})$. Admite-se que exista um potencial $v_{s}(\boldsymbol{r})$ tal que a mesma densidade pode ser obtida para o estado fundamental (também não degenerado) do sistema, não interagente, de hamiltoniana $\mathcal{H}_{s}=\mathcal{T}+\mathcal{V}_{s}$. Esta suposição é o ponto fundamental desta abordagem.

Para o sistema não interagente, é possível achar a solução em termos de $\mathrm{N}$ orbitais de uma só partícula, novamente representados pelo determinante de Slater, obtidos da equação de Schrödinger

$$
\left(-\frac{\hbar^{2}}{2 m} \nabla^{2}+v_{s}(\boldsymbol{r})\right)\left|\phi_{i}\right\rangle=\epsilon_{i}\left|\phi_{i}\right\rangle
$$

de forma que

$$
n(\boldsymbol{r})=\sum_{i=1}^{N}\left|\phi_{i}(\boldsymbol{r})\right|^{2}
$$

Para este sistema não interagente, o Teorema de Hohenberg-Kohn nos diz que os orbitais de uma partícula obtidos acima e a energia cinética do sistema não interagente são ambos funcionais da densidade $n(\boldsymbol{r})$ :

$$
\begin{aligned}
\phi_{i}(\boldsymbol{r}) & =\phi_{i}([n] ; \boldsymbol{r}) \\
T_{s}[n] & =\sum_{i=1}^{N}\left\langle\phi_{i}\left|-\frac{\hbar^{2}}{2 m} \nabla^{2}\right| \phi_{i}\right\rangle
\end{aligned}
$$

Devemos agora obter o potencial $\mathcal{V}_{s}(\boldsymbol{r})$ associado ao sistema não interagente. Para isto, fixemos um sistema específico, sujeito a um potencial externo $u_{0}(\boldsymbol{r})$ e cujo estado fundamental tem uma densidade $n(\boldsymbol{r})$. Precisamos então encontrar qual potencial $v_{s, 0}(\boldsymbol{r})$ gera esta densidade de acordo com as equações 2.4$]$ e 2.42 . 
Para o sistema auxiliar (não interagente), temos que:

$$
E_{s, v_{s, 0}}[n]=T_{s}[n]+\int v_{s, 0}(\boldsymbol{r}) n(\boldsymbol{r}) \mathrm{d} \boldsymbol{r}
$$

e para o sistema original (interagente):

$$
E_{v_{0}}[n]=F[n]+\int u_{0}(\boldsymbol{r}) n(\boldsymbol{r}) \mathrm{d} \boldsymbol{r}
$$

onde definimos o funcional universal (por não depender de $\mathcal{U}$ ) $F[n]=T[n]+V[n]$ ).

Como para ambos a densidade do estado fundamental é $n_{0}(\boldsymbol{r})$, ambos os funcionais devem ser estacionários para pequenas variações $\delta n(\boldsymbol{r})$ em torno de $n_{0}(\boldsymbol{r})$, impondo a condição que o número de partículas se mantenha. Esta condição é mantida usando-se dos multiplicadores de Lagrange, de forma que a variação

$$
\delta\left[E[n]-\mu\left(\int n(\boldsymbol{r}) \mathrm{d} \boldsymbol{r}-N\right)\right]=0
$$

Para o sistema auxiliar isto significa que:

$$
\mu_{s}=\delta E_{s, v_{s, 0}}=E_{s, v_{s, 0}}\left[n_{0}+\delta n\right]-E_{s, v_{s, 0}}\left[n_{0}\right]=\delta T_{s}+\int v_{s, 0}(\boldsymbol{r}) \delta n(\boldsymbol{r}) \mathrm{d} \boldsymbol{r}
$$

e para o sistema original,

$$
\mu=\delta E_{u_{0}}=E_{u_{0}}\left[n_{0}+\delta n\right]-E_{u_{0}}[n]=\delta T+\delta V+\int u_{0}(\boldsymbol{r}) \delta n(\boldsymbol{r}) \mathrm{d} \boldsymbol{r}
$$

Queremos, porém, que os dois sistemas sejam equivalentes, e portanto devemos ter $\mu_{s}=$ 4. Assim:

$$
\begin{aligned}
& \delta T_{s}+\int v_{s, 0}(\boldsymbol{r}) \delta n(\boldsymbol{r}) \mathrm{d} \boldsymbol{r}=\delta T+\delta V+\int u_{0}(\boldsymbol{r}) \delta n(\boldsymbol{r}) \mathrm{d} \boldsymbol{r} \\
\Rightarrow \quad & \int \delta n(\boldsymbol{r})\left(v_{s, 0}(\boldsymbol{r})+\frac{\delta T_{s}}{\delta n}-u_{0}(\boldsymbol{r})-\frac{\delta T}{\delta n}-\frac{\delta V}{\delta n}\right) \mathrm{d} \boldsymbol{r}=0 \\
\Rightarrow \quad & v_{s, 0}(\boldsymbol{r})=u_{0}(\boldsymbol{r})+\frac{\delta T}{\delta n}+-\frac{\delta T_{s}}{\delta n}+\frac{\delta V}{\delta n}
\end{aligned}
$$

onde as derivadas funcionais devem ser calculadas para $n=n_{0}$ 
A partir desta equação, como sabemos que uma parte importante da interação $V$ está descrita no termo de Hartree, somamos e subtraimos o termo $1 / 2 \int v\left(\boldsymbol{r}, \boldsymbol{r}^{\prime}\right) n_{0}\left(\boldsymbol{r}^{\prime}\right) \mathrm{d} \boldsymbol{r}^{\prime}$ e chegamos finalmente à forma de $v_{s, 0}(\boldsymbol{r})$

$$
\begin{aligned}
v_{s, 0}(\boldsymbol{r}) & =u_{0}(\boldsymbol{r})+\int v\left(\boldsymbol{r}, \boldsymbol{r}^{\prime}\right) \mathrm{d} \boldsymbol{r}^{\prime} n_{0}\left(\boldsymbol{r}^{\prime}\right)+v_{x c}\left(\left[n_{0}\right] ; \boldsymbol{r}\right) \\
v_{x c}\left(\left[n_{0}\right] ; \boldsymbol{r}\right) & =\left.\frac{\delta E_{x c}[n]}{\delta n(\boldsymbol{r})}\right|_{n_{0}}
\end{aligned}
$$

cujos termos são o potencial externo original, o termo de Hartree e um último termo associado à energia de troca e correlação $E_{x c}$, definida como

$$
E_{x c}[n]=\left(V[n]-\frac{1}{2} \iint n(\boldsymbol{r}) v\left(\boldsymbol{r}, \boldsymbol{r}^{\prime}\right) n\left(\boldsymbol{r}^{\prime}\right)\right)+\left(T[n]-T_{s}[n]\right)
$$

ou seja, as diferenças entre as formas aproximadas introduzidas e os termos originais da interação total $V$ e da energia cinética $T$.

As "Equações de Kohn-Sham" são o conjunto de equações [2.4], [2.42 e [2.5], que se desenvolvem na equação para a energia total:

$$
E_{\mathrm{KS}}[n]=T_{s}[n]+\int n(\boldsymbol{r}) u_{0}(\boldsymbol{r}) \mathrm{d} \boldsymbol{r}+\iint v\left(\boldsymbol{r}, \boldsymbol{r}^{\prime}\right) n_{0}(\boldsymbol{r}) n_{0}\left(\boldsymbol{r}^{\prime}\right) \mathrm{d} \boldsymbol{r} \mathrm{d} \boldsymbol{r}^{\prime}+E_{\mathrm{xc}}[n]
$$

Como o potencial de uma partícula depende da densidade eletrônica, novamente as soluções da equação 2.4$]$ devem ser procuradas de forma auto-consistente.

Não se conhece a forma exata para o termo de Troca e Correlação, e diversas aproximações existem para este termo. A mais simples delas é a chamada LDA (Local Density Approximation), onde se supõe que a dependência de $E_{x c}$ pode ser aproximada por uma relação local:

$$
E_{x c}^{L D A}[n]=\int n(\boldsymbol{r}) \epsilon_{x c}^{\mathrm{LDA}}(n(\boldsymbol{r})) \mathrm{d} \boldsymbol{r}
$$

onde $\epsilon_{x c}^{\mathrm{LDA}}(n)$ é a densidade de energia de troca e correlação de um gás homogêneo de elétrons de densidade $n$. A escolha desse funcional não é única. A aproximação de Perdew e Zunger LDA-PZ[44] utiliza os resultados incluindo correlação, através de método de Monte Carlo, de Ceperley e Alder[45] para um gás de elétrons de densidade uniforme, e faz a associação direta $\epsilon_{x c}(n(\boldsymbol{r}))=\epsilon_{x c}(\bar{n})$. 
Aproximações subsequentes envolvem o uso de funcionais que incluam a variação local da densidade, utilizando-se também de suas derivadas. Estes funcionais são chamados de GGA (Generalized Gradient Approximation), ou também de semi-locais, e tomam a forma geral

$$
E_{x c}^{G G A}[n]=\int n(\boldsymbol{r}) \epsilon_{x c}^{\mathrm{GGA}}(n(\boldsymbol{r}), \nabla n(\boldsymbol{r})) \mathrm{d} \boldsymbol{r}
$$

Existem diferentes propostas de inclusão da variação local da densidade $n$, como por exemplo aqueles conhecidos por PW91[46] e PBE[47].

Independente do funcional escolhido, porém, a interpretação dos autovalores de energia apresenta problemas. Enquanto para Hartree-Fock vale o Teorema de Koopmans, para a DFT vale o Terorema de Janak[48] que relaciona os autovalores com a derivada da energia total em relação à ocupação daquele orbital. Aqui entretanto apenas para o estado mais alto ocupado o autovalor assume um significado especial, a saber o potencial de ionização ou o potencial químico do sistema.

Seja para HF ou DFT, um modo mais confiável de se obter estes valores é através de um cálculo $\triangle \mathrm{SCF}$, ou seja, através da diferença de energias totais entre dois cálculos com ocupações distintas. O estudo de sistemas carregados, porém, traz outros problemas, principalmente para modelos periódicos.

Destacamos aqui que frequentemente se discute a validade da interpretação dos autovalores de Kohn-Sham como energias dos níveis do sistema real, pois eles seriam o resultado da construção matemática do sistema auxiliar. Görling[4.9], porém, demonstrou através de um tratamento perturbativo que diferenças entre autovalores de Kohn-Sham representam uma aproximação de ordem zero (na interação elétron-elétron) para as energias de excitação. As correções de primeira ordem seriam inteiramente relacionadas à troca, e apenas a partir da segunda ordem seria incluida a correlação.

Mesmo que justificada, a comparação entre autovalores de Kohn-Sham e valores experimentais em geral não apresenta bons resultados, e dois são os motivos para isso.

O primeiro está relacionado à auto-interação, ou seja, a interação entre um elétron e ele mesmo. Nos elementos de matriz diagonais do Hartree-Fock o termo de troca cancela exatamente o termo de Hartree, de forma que podemos incluir o termo diagonal na somatória de termos sem problemas. Já no DFT, devido à forma como definimos o potencial $v_{s}(\boldsymbol{r})$, não ocorre este cancelamento, e portanto não é nula a interação de um elétron consigo mesmo. O não cancelamento da auto-interação afeta de forma mais drástica sistemas localizados, no 
qual esta interação espúria é intensificada; este é um dos motivos para que sistemas isolados ou isolantes no DFT sejam em geral pior descritos que sistemas cristalinos metálicos.

Já o segundo está relacionado ao chamado "problema da descontinuidade"[50]. Ao analisarmos o potencial químico de um átomo de número atômico Z em função de uma variação contínua do número de elétrons $N$, percebe-se que

$$
\mu=\left\{\begin{array}{rr}
-\mathrm{PI} & Z-1<N<Z \\
-\mathrm{AE} & Z<N<Z+1
\end{array}\right.
$$

ou seja, que quando retiramos frações de elétrons o potencial químico assume o negativo do potencial de ionização, e que quando adicionamos frações de elétrons o potencial químico assume o negativo da afinidade eletrônica. Dessa forma, o potencial químico é descontínuo com variações do número de partículas, ao passar por um número inteiro. Esta descontinuidade, porém, não é descrita nos funcionais de troca e correlação, e portanto não é espelhada na DFT. Mais que isso, como pelo teorema de Janak o autovalor do estado ocupado mais alto está relacionado ao potencial químico, sem a descontinuidade este assume um valor intermediário entre potencial de ionização e afinidade eletrônica, e não o potencial de ionização como esperado[5]].

\subsubsection{DFT generalizada}

Na formulação da DFT (seção 2.」.2) foi definido o "potencial de troca e correlação", um potencial de uma partícula que resgataria a interação com os demais elétrons do sistema; esse potencial porém não possui uma forma algébrica conhecida.

Por outro lado, a forma do potencial de troca é bem conhecida, sendo utilizada explicitamente no método de Hartree-Fock. Ali, entretanto, não há correlação alguma, que deve ser adicionada a posteriori através de correções.

Em um Funcional Híbrido é introduzida uma porcentagem do potencial de troca exato, mantendo-se o termo de correlação da aproximação escolhida da DFT. Esta metodologia também é conhecida pelo termo troca exata, mas não pode ser chamada de Hartree-Fock, pois ainda é incluido o termo (aproximado) para a correlação. Além disso, como os orbitais de Kohn-Sham aparecem explicitamente na formulação do potencial de troca, este não é mais um funcional exclusivo da densidade, e portanto não está rigorosamente coberto pela DFT; para esta formulação que inclui também os orbitais dá-se ainda o nome de Generalized-DFT. 
A explicação teórica para a adição da troca exata segue abaixo.

Partimos do Hamiltoniano do sistema interagente

$$
\mathcal{H}_{1}=\mathcal{T}+\mathcal{V}+\mathcal{U}
$$

onde $\mathcal{T}$ e $\mathcal{V}$ são os termos de energia cinética e de interação Coulombiana do sistema, e $\mathcal{U}$ o potencial externo. Pelo teorema de Hohenberg e Kohn podemos construir um potencial $v_{0}^{\mathrm{KS}}=v_{s, 0}-u_{0}$ (o potencial de Kohn-Sham, retirado o termo do potencial externo) de tal forma que o sistema não interagente dado por

$$
\mathcal{H}_{0}=\mathcal{T}+\mathcal{V}_{0}^{\mathrm{KS}}+\mathcal{U}
$$

tenha a mesma densidade eletrônica que o sistema original.

Esta mudança do sistema interagente para o não interagente pode ser entretanto realizada de forma adiabática através da introdução do parâmetro $\lambda$ :

$$
\mathcal{H}_{\lambda}=\mathcal{T}+\lambda \mathcal{V}+\mathcal{V}_{\lambda}^{\mathrm{KS}}+\mathcal{U}
$$

Aqui definimos o termo $\mathcal{V}_{\lambda}^{\mathrm{KS}}$ de tal forma que a densidade do sistema para um valor intermediário de $\lambda$ permaneça igual ao do sistema interagente. Desta última equação podemos recair no caso interagente $\operatorname{com} \lambda=1\left(\mathcal{V}_{1}^{\mathrm{KS}}=0\right)$ e no caso não interagente (equação de Kohn-Sham) com $\lambda=0$.

Se a energia do sistema é dada por

$$
E_{\lambda}=\left\langle\Psi_{\lambda}\left|\mathcal{H}_{\lambda}\right| \Psi_{\lambda}\right\rangle
$$

onde $\Psi_{\lambda}$ é a função de onda do estado fundamental do Hamiltoniano $\mathcal{H}_{\lambda}$, então podemos escrever

$$
E_{1}=E_{0}+\int_{0}^{1} \mathrm{~d} \lambda \frac{\mathrm{d} E_{\lambda}}{\mathrm{d} \lambda}=E_{0}+\int_{0}^{1} \mathrm{~d} \lambda\left\langle\Psi_{\lambda}\left|\mathcal{V}+\frac{\mathrm{d} \mathcal{V}_{\lambda}^{\mathrm{KS}}}{\mathrm{d} \lambda}\right| \Psi_{\lambda}\right\rangle
$$

Utilizando-se do fato que $\mathcal{V}_{\lambda}^{\mathrm{KS}}$ é um operador de uma partícula, e que por construção $n(\boldsymbol{r})$ não depende de $\lambda$, podemos simplificar o último termo da equação acima:

$$
\int_{0}^{1} \mathrm{~d} \lambda\left\langle\Psi_{\lambda}\left|\frac{\mathrm{d} \mathcal{V}_{\lambda}^{\mathrm{KS}}}{\mathrm{d} \lambda}\right| \Psi_{\lambda}\right\rangle=\int_{0}^{1} \mathrm{~d} \lambda \int \mathrm{d} \boldsymbol{r} \frac{\mathrm{d} V_{\lambda}^{\mathrm{KS}}(\boldsymbol{r})}{\mathrm{d} \lambda} n(\boldsymbol{r})=-\int \mathrm{d} \boldsymbol{r} v_{0}^{\mathrm{KS}}(\boldsymbol{r}) n(\boldsymbol{r})
$$


onde utilizamos o fato que $V_{1}^{\mathrm{KS}}=0$. Podemos utilizar esta mesma simplificação para escrever a energia do sistema não-interagente:

$$
E_{0}[n]=T_{0}[n]+\int \mathrm{d} \boldsymbol{r} v_{0}^{\mathrm{KS}}(\boldsymbol{r}) n(\boldsymbol{r})+U[n]
$$

Por outro lado, pela formulação de Kohn-Sham a energia do sistema interagente pode ser obtida através da equação

$$
E_{1}[n]=T_{0}[n]+\frac{1}{2} \int \mathrm{d} \boldsymbol{r} \mathrm{d} \boldsymbol{r}^{\prime} v\left(\boldsymbol{r}, \boldsymbol{r}^{\prime}\right) n(\boldsymbol{r}) n\left(\boldsymbol{r}^{\prime}\right)+E^{\mathrm{xc}}[n]+U[n]
$$

e, finalmente, utilizando as equações [2.62], [2.63], [2.64 e [2.65, podemos escrever o termo de troca e correlação como:

$$
\begin{aligned}
E^{\mathrm{xc}}[n] & =\int_{0}^{1} \mathrm{~d} \lambda\left\{\left\langle\Psi_{\lambda}|\mathcal{V}| \Psi_{\lambda}\right\rangle-\frac{1}{2} \int \mathrm{d} \boldsymbol{r} \mathrm{d} \boldsymbol{r}^{\prime} v\left(\boldsymbol{r}, \boldsymbol{r}^{\prime}\right) n(\boldsymbol{r}) n\left(\boldsymbol{r}^{\prime}\right)\right\} \\
& =\int_{0}^{1} \mathrm{~d} \lambda E_{\lambda}^{\mathrm{xc}}
\end{aligned}
$$

Em um cálculo DFT convencional, utilizamos no lugar desta integral apenas o termo de $\lambda=0$. Em um funcional híbrido, utilizamos também o termo $\lambda=1$, de forma a aproximar melhor a integral acima. Uma primeira aproximação foi a "meio-a-meio" de Becke[52]:

$$
E^{\mathrm{xc}}=\frac{1}{2}\left(E_{\lambda=0}^{\mathrm{xc}}+E_{\lambda=1}^{\mathrm{xc}}\right)
$$

depois generalizada para a forma

$$
E^{\mathrm{xc}}=a E_{\lambda=1}^{\mathrm{x}}+(1-a) E_{\lambda=0}^{\mathrm{x}}+E_{\lambda=0}^{\mathrm{c}}
$$

na qual foram separados os termos de troca e de correlação, este ficando inteiramente descritos pela sua forma DFT e aquele dividido entre forma DFT e forma exata, através do parâmetro de mistura $a$, que seria escolhido de forma empírica.

Perdew, Ernzerhof e Burke mostraram[5:3], por modelos perturbativos, que o parâmetro de mistura é melhor fixado no valor $a=1 / 4$, podendo sofrer pequenas alterações ao redor deste valor dependendo da propriedade que está sendo estudada. O funcional proposto por eles (PBE0) utiliza este valor de $a$, e se baseia no funcional PBE para o termo DFT. 
Outra opção de escolha do valor de $a$ é basear-se em cálculos mais precisos, como o GW. É nisso que se baseia o método o-PBEh[54], segundo o qual o valor a ser adotado é aquele que minimize a diferença entre o resultado do cálculo com o funcional híbrido e o resultado de um cálculo GW a partir daquele híbrido. Para sistemas moleculares, uma análise realizada em nosso grupo de pesquisa[5.5] resultou em um valor ótimo de $a=0,75$.

De forma a melhorar a velocidade de cálculo do termo de troca, Heyd, Scuseria e Ernzerhof propuseram um novo funcional híbrido, o HSE[56], no qual o termo de troca exata é dividido em componentes de curto e de longo alcance(c-a e l-a, respectivamente), através da separação

$$
\frac{1}{r}=\underbrace{\frac{\operatorname{erfc}(\omega r)}{r}}_{\mathrm{c}-\mathrm{a}}+\underbrace{\frac{\operatorname{erf}(\omega r)}{r}}_{\mathrm{l}-\mathrm{a}}
$$

onde erf é a função erro $\operatorname{erf}(x)=\frac{2}{\pi} \int_{0}^{x} e^{-t^{2}} \mathrm{~d} t$, erfc é a função erro complementar $\operatorname{erfc}(x)=$ $1-\operatorname{erf}(x)$, e $\omega$ é o parâmetro de blindagem (por motivos que ficarão mais claros abaixo).

Fazendo esta separação em todos os termos de troca da equação [2.68 chegamos a

$$
E^{x}=a E_{\lambda=1}^{x, \mathrm{c}-\mathrm{a}}(\omega)+a E_{\lambda=1}^{x, \mathrm{l}-\mathrm{a}}(\omega)+(1-a) E_{\lambda=0}^{x, \mathrm{c}-\mathrm{a}}+(1-a) E_{\lambda=0}^{x, \mathrm{l}-\mathrm{a}}
$$

A convergência do termo de longo alcance para a troca exata é muito lenta, e seu valor difere muito pouco do termo aproximado. A interação de longo alcance volta, então, à sua forma aproximada, deixando a correção de troca exata apenas para o termo de curto-alcance, como se esta interação fosse "blindada":

$$
E^{x}=a E_{\lambda=1}^{x, \mathrm{c}-\mathrm{a}}(\omega)+(1-a) E_{\lambda=0}^{x, \mathrm{c}-\mathrm{a}}+E_{\lambda=0}^{x, \mathrm{l}-\mathrm{a}}
$$

Daqui poderíamos recair no DFT original no limite $\omega \rightarrow \infty$, e no funcional PBE0 com $\omega=0$. O valor sugerido é de $\omega=0,11 \mathrm{bohr}^{-1}$ [57]. Existem, porém, muitas outras implementações, cada qual com suas vantagens e desvantagens.

\subsection{Implementações principais}

Na sessão anterior foram discutidas as principais metodologias para estrutura eletrônica. Cada uma delas, porém, apresenta diferentes possibilidades de implementação, que serão discutidas a seguir. 
Primeiramente, notamos a diferença existente entre sistemas finitos e sistemas infinitos. Por sistemas finitos entendemos uma molécula, agregado ou cluster isolado, ao passo que superfícies, fios e cristais são exemplos de sistemas infinitos.

Dentre os códigos computacionais de estrutura eletrônica temos também uma diferenciação semelhante. Alguns códigos computacionais são implementados no espaço real, e são recomendados para tratar sistemas finitos, como aglomerados ou moléculas; outros são implementados no espaço recíproco, para tratar sistemas periódicos, ou sistemas finitos com a aproximação de "super-células".

Outro ponto de diferenciação entre códigos computacionais é quanto à base utilizada para a expansão das funções de onda. Bases locais (ou seja, centradas nos átomos) podem ser utilizadas tanto no espaço real quanto no espaço recíproco, e são utilizadas por exemplo nos programas Gaussian[58] e MSINDO[5.9] (utilizados aqui em cálculos de Hartree-Fock e Interação de Configurações, seção [3.2). Outros códigos, como Siesta[60] e FHI-Aims[6]], utilizam esta implementação na DFT, mas não foram utilizados neste trabalho.

Outra possibilidade de implementação é o uso de ondas planas, realizando o cálculo no espaço recíproco. Esta abordagem é especialmente desenvolvida para sistemas infinitos tridimensionais, mas pode também ser utilizada para sistemas de menor dimensionalidade (incluindo sistemas finitos), através do uso de uma super célula com tamanho suficiente para não permitir a interação entre uma unidade e a sua cópia periódica. Códigos computacionais que utilizam esta abordagem são por exemplo Abinit[62] e Quantum-ESPRESSO[63], este último utilizado neste trabalho.

Abaixo descrevemos implementações específicas para os métodos descritos acima, que foram utilizadas no nosso trabalho.

\subsubsection{Combinação Linear de Orbitais Atômicos}

A priori, qualquer base infinita poderia ser utilizada para expansão das funções de onda do sistema. Uma base por vezes conveniente é aquela a formada pelos orbitais atômicos dos componentes do sistema. Apesar de ser utilizada tanto com Hartree-Fock quanto com DFT, neste trabalho foi aplicada apenas com o Hartree-Fock, e portanto descreveremos com mais detalhe a sua implementação para este formalismo.

O uso de uma combinação linear de orbitais atômicos para a solução da equação de Hartree-Fock iniciou-se com Roothaan[64]. Nesta formulação as funções de onda de um 
elétron são expandidas em orbitais atômicos $\chi_{i}$ (Atomic Orbitals, AOs) correspondentes aos átomos do sistema.

$$
\left|\psi_{i}\right\rangle=\sum_{p} C_{p i}\left|\chi_{p}\right\rangle, \quad i=1,2, \ldots, n
$$

onde os AOs foram denominados $\chi_{p}$, e cada índice $p$ representa um par átomo - número quântico $(A, m)$. Todos os AOs são admitidos já normalizados $\left(\left\langle\chi_{p} \mid \chi_{p}\right\rangle=1\right)$. Dois AOs de um mesmo átomo $A$ são ortonormais entre si, mas dois AOs de átomos diferentes não. Assim, existe sobreposição (overlap) entre eles, definido como

$$
S_{p q}=\left\langle\chi_{p} \mid \chi_{q}\right\rangle
$$

onde $\chi_{p}$ e $\chi_{q}$ são provenientes de átomos diferentes.

Ao reescrever as funções de onda em termos desta base, nosso problema passa a ser encontrar o conjunto de coeficientes $C_{p i}$ de tal forma que $\psi_{i}$ seja solução da Equação de Hartree-Fock. Este problema fica melhor representado na notação matricial:

$$
\begin{aligned}
\chi= & \left(\left|\chi_{1}\right\rangle,\left|\chi_{2}\right\rangle, \cdots\left|\chi_{m}\right\rangle\right) \\
\boldsymbol{c}_{i}= & \left(\begin{array}{l}
C_{1 i} \\
C_{2 i} \\
\vdots \\
C_{m i}
\end{array}\right) \\
\boldsymbol{C} & =\left(\begin{array}{llll}
C_{11} & C_{12} & \cdots & C_{1 n} \\
C_{21} & C_{22} & \cdots & C_{2 n} \\
\vdots & \vdots & \ddots & \vdots \\
C_{n 1} & C_{n 2} & \cdots & C_{n n}
\end{array}\right) \\
\left|\psi_{i}\right\rangle= & \boldsymbol{c}_{i}|\chi\rangle \\
\boldsymbol{\psi} & =\chi \boldsymbol{C}
\end{aligned}
$$

Se para cada operador de um elétron $\mathcal{M}$ definirmos os elementos da matriz $\boldsymbol{M}$ como:

$$
M_{p q}=\left\langle\chi_{p}|\mathcal{M}| \chi_{q}\right\rangle
$$


poderíamos reescrever os termos da equação 2.18 na notação matricial:

$$
\begin{array}{r}
H_{i}=\boldsymbol{c}_{i}^{\dagger} \boldsymbol{H} \boldsymbol{c}_{i} \\
J_{i j}=\boldsymbol{c}_{i}^{\dagger} \boldsymbol{J}_{j} \boldsymbol{c}_{i}=\boldsymbol{c}_{j}^{\dagger} \boldsymbol{J}_{i} \boldsymbol{c}_{j} \\
K_{i j}=\boldsymbol{c}_{i}^{\dagger} \boldsymbol{K}_{j} \boldsymbol{c}_{i}=\boldsymbol{c}_{j}^{\dagger} \boldsymbol{K}_{i} \boldsymbol{c}_{j}
\end{array}
$$

Assim, a equação de Hartree-Fock poderia ser reescrita como

$$
F C=S C \epsilon
$$

Supondo sem perda de generalidade que $\boldsymbol{\epsilon}$ é diagonal, temos finalmente:

$$
\boldsymbol{F} \boldsymbol{c}_{i}=\epsilon_{i} \boldsymbol{S} \boldsymbol{c}_{i}
$$

Para resolver esta equação se usa o procedimento de auto-consistência. Começando com uma tentativa inicial $\boldsymbol{C}^{(0)}$, calculamos o respectivo operador de Fock, e chegamos ao problema matricial:

$$
\boldsymbol{F}^{(0)} \boldsymbol{c}^{(1)}=\epsilon^{(1)} \boldsymbol{S}^{(0)} \boldsymbol{c}^{(1)} \quad \Rightarrow \quad\left(\boldsymbol{F}^{(0)}-\epsilon^{(1)} \boldsymbol{S}^{(0)}\right) \boldsymbol{c}^{(1)}=0
$$

que é um problema de autovalores na métrica $\boldsymbol{S}$. Este problema tem as mesmas propriedades de um problema de autovalores convencional, se considerarmos que dois vetores ortogonais agora são dados por $\boldsymbol{c}_{i}^{\dagger} \boldsymbol{S} \boldsymbol{c}_{j}=0$.

Como o operador de Fock depende da função de onda, utilizamos a solução deste primeiro problema para construir um novo operador de Fock, criando assim um novo problema de autovalores a ser resolvido.

Repete-se o processo utilizando os novos autovetores, até encontrar a convergência do processo, ou seja, quando após um ciclo de auto-consistência a mudança na energia total ou na função de onda for menor que um determinado critério.

\subsubsection{Métodos Semi-empíricos}

Cálculos ab-initio envolvem um custo computacional elevado. Uma forma de reduzir este custo computacional, e ao mesmo tempo corrigir os problemas conhecidos do Hartree- 
Fock original, é utilizar um método semi-empírico. Com o uso de algumas aproximações, e da parametrização das integrais, reduz-se consideravelmente o trabalho computacional envolvido[65] e chegamos a resultados que se aproximam do resultado experimental (por exemplo geometrias, potencial de ionização) para muitos sistemas.

Tratar todos os elétrons do sistema por vezes torna-se dispendioso, quando para a maioria das propriedades químicas sabemos que apenas os elétrons de valência são importantes. Uma aproximação utilizada comumente é a de "caroço"[66], segundo a qual trabalhamos apenas com os elétrons de valência, enquanto que os elétrons das camadas atômicas internas são tomados juntamente com seu núcleo, formando um caroço atômico de carga efetiva igual à carga de valência do átomo neutro. Além disso, é também utilizado um conjunto mínimo de funções-base (por exemplo, apenas orbitais $s$ e $p$ da camada de valência do Carbono ou Oxigênio).

Outro ponto que envolve um alto custo computacional é o cálculo das integrais espaciais para os termos de Coulomb e troca. Ao efetuar a expansão de cada um dos orbitais na base LCAO surgem termos cruzados na forma

$$
\left\langle\chi_{p}^{\mu} \chi_{q}^{\nu}\left|\mathcal{V}^{\mu \nu}\right| \chi_{r}^{\mu} \chi_{s}^{\nu}\right\rangle
$$

Quando estes diversos orbitais atômicos pertencem ao mesmo átomo (integrais de um centro), através de simetria e de expansões algébricas as integrais podem ser calculadas; por outro lado, se eles pertencem a átomos diferentes, simetrias já não podem ser aplicadas, e a integral deve ser resolvida numericamente (integrais de dois, três ou quatro centros, dependendo do número de átomos).

De modo a evitar o cálculo destas integrais, nos métodos semi-empíricos estes termos, assim como o termo de overlap (eq.[2.73), são aproximados e parametrizados; a forma como eles são tratados é o principal diferencial entre os vários métodos semi-empíricos.

Na aproximação mais simples, conhecida por ZDO (Zero Differential Overlap[67]), é assumido que é nulo o overlap entre quaisquer 2 orbitais diferentes, e que as integrais de interação só são não nulas quando $p=r$ e $q=s$ na equação [2.86], ou seja, considerando apenas algumas das integrais coulombianas de um ou dois centros (mas não as de troca, nem as de 3 ou 4 centros). Esta aproximação, porém, mostra-se drástica demais, não só devido aos resultados obtidos, mas também porque com ela o Hamiltoniano deixa de ser invariante por rotações do sistema de coordenadas. A aproximação CNDO (Complete Neglect Differential 
Overlap[68]) busca corrigir isto, tornando as integrais de um e dois centros dependentes apenas do átomo ao qual os orbitais em questão pertencem, e não do orbital em si, o que reestabelece a invariância por rotações do sistema de coordenadas.

No método INDO (Intermediate Neglect Differential Overlap[6.9]) a restrição de que $p=r$ e $q=s$ é retirada, mas apenas quando todos os orbitais atômicos $p, q, r$ e $s$ pertencem a um mesmo átomo. Desta forma, todas as interações de um centro são calculadas, em especial as de troca (quando $p=s \neq q=r$ ).

Outro método é o NDDO (Neglect of Diatomic Differential Overlap[68]). Aqui são reintroduzidos termos em que $p \neq r$ e $q \neq s$ quando os orbitais $p$ e $r$ pertencem a um mesmo átomo $A$, e $q$ e $s$ a um átomo $B$ (igual ou não a $A$ ). Desta forma, além dos termos de um centro introduzidos pelo INDO, também outros termos de dois centros são calculados.

A partir destas 3 principais metodologias, diversas outras foram criadas, com pequenas variações nas aproximações envolvidas, mas diferindo principalmente na forma como as integrais foram parametrizadas[[0]. Do NDDO, por exemplo, derivou-se o MNDO (Modified Neglect Differential Overlap[[1] ), que por sua vez foi reparametrizado no AM1 (Austin Model 1 [72]), utilizado neste trabalho.

Já a partir do INDO criou-se o SINDO (Symmetrically orthogonalized INDO[[r3, [4]]), que incluiu parametrização para orbitais d, e incluiu os pseudopotenciais de Zerner[6̧]] para a descrição do caroço (idéia semelhante aos pseudopotenciais descritos na sessão [2.2.4). Outra modificação do SINDO foi a ortogonalização explícita das funções de base, de forma a melhorar não o termo coulombiano ou de troca, mas a descrição dos demais termos do Hamiltoniano. Para tal, parte-se de

$$
\boldsymbol{\lambda}=\boldsymbol{S}^{-1 / 2} \boldsymbol{\chi}
$$

e utilizando $\boldsymbol{S}=\mathbf{1}+\boldsymbol{\sigma}$, podemos expandir $\boldsymbol{S}^{-1 / 2}$ como

$$
\boldsymbol{S}^{-1 / 2}=\mathbf{1}-\frac{1}{2} \boldsymbol{\sigma}+\frac{3}{8} \boldsymbol{\sigma}^{2}+\cdots
$$

Assim, o Hamiltoniano diagonal

$$
\boldsymbol{H}^{\lambda}=\boldsymbol{S}^{-1 / 2} \boldsymbol{H} \boldsymbol{S}^{-1 / 2}
$$

pode ser obtido utilizando a expansão acima até termos de segunda ordem em $\boldsymbol{\sigma}$. 
Entre os diversos métodos semi-empíricos, a parametrização das integrais pode seguir diversos caminhos, dependendo de qual propriedade se quer descrever. Para os métodos citados acima, foram utilizados por exemplo calores de formação, distâncias de ligação, potenciais de ionização e momentos de dipolo.

Outra possibilidade na escolha dos parâmetros é a adoção da parametrização espectroscópica, que procura descrever o espectro ótico dos sistemas em um cálculo de Interação de Configurações (descrito no próximo capítulo). São parametrizados assim os métodos ZINDO (Zerner's INDO[75]) e MSINDO (Modified SINDO[5.9]), ambos utilizados neste trabalho.

\subsubsection{Ondas Planas}

Na DFT-KS não é definida a priori uma base, e diversas opções existem. Uma opção comum é utilizar uma base local, ou seja, funções centradas em $\left\{\boldsymbol{R}_{i}\right\}$ (em geral átomos do sistema, mas podem inclusive ser interstícios), que são expandidas em termos do momento angular. O uso de uma base local é importante e às vezes necessário para tratar estados eletrônicos muito localizados; ele traz porém um problema sério ao não temos um critério de convergência bem definido para o truncamento da base, e o resultado do cálculo passa a depender fortemente não só do número mas também do tipo de funções utilizadas.

Neste trabalho optamos pela base de Ondas Planas (Plane Waves, PWs), como implementado no código Quantum-ESPRESSO. Esta base apresenta algumas características úteis, como tratar igualmente todas as regiões do espaço, não depender das coordenadas dos núcleos, ser inerentemente periódica e principalmente ter um critério de convergência para o truncamento bem definido (energia de corte). Este tipo de base pode porém apresentar problemas para sistemas finitos, já que a dimensão da supercélula também interfere no mínimo de ondas planas necessário para a descrição do sistema.

O potencial periódico é escrito como

$$
V(\boldsymbol{r})=\sum_{\boldsymbol{G}} V_{\boldsymbol{G}} e^{i \boldsymbol{G} \cdot \boldsymbol{r}}
$$

em que $\{\boldsymbol{G}\}$ são vetores da rede recíproca, e a função de onda é escrita como

$$
\left\langle\boldsymbol{r} \mid \psi_{\boldsymbol{k}}\right\rangle=\psi_{\boldsymbol{k}}(\boldsymbol{r})=\sum_{\boldsymbol{G}} C_{\boldsymbol{k}+\boldsymbol{G}} e^{i(\boldsymbol{k}+\boldsymbol{G}) \cdot \boldsymbol{r}}
$$


em que $\boldsymbol{k}$ define as propriedades de simetria daquele estado.

As somatórias em $\boldsymbol{G}$ são limitadas pela energia de corte, o valor máximo para a "energia das ondas planas" e estabelecendo o critério de convergência descrito acima. Funções de onda de estados mais internos aos átomos precisariam de uma energia de corte muito alta para serem bem descritas, o que elevaria o tempo de cálculo sem melhorar a qualidade dos resultados para a valência, que em geral é o que nos interessa. Para resolver isto diversos métodos foram criados, para diferenciar a região do caroço da região inter-atômica, como os métodos PAW[76], LAPW[77], e também o método dos pseudopotenciais, utilizado neste trabalho e descrito na próxima seção.

\subsubsection{Aproximação de Pseudopotenciais}

A expansão da função de onda em ondas planas é boa quando estas são funções suaves; para funções com variações abruptas são necessários muitos termos para uma boa aproximação. Em especial, funções de onda de estados de caroço são abruptas, e as de estados de valência por lhes serem ortogonais oscilam muito próximo ao núcleo. Neste ponto podemos nos perguntar: A descrição do caroço é importante? Em alguns sistemas, a descrição exata dos elétrons de caroço é essencial, mas em outros não. Em muitos casos, por exemplo para várias propriedades em sistemas semicondutores, apenas a descrição da valência deve ser precisa, e a do caroço pode ser aproximada.

Nesse caso, substitui-se o total das interações dos elétrons de valência com o núcleo e os elétrons de caroço por um potencial efetivo, o pseudopotencial, definido de forma que não haja alteração significativa nas energias dos orbitais de valência para o átomo livre. Ao mesmo tempo, eliminamos as oscilações radiais, na região do caroço, das funções de valência.

Para escrever esta nova função de onda suavizada, chamada de pseudo-função de onda, subtraímos a solução para o caroço da função de onda da valência:

$$
\left|\tilde{\psi}_{v}\right\rangle=\left|\psi_{v}\right\rangle+\sum_{c} \alpha_{c v}\left|\psi_{c}\right\rangle
$$

onde $\left|\psi_{v}\right\rangle$ e $\left|\psi_{c}\right\rangle$ são soluções de valência e de caroço do Hamiltoniano de Kohn-Sham $\mathcal{H}$.

Esta pseudo-função de onda satisfaz à equação modificada:

$$
\left[\mathcal{H}+\sum_{c}\left(\epsilon_{v}-\epsilon_{c}\right)\left|\psi_{c}\right\rangle\left\langle\psi_{c}\right|\right]\left|\tilde{\psi}_{v}\right\rangle=\epsilon_{v}\left|\tilde{\psi}_{v}\right\rangle
$$


ou seja, podemos criar o Hamiltoniano modificado $\mathcal{H}_{P S}$ cujas autofunções são suaves, mas que possuem os mesmos autovalores de $\mathcal{H}$ para a região de interesse. Definimos assim o pseudopotencial:

$$
\mathcal{U}_{P S}=\mathcal{U}+\sum_{c}\left(\epsilon_{v}-\epsilon_{c}\right)\left|\psi_{c}\right\rangle\left\langle\psi_{c}\right|
$$

Esta forma de pseudopotencial é chamada local, por ter a mesma forma para toda a função de onda. Em outra formulação, chamada semi-local, podemos decompô-la em alguns termos que agem em diferentes componentes de momento angular:

$$
\mathcal{U}_{P S}=\sum_{l=0}^{\infty} u_{P S}^{l}(\boldsymbol{r}) \mathcal{P}_{l}
$$

Em geral, destaca-se um termo local para agir em todos os momentos angulares, e truncase a soma remanescente em um determinado valor $l_{\text {max }}$ :

$$
\mathcal{U}_{P S}=u_{P S}^{l o c}(\boldsymbol{r})+\sum_{l=0}^{l_{\max }} \Delta u_{P S}^{l}(\boldsymbol{r}) \mathcal{P}_{l}
$$

Entre as diferentes metodologias para a definição do pseudopotencial, destacamos a de Norma Conservada. Na criação de um pseudopotencial devem ser levados em consideração o decréscimo que ele trará ao custo computacional e a sua transferibilidade, ou seja, o quão adequado ele se mostrará em configurações diferentes daquela em que foi gerado. Para isso, 4 condições foram estabelecidas:

1. Pseudo-funções de onda dos primeiros estados considerados da valência não têm nós radiais

2. Pseudo-funções de onda e funções de onda "all-electron" (AE) são idênticas a partir de um "raio de caroço" $r_{c}$

3. Auto-energias se mantêm: $\epsilon_{l}^{P S}=\epsilon_{l}^{A E}$

4. Carga dentro de $r_{c}$ é igual para cálculo PS e AE (conservação da norma):

$$
\int_{0}^{r_{c}}\left|r R_{l}^{P S}(\boldsymbol{r})\right|^{2} \mathrm{~d} r=\int_{0}^{r_{c}}\left|r R_{l}^{A E}(\boldsymbol{r})\right|^{2} \mathrm{~d} r
$$


A importância da conservação da norma se dá pelo aumento da transferibilidade do pseudopotencial, já que a sua variação com a energia se torna de segunda ordem:

$$
-\frac{1}{2}\left\{\left[r R_{l}(\epsilon, \boldsymbol{r})\right]^{2} \frac{\mathrm{d}}{\mathrm{d} \epsilon} \frac{\mathrm{d}}{\mathrm{d} r} \ln \left(R_{l}(\epsilon, \boldsymbol{r})\right)\right\}_{r_{c}}=\int_{0}^{r_{c}}\left|r R_{l}(\boldsymbol{r})\right|^{2} \mathrm{~d} r
$$

Na construção de um pseudopotencial, o primeiro passo é escolher um estado de referência, e resolver o problema $\mathrm{AE}$ :

$$
\begin{gathered}
\left\{-\frac{1}{2} \frac{\mathrm{d}^{2}}{\mathrm{~d} r^{2}}+\frac{l(l+1)}{2 r^{2}}+v_{s}[n](\boldsymbol{r})\right\} r R_{A E}^{n l}(\boldsymbol{r})=\epsilon_{n l} R_{A E}^{n l}(\boldsymbol{r}) \\
v_{s}[n](\boldsymbol{r})=-Z v(\boldsymbol{r}, 0)+\int n\left(\boldsymbol{r}^{\prime}\right) v\left(\boldsymbol{r}, \boldsymbol{r}^{\prime}\right) \mathrm{d} r^{\prime}+v_{X C}[n]
\end{gathered}
$$

O padrão na escolha do estado de referência é escolher o estado neutro do átomo, mas podemos também escolher um estado mais próximo da configuração em que o átomo será colocado, ou então um estado para descrever melhor orbitais de determinado $l$; por exemplo, como pseudopotencial para o Potássio podemos escolher como referência o átomo K neutro, na configuração $\left[1 s^{2} 2 s^{2} 2 p^{6} 3 s^{2} 3 p^{6}\right] 4 s^{1}$, ou o cátion $\mathrm{K}^{+}\left[1 s^{2} 2 s^{2} 2 p^{6}\right] 3 s^{2} 3 p^{6}$.

Em seguida, deve-se definir a forma analítica das pseudo-funções de onda para $r<r_{c}$, e assim determiná-las. Existem diversas "receitas" para a construção da pseudo-função, entre as comumente empregadas podemos citar:

Troullier-Martins[78] $R_{T M}^{l}(\boldsymbol{r})=r^{l} e^{p(r)}$, onde $p(r)$ é um polinômio de grau 6 em $r^{2}$, cujos parâmetros são determinados através das condições: conservação de norma, continuidade da função e 4 derivadas, e curvatura 0 na origem.

RRKJ[79] $R_{R R K J}^{l}(\boldsymbol{r})=\sum \alpha_{i} j_{l}\left(\boldsymbol{G}_{i} \cdot \boldsymbol{r}\right)$, onde $j_{l}$ são funções de Bessel. Os vetores $\boldsymbol{G}_{i}$ são escolhidos de forma a igualar a derivada logarítmica, e parâmetros $\alpha_{i}$ para garantir normalização, continuidade de 2 derivadas, e minimizar a energia cinética para PWs $\operatorname{com}|\boldsymbol{G}|>G_{n}$.

Com a pseudo-função determinada, devemos resolver a equação de Schrödinger inversa para o pseudopotencial:

$$
u_{P S}^{(s c) l}(\boldsymbol{r})=\epsilon_{l}-\frac{l(l+1)}{2 r^{2}}+\frac{1}{2 r R_{P S}^{l}(\boldsymbol{r})} \frac{\mathrm{d}^{2}}{\mathrm{~d} r^{2}}\left[r R_{P S}^{l}(\boldsymbol{r})\right]
$$


e em seguida deve-se retirar o termo referente à valência, ficando apenas com o pseudopotencial iônico (unscreened):

$$
\begin{aligned}
u_{P S}^{l}(\boldsymbol{r}) & =v_{P S}^{(s c) l}(\boldsymbol{r})-\int \frac{n_{v}\left(\boldsymbol{r}^{\prime}\right)}{\left|\boldsymbol{r}-\boldsymbol{r}^{\prime}\right|} \mathrm{d} r^{\prime}-v_{X C}\left[n_{v}\right](\boldsymbol{r}) \\
n_{v}(\boldsymbol{r}) & =\sum_{l=0}^{l_{\max }} \sum_{m=-l}^{l}\left|r R_{P S}^{l}(\boldsymbol{r})\right|^{2}
\end{aligned}
$$

\subsubsection{Outras formas para o Pseudopotencial}

Uma correção possível é conhecida como "de caroço não linear". Se o overlap entre as densidades de carga de valência e de caroço for grande, o processo de "unscreening" descrito acima não vai produzir bons resultados, pois nesses casos $E_{X C}\left[n_{v}+n_{c}\right] \neq E_{X C}\left[n_{c}\right]+E_{X C}\left[n_{v}\right]$, ou seja, dizemos que a energia de troca e correlação não é linear com a densidade do caroço. Nestes casos, devemos substituir $v_{X C}\left[n_{v}\right]$ por $v_{X C}\left[n_{c}+n_{v}\right]$ no "unscreening", e no cálculo SCF computamos o valor de $E_{X C}$ total (não só valência), usando a densidade de carga do caroço congelado ("frozen core"). Como $n_{c}(\boldsymbol{r})$ não é suave, podemos substituí-la por uma função analítica ajustada.

Já uma outra modificação, destinada mais à factibilidade de cálculo, é a utilização de formas não-locais separáveis, de Kleinman-Bylander[80]. O cálculo dos termos semi-locais é muito dispendioso computacionalmente, já que segue $\mathcal{O}\left(N M^{2}\right)$, onde $\mathrm{N}$ é o número de átomos do sistema e M o número de funções da base, e cada termo de matriz do potencial assumiria a seguinte forma:

$$
U_{P S}^{\alpha \beta}=\left\langle\psi_{\alpha}\left|\mathcal{U}_{P S}\right| \psi_{\beta}\right\rangle=U_{P S}^{l o c}(\alpha) \delta_{\alpha \beta}+\sum_{l=0}^{l_{\max }} \Delta U_{P S}^{l}(\alpha, \beta)
$$

Foi sugerido por Kleinman e Bylander a simplificação:

$$
\Delta \mathcal{U}_{K B}^{l}=\frac{\left|\Delta \mathcal{U}_{P S}^{l} \psi_{P S}^{l}\right\rangle\left\langle\psi_{P S}^{l} \Delta \mathcal{U}_{P S}^{l}\right|}{\left\langle\psi_{P S}^{l}\left|\Delta \mathcal{U}_{P S}^{l}\right| \psi_{P S}^{l}\right\rangle}
$$

onde $\left|\psi_{P S}^{l}\right\rangle$ é a pseudo-função de onda gerada com componente $l$.

Assim, ao invés de fazer a conta para toda a base, basta tratar a projeção na pseudofunção de referência. Neste caso, vê-se facilmente que $\Delta \mathcal{U}_{K B}^{l}\left|\psi_{P S}^{l}\right\rangle=\Delta \mathcal{U}_{P S}^{l}\left|\psi_{P S}^{l}\right\rangle$. 
Esta simplificação, porém, pode trazer problemas, na forma de estados espúrios (também chamados de "Ghost States")[8]]. São estados não físicos, cujas funções de onda têm mais nós que deveriam. Eles podem ser detectados através de descontinuidades na derivada logaritmica que não deveriam existir.

Estes estados espúrios surgem em sistemas onde a parte local do pseudopotencial é muito mais profunda que as demais contribuições. Neste caso, além do estado fundamental (sem nós), outras soluções (com nós) podem surgir em energias próximas. Isto acontece porque o projetor de Kleinman-Bylander é ortogonal aos estados com nós, já que ele foi construído apenas apartir de $\psi_{P S}^{l}$, que não tem nós. Desta forma, estes estados não são afetados pela parte não-local do PP (ou seja, o operador não-local aplicado a estes estados praticamente não os altera), e se tornam soluções do Hamiltoniano total. A solução para este problema seria mudar a parte local do potencial, retirando estas outras soluções, ou então utilizar mais projetores por momento angular.

Finalmente, temos as formas separáveis generalizadas. Se $\left|\psi_{i}\right\rangle$ é um conjunto completo, então:

$$
\begin{array}{r}
\Delta \mathcal{U}_{P S}^{l}=\sum_{i j}\left|\Delta \mathcal{U}_{P S}^{l} \psi_{i}\right\rangle \Theta_{i j}\left\langle\psi_{j} \Delta \mathcal{U}_{P S}^{l}\right| \\
\text { e } \quad \sum_{k} \Theta_{i k}\left\langle\psi_{k}\left|\Delta \mathcal{U}_{P S}^{l}\right| \psi_{j}\right\rangle=\delta_{i j}
\end{array}
$$

Através de transformações unitárias, pode-se diagonalizar $\Theta_{i j}$ formando um novo conjunto base $\bar{\psi}_{i}$ :

$$
\Delta \mathcal{U}_{P S}^{l}=\sum_{i} \frac{\left|\Delta \mathcal{U}_{P S}^{l} \bar{\psi}_{i}\right\rangle\left\langle\bar{\psi}_{i} \Delta \mathcal{U}_{P S}^{l}\right|}{\left\langle\bar{\psi}_{i}\left|\Delta \mathcal{U}_{P S}^{l}\right| \bar{\psi}_{i}\right\rangle}
$$

Como não podemos usar uma base completa, devemos truncar esta série. Se adotarmos apenas um termo, recaímos no método de Kleinman-Bylander. Utilizar 2 ou 3 termos já é o suficiente para excluirmos os estados espúrios.

Outra vantagem de se utilizar esta forma é a possibilidade de utilizar mais de um projetor por momento angular, o que nos possibilita criar um pseudopotencial com "semi-caroço" explícito, ou seja, com uma camada a mais de elétrons ativos além dos últimos elétrons de valência de cada $l$. Por exemplo, podemos incluir os orbitais $3 \mathrm{~s}$ e $3 \mathrm{p}$ no pseudopotencial para o Titânio, cuja valência seria apenas $3 \mathrm{~d}$ e $4 \mathrm{~s}$, e teríamos tanto o $3 \mathrm{~s}$ quanto o $4 \mathrm{~s}$. A adição destes orbitais ao cálculo aumenta o custo computacional, mas em alguns sistemas é 
necessária para melhor descrição do sistema.

Aqui utilizamos quase sempre pseudopotenciais de Norma Conservada, e sem o semicaroço. Apenas para o Titânio verificou-se ser importante a inclusão do semi-caroço, e também foi utilizada a descrição de formas separáveis para possibilitar a descrição de dois orbitais diferentes de mesmo momento angular ( $3 s$ e $4 s)$.

\subsubsection{Otimização de Geometria}

A teoria de campo médio também pode ser utilizada para otimizações de geometria. As forças sobre cada núcleo atômico são determinadas a partir do teorema de HellmannFeynman; em seguida utilizando-se de algum método de minimização (gradientes conjugados, por exemplo) a energia total é minimizada.

O Teorema de Hellmann-Feynman[ [02] nos diz que, uma vez determinada a distribuição espacial dos elétrons, as forças do sistema podem ser calculadas através de eletrostática clássica. Em especial, é válida a relação:

$$
\frac{\mathrm{d} E}{\mathrm{~d} \lambda}=\int \psi^{*}(\lambda) \frac{\partial \mathcal{H}}{\partial \lambda} \psi(\lambda) \mathrm{d} \tau
$$

onde $\mathcal{H}$ é o Hamiltoniano do sistema, dependente do parâmetro $\lambda$, e $\psi$ uma autofunção deste Hamiltoniano, com dependência implícita em $\lambda$.

Aplicando a equação acima, obtemos que a força sobre um núcleo $i$ pode ser escrita como

$$
\boldsymbol{F}_{i}=-\frac{\mathrm{d} E}{\mathrm{~d} \boldsymbol{R}_{i}}=-\int \mathrm{d} \boldsymbol{r} n(\boldsymbol{r}) \frac{\partial u_{0}(\boldsymbol{r})}{\partial \boldsymbol{R}_{i}}-\frac{\partial E_{\text {ion-ion }}}{\partial \boldsymbol{R}_{i}}-\tilde{\boldsymbol{F}}_{i}
$$

cujos componentes são a resposta da densidade atual com uma mudança no potencial externo aplicado sobre os átomos, o potencial (clássico) de interação íon-íon, e um terceiro termo $\tilde{\boldsymbol{F}}_{i}$, chamado de Força de Pulay, que vem da derivação implícita através dos orbitais de Kohn-Sham:

$$
\tilde{\boldsymbol{F}}_{i}=\sum_{k} \int\left(\frac{\partial \psi_{k}^{*}(\boldsymbol{r})}{\partial \boldsymbol{R}_{i}} \frac{\partial E}{\partial \psi_{k}^{*}(\boldsymbol{r})}+\frac{\partial \psi_{k}(\boldsymbol{r})}{\partial \boldsymbol{R}_{i}} \frac{\partial E}{\partial \psi_{k}(\boldsymbol{r})}\right) \mathrm{d} \boldsymbol{r}
$$

Utilizando-se do fato que

$$
\frac{\partial E}{\partial \psi_{k}^{*}(\boldsymbol{r})}=\mathcal{H}^{\mathrm{KS}} \psi_{k}(\boldsymbol{r})
$$


e subtraindo o seguinte termo multiplicado por $\epsilon_{k}$

$$
0=\frac{\mathrm{d}}{\mathrm{d} \boldsymbol{R}_{i}} \int\left|\psi_{k}(\boldsymbol{r})\right|^{2} \mathrm{~d} \boldsymbol{r}=\left(\frac{\mathrm{d} \psi_{k}^{*}(\boldsymbol{r})}{\boldsymbol{R}_{i}} \psi_{k}(\boldsymbol{r}) \mathrm{d} \boldsymbol{r}+\psi_{k}^{*}(\boldsymbol{r}) \frac{\mathrm{d} \psi_{k}(\boldsymbol{r})}{\boldsymbol{R}_{i}} \mathrm{~d} \boldsymbol{r}\right)
$$

podemos reescrever a força de Pulay como:

$$
\tilde{\boldsymbol{F}}_{i}=\sum_{k} \int\left(\frac{\mathrm{d} \psi_{k}^{*}(\boldsymbol{r})}{\mathrm{d} \boldsymbol{R}_{i}}\left(H-\epsilon_{k}\right) \psi_{k}(\boldsymbol{r})+\frac{\mathrm{d} \psi_{k}(\boldsymbol{r})}{\mathrm{d} \boldsymbol{R}_{i}}\left(H-\epsilon_{k}\right) \psi_{k}^{*}(\boldsymbol{r})\right) \mathrm{d} \boldsymbol{r}
$$

Caso estejamos com funções de onda e densidade completamente convergidos para o estado fundamental, este termo se anula. Durante um cálculo, porém, isso não acontece. Em especial, a base na qual expandimos nossa função de onda não é completa, o que pode colocar em risco esta suposição. Como veremos a seguir, porém, mais uma das vantagens de se utilizar ondas planas como funções base é que as forças de Pulay são naturalmente nulas.

Se expandimos nossa função de onda de Kohn-Sham em uma determinada base ortonormal:

$$
\psi_{k}(\boldsymbol{r})=\sum_{p} C_{p i} \chi_{p}(\boldsymbol{r})
$$

chegamos a uma equação da forma

$$
\sum_{p}\left(H_{n p}-\epsilon_{i}\right) C_{p i}=0
$$

Inserindo a expansão da base na equação da força de Pulay, recaímos em:

$$
\tilde{\boldsymbol{F}}_{i}=\sum_{k} \sum_{m n} \frac{\partial C_{n k}}{\partial \boldsymbol{R}_{i}}\left(H_{m n}-\epsilon_{k}\right) C_{m k}+\sum_{m n} C_{n k} C_{m k} \int \frac{\partial \chi_{n}^{*}(\boldsymbol{r})}{\boldsymbol{R}_{i}}\left(H-\epsilon_{k}\right) \chi_{m}(\boldsymbol{r}) \mathrm{d} \boldsymbol{r}+\text { c.c. }
$$

Da equação anterior, o primeiro termo é automaticamente zero, mesmo em uma base incompleta. Já o segundo termo se anula pois a base de ondas planas não depende explicitamente das posições dos átomos; para outras bases isto não é verdade e este termo deve ser levado em conta. 


\subsubsection{Método LDA- $1 / 2$}

Muitas vezes, e por diferentes razões, os autovalores obtidos através da DFT mesmo para o HOMO apresentam problemas. O método LDA-1/2 [83] proposto por Luiz G. Ferreira e colaboradores se propõe a corrigir os níveis de energia do sistema. A idéia básica por trás deste método é introduzir um potencial perturbador em cada núcleo atômico, calculado $a$ priori, de forma que o cálculo DFT em si não sofre de nenhum acréscimo de custo computacional. A seguir esboçamos brevemente demonstração de como se obtêm a forma desse potencial perturbador.

Seja $f_{\alpha}$ uma função da ocupação do estado de uma partícula $\phi_{\alpha}$, de forma que $f_{\alpha}=0$ no estado fundamental e $f_{\alpha}=-1$ representa o sistema onde foi retirado um elétron do estado $\alpha$; então, de acordo com o teorema de Janak:

$$
\frac{\partial E}{\partial f_{\alpha}}=\mu_{\alpha}=e_{\alpha}\left(f_{\alpha}\right)
$$

onde $E$ é a energia total do sistema, e $e_{\alpha}$ é o autovalor daquele estado. Como $e_{\alpha}\left(f_{\alpha}\right)$ é praticamente linear com $f_{\alpha}$, integrar em ambos os lados entre $f_{\alpha}=-1$ e $f_{\alpha}=0$ nos dá

$$
E(0)-E(-1)=e_{\alpha}(-1 / 2)=- \text { potencial de ionização }
$$

Se chamamos

$$
\frac{\partial e_{\alpha}}{\partial f_{\alpha}}=2 S_{\alpha}
$$

de auto-energia do estado $\alpha$, e utilizarmos novamente a linearidade de $e_{\alpha}$, podemos escrever

$$
e_{\alpha}(-1 / 2)=e_{\alpha}(0)-S_{\alpha}
$$

e então

$$
E(0)=E(-1)+e_{\alpha}(0)-S_{\alpha}
$$


Da forma como definimos acima, a auto-energia assume a forma:

$$
\begin{aligned}
S_{\alpha}= & \iint \mathrm{d} \boldsymbol{r} \mathrm{d} \boldsymbol{r}^{\prime} n_{\alpha}(\boldsymbol{r}) n_{\alpha}\left(\boldsymbol{r}^{\prime}\right) v\left(\boldsymbol{r}, \boldsymbol{r}^{\prime}\right)+\frac{1}{2} \iint \mathrm{d} \boldsymbol{r} \mathrm{d} \boldsymbol{r}^{\prime} n_{\alpha}(\boldsymbol{r}) \frac{\delta^{2} E_{x c}}{\delta n(\boldsymbol{r}) \delta n\left(\boldsymbol{r}^{\prime}\right)} n_{\alpha}\left(\boldsymbol{r}^{\prime}\right) \\
& +\iint \mathrm{d} \boldsymbol{r} \mathrm{d} \boldsymbol{r}^{\prime} n_{\alpha}(\boldsymbol{r}) v\left(\boldsymbol{r}, \boldsymbol{r}^{\prime}\right) \sum_{\beta} f_{\beta} \frac{\partial n_{\beta}\left(\boldsymbol{r}^{\prime}\right)}{\partial f_{\alpha}} \\
& +\frac{1}{2} \iint \mathrm{d} \boldsymbol{r} \mathrm{d} \boldsymbol{r}^{\prime} n_{\alpha}(\boldsymbol{r}) \frac{\delta^{2} E_{x c}}{\delta n(\boldsymbol{r}) \delta n\left(\boldsymbol{r}^{\prime}\right)} \sum_{\beta} f_{\beta} \frac{\partial n_{\beta}\left(\boldsymbol{r}^{\prime}\right)}{\partial f_{\alpha}}
\end{aligned}
$$

que pode ser escrita em termos de um "potencial de auto-energia" $U_{S}(\boldsymbol{r})$ de forma que

$$
S_{\alpha}=\int n_{\alpha}(\boldsymbol{r}) U_{S, \alpha}(\boldsymbol{r}) \mathrm{d} \boldsymbol{r}
$$

Este potencial de auto-energia será adicionado ao nosso Hamiltoniano átomo a átomo. Para isso, demonstramos que esse potencial de auto-energia pode ser reescrito como a diferença do potencial atômico $U\left(f_{\alpha}, \boldsymbol{r}\right)$ entre o meio-íon $f_{\alpha}=-1 / 2$ e o átomo neutro $f_{\alpha}=0$ :

$$
\begin{aligned}
U(-1 / 2, \boldsymbol{r})-U(0, \boldsymbol{r})= & \int_{0}^{-1 / 2} \mathrm{~d} f_{\alpha} \frac{\partial}{\partial f_{\alpha}}\left\{-2 Z v(\boldsymbol{r}, 0)+2 \int \mathrm{d} \boldsymbol{r}^{\prime} n_{\alpha}\left(\boldsymbol{r}^{\prime}\right) v\left(\boldsymbol{r}-\boldsymbol{r}^{\prime}\right)+\frac{\delta E_{x c}}{\delta n(\boldsymbol{r})}\right\} \\
= & \int_{0}^{-1 / 2} \mathrm{~d} f_{\alpha}\left\{2 \int \mathrm{d} \boldsymbol{r}^{\prime} n_{\alpha}\left(\boldsymbol{r}^{\prime}\right) v\left(\boldsymbol{r}, \boldsymbol{r}^{\prime}\right)+\int \mathrm{d} \boldsymbol{r}^{\prime} \frac{\delta^{2} E_{x c}}{\delta n(\boldsymbol{r}) \delta n\left(\boldsymbol{r}^{\prime}\right)} n_{\alpha}\left(\boldsymbol{r}^{\prime}\right)\right\} \\
& +\int_{0}^{-1 / 2} \mathrm{~d} f_{\alpha}\left\{2 \int \mathrm{d} \boldsymbol{r}^{\prime} v\left(\boldsymbol{r}, \boldsymbol{r}^{\prime}\right) \sum_{\beta} f_{\beta} \frac{\partial n_{\beta}\left(\boldsymbol{r}^{\prime}\right)}{\partial f_{\alpha}}\right. \\
& \left.+\int \mathrm{d} \boldsymbol{r}^{\prime} \frac{\delta^{2} E_{x c}}{\delta n(\boldsymbol{r}) \delta n\left(\boldsymbol{r}^{\prime}\right)} \sum_{\beta} f_{\beta} \frac{\partial n_{\beta}\left(\boldsymbol{r}^{\prime}\right)}{\partial f_{\alpha}}\right\}
\end{aligned}
$$

ou, segundo o teorema do valor médio, para um determinado valor de $f_{\alpha} \in[-1 / 2,0]$

$$
\begin{aligned}
U(-1 / 2, \boldsymbol{r})-U(0, \boldsymbol{r})= & \int \mathrm{d} \boldsymbol{r}^{\prime} n_{\alpha}\left(\boldsymbol{r}^{\prime}\right) v\left(\boldsymbol{r}, \boldsymbol{r}^{\prime}\right)+\frac{1}{2} \int \mathrm{d} \boldsymbol{r}^{\prime} \frac{\delta^{2} E_{x c}}{\delta n(\boldsymbol{r}) \delta n\left(\boldsymbol{r}^{\prime}\right)} n_{\alpha}\left(\boldsymbol{r}^{\prime}\right) \\
& +\int \mathrm{d} \boldsymbol{r}^{\prime} v\left(\boldsymbol{r}, \boldsymbol{r}^{\prime}\right) \sum_{\beta} f_{\beta} \frac{\partial n_{\beta}\left(\boldsymbol{r}^{\prime}\right)}{\partial f_{\alpha}} \\
& +\frac{1}{2} \int \mathrm{d} \boldsymbol{r}^{\prime} \frac{\delta^{2} E_{x c}}{\delta n(\boldsymbol{r}) \delta n\left(\boldsymbol{r}^{\prime}\right)} \sum_{\beta} f_{\beta} \frac{\partial n_{\beta}\left(\boldsymbol{r}^{\prime}\right)}{\partial f_{\alpha}} \\
= & U_{S, \alpha}(\boldsymbol{r})
\end{aligned}
$$


Este potencial de auto-energia é então adicionado ao potencial atômico de cada espécie atômica do sistema (no nosso caso, ao termo local do pseudopotencial, vide eq. 2.96]). Como este termo tem uma cauda de longo alcance, utilizamos também uma função de cut-off da forma

$$
\Theta(r)=\left\{\begin{aligned}
{\left[1-\left(\frac{r}{C U T}\right)^{8}\right]^{3}, } & r \leq C U T \\
0, & r>C U T
\end{aligned}\right.
$$

onde o parâmetro CUT, que define o alcance da interação, é escolhido de forma a achar um extremo para o gap de energia do sistema estudado.

Este procedimento é utilizado apenas para obter a correção aos autovalores de energia, após o cálculo DFT completo ter sido realizado para otimização de geometria, com o pseudopotencial correspondente original. 


\section{Capítulo 3}

\section{Métodos de Muitos Corpos}

Conforme descrito no capítulo anterior, para descrever propriedades relacionadas a estados excitados é indispensável ir além da aproximação de partícula independente, e tratar o problema de muitos corpos.

Existem dois tipos principais de metodologias neste grau teórico: aquelas adequadas para descrever excitações de uma partícula (adição ou remoção de um elétron), que nos dão valores precisos para Afinidade Eletrônica, Potencial de Ionização e gap elétrico; e aquelas adequadas para descrever excitações duplas neutras (remoção e adição simultânea de um elétron em estados diferentes), voltadas para transições óticas do sistema, e que nos dão o gap ótico, espectro de absorção e nos permitem caracterizar os excitons do sistema.

Esta diferenciação das excitações em dois grupos deve ser clara para que não sejam feitas comparações entre propriedades distintas, como o gap elétrico e ótico, ao compararmos resultados teóricos e experimentais.

Abaixo descrevemos as metodologias utilizadas neste trabalho. Do primeiro grupo apresentamos a teoria de perturbação de Møller-Plesset e a aproximação GW, e do segundo grupo o método de Interação de Configurações, em sua forma original ab-initio e na forma parametrizada MSINDO.

\subsection{Estado Fundamental: Teoria de Perturbação}

Conforme comentado anteriormente, no Hartree-Fock por definição não é incluido o tratamento da correlação eletrônica, que pode inclusive ser definida como a diferença entre a 
energia exata do estado fundamental do sistema de $\mathrm{N}$ elétrons, $E_{0}$, e a energia obtida pela aproximação Hartree-Fock:

$$
E_{\text {corr }}=E_{0}-E_{\mathrm{HF}}
$$

Uma forma de recuperarmos a correlação é expandirmos a energia exata do sistema em termos perturbativos. Na teoria de perturbação de Rayleigh-Schrödinger, a um Hamiltoniano qualquer se adiciona uma perturbação $\Lambda$ :

$$
\mathcal{H}=\mathcal{H}_{0}+\Lambda
$$

onde $\mathcal{H}_{0}$ é o Hamiltoniano não perturbado, com energias $E_{i}^{(0)}$ e autofunções $\left|\phi_{i}^{(0)}\right\rangle$, ou seja:

$$
\mathcal{H}_{0}\left|\phi_{i}^{(0)}\right\rangle=E_{i}^{(0)}\left|\phi_{i}^{(0)}\right\rangle
$$

Se $\mathcal{H}$ é o Hamiltoniano perturbado, e a auto-função do estado fundamental e sua respectiva energia são $\left|\phi_{0}\right\rangle$ e $E_{0}$

$$
\mathcal{H}\left|\phi_{0}\right\rangle=E_{0}\left|\phi_{0}\right\rangle
$$

podemos obtê-las em princípio por expansões em termos sucessivos:

$$
\begin{aligned}
E_{0} & =E_{0}^{(0)}+\delta E_{0}^{(1)}+\delta E_{0}^{(2)}+\cdots \\
\left|\phi_{0}\right\rangle & =\left|\phi_{0}^{(0)}\right\rangle+\left|\phi_{0}^{(1)}\right\rangle+\left|\phi_{0}^{(2)}\right\rangle+\cdots
\end{aligned}
$$

onde $\delta E_{0}^{(j)}$ e $\left|\phi_{0}^{(j)}\right\rangle$, com $j \geq 1$, são correções de $j$-ésima ordem que satisfazem as condições

$$
\left\langle\phi_{0}^{(0)} \mid \phi_{0}^{(j)}\right\rangle=0
$$

Os termos de correção na energia são calculados como:

$$
\begin{aligned}
\delta E_{0}^{(1)}= & \left\langle\phi_{0}^{(0)}|\Lambda| \phi_{0}^{(0)}\right\rangle \\
\delta E_{0}^{(2)}= & \left\langle\phi_{0}^{(0)}|\Lambda| \phi_{0}^{(1)}\right\rangle \\
\delta E_{0}^{(3)}= & \left\langle\phi_{0}^{(0)}|\Lambda| \phi_{0}^{(2)}\right\rangle \\
& \vdots \\
\delta E_{0}^{(n)}= & \left\langle\phi_{0}^{(0)}|\Lambda| \phi_{0}^{(n-1)}\right\rangle
\end{aligned}
$$


Já para a auto-função, a correção de primeira ordem é dada por:

$$
\left|\phi_{0}^{(1)}\right\rangle=\sum_{i \neq 0} \frac{\left\langle\phi_{i}^{(0)}|\Lambda| \phi_{0}^{(0)}\right\rangle}{\left(E_{0}^{(0)}-E_{i}^{(0)}\right)}\left|\phi_{i}^{(0)}\right\rangle
$$

que substituída na equação da energia de segunda ordem nos dá:

$$
E_{0}^{(2)}=\sum_{i \neq 0} \frac{\left|\left\langle\phi_{0}^{(0)}|\Lambda| \phi_{i}^{(0)}\right\rangle\right|^{2}}{E_{0}^{(0)}-E_{i}^{(0)}}
$$

Esta expansão é válida para qualquer Hamiltoniano e qualquer perturbação. Para aplicar esta teoria à nossa formulação do Hartree-Fock devemos usar a separação de Møller-Plesset [84] para o Hamiltoniano, obtendo a assim chamada Teoria de Perturbação de Møller-Plesset. Neste caso, o hamiltoniano não perturbado e a perturbação são escritos, respectivamente, como:

$$
\begin{aligned}
\mathcal{H}_{0} & =\sum_{\mu=1}\left\{\mathcal{H}^{\mu}+\sum_{i=1}\left[\mathcal{J}_{i}^{\mu}-\mathcal{K}_{i}^{\mu}\right]\right\}=\sum_{\mu=1} F^{\mu} \\
\Lambda & =\sum_{\mu=1}\left\{\frac{1}{2} \sum_{\nu \neq \mu} \mathcal{V}^{\mu \nu}-\sum_{i=1}\left[\mathcal{J}_{i}^{\mu}-\mathcal{K}_{i}^{\mu}\right]\right\}
\end{aligned}
$$

de modo que $\mathcal{H}_{0}$ é o Hamiltoniano utilizado na aproximação de Hartree-Fock (equação 2.17 ) e $\mathcal{H}$ é o Hamiltoniano original de $\mathrm{N}$ partículas (equação ए.4). Adota-se também que $\phi_{0}^{(0)}=\Psi_{0}$, a função de onda total (determinante de Slater) obtida pelo método Hartree-Fock.

As demais funções $\phi_{0}^{(i)}$ para a expansão perturbativa são definidas como as funções de onda determinantais $\left|\Psi_{a b \ldots .}^{r s . .}\right\rangle$, obtidas também a partir da solução original de Hartree-Fock para aquele sistema, pela "promoção" de elétrons de spin-orbitais $\left|\psi_{a}\right\rangle,\left|\psi_{b}\right\rangle, \ldots$ originalmente ocupados, para spin-orbitais virtuais $\left|\psi_{r}\right\rangle,\left|\psi_{s}\right\rangle, \cdots, \operatorname{com} r, s, \cdots>N$. As energias associadas a estas auto-funções são, nesta aproximação, tomadas como

$$
E_{a b \cdots \rightarrow r s \ldots}^{(0)}=E_{0}^{(0)}+\epsilon_{r}+\epsilon_{s}+\cdots-\epsilon_{a}-\epsilon_{b}-\ldots
$$


Pela definição de $\mathcal{H}_{0}$ e do estado de referência $\left|\Psi_{0}\right\rangle$, teríamos que

$$
E_{0}^{(0)}=\sum_{k=1}^{N} \epsilon_{k},
$$

mas já no Hartree-Fock a energia total do sistema não é dada simplesmente pela soma das energias de uma partícula. Ao aplicar a correção de primeira ordem, recaímos na expressão para a energia total já obtida anteriormente (equação [2.19).

Um cálculo de energia com correção até segunda ordem é conhecido como Teoria de Perturbação de Møller-Plesset de Segunda Ordem (MP2), e a correção à energia total do Estado Fundamental por ele introduzida é escrita, a partir de [.], como:

$$
E_{0}^{(2)}=\sum_{\substack{a<b \\ r<s}} \frac{\left|\left\langle\Phi_{0}|\Lambda| \Phi_{a b}^{r s}\right\rangle\right|^{2}}{\epsilon_{r}+\epsilon_{s}-\epsilon_{a}-\epsilon_{b}}
$$

Nesta somatória estão inclusos o estado fundamental e a princípio todas as excitações duplas.

Ordens maiores de perturbação poderiam ser utilizadas, mas a relação "custo-benefício" nessa segunda ordem é muito boa. Utilizando MP2 recuperamos cerca de 80-90\% da energia de correlação, na maioria dos casos [85], e é assim extensivamente utilizado para obtenção de propriedades típicas de estado fundamental, como por exemplo a geometria de equilíbrio.

\subsection{Excitações Duplas Neutras: Interação de Configura- ções}

Uma forma de se estudar estados excitados é através do método de Interação de Configurações (Configuration Interaction, CI), adequado ao Hartree-Fock como ponto de partida, e que pode ser utilizado tanto de forma ab-initio quanto parametrizada (métodos semiempíricos, seção [2:2]).

Neste método passamos do espaço de 1 elétron, no qual nossa base de funções são spinorbitais (de um elétron) $\psi_{i}$, ao espaço de $\mathrm{N}$ elétrons, em que utilizamos, já como base, funções determinantais de Slater, construídas a partir de diferentes conjuntos de estados de um elétron. O estado de partida para construção da base é aquele vindo dos orbitais de um 
elétron ocupados $\psi_{1}, \ldots, \psi_{N}$ :

$$
\Psi_{0}^{0}=\operatorname{det}\left(\psi_{1}, \ldots, \psi_{N}\right)
$$

obtidos no cálculo Hartree-Fock para aquele sistema. Substituindo neste determinante um estado ocupado $i$ por um estado desocupado $a$, obtemos uma função base

$$
\Psi_{i}^{a}=\operatorname{det}\left(\psi_{1}, \ldots, \psi_{i-1}, \psi_{a}, \psi_{i+1}, \ldots, \psi_{N}\right)
$$

Esta função de onda $\Psi_{i}^{a}$ equivaleria à criação de um "buraco" $i$ abaixo do nível de Fermi e uma "partícula" a acima do nível de Fermi, ou seja, uma configuração eletrônica "excitada neutra". De forma equivalente, podemos substituir dois, três ou mais níveis ocupados por outros desocupados, criando assim configurações com excitações duplas, triplas, etc.

Estes determinantes formam em princípio uma base completa, e portanto qualquer função de onda exata de $N$ elétrons (estado fundamental ou excitado do sistema) poderia ser escrita como uma combinação linear destes determinantes:

$$
\Psi=c_{0}^{0} \Psi_{0}^{0}+\sum_{i=1}^{N} \sum_{a=N+1} c_{i}^{a} \Psi_{i}^{a}+\sum_{i>j=1}^{N} \sum_{a>b=N+1} c_{i j}^{a b} \Psi_{i j}^{a b}+\sum_{i>j>k=1}^{N} \sum_{a>b>c=N+1} c_{i j k}^{a b c} \Psi_{i j k}^{a b c}+\cdots
$$

A determinação dos coeficientes $c$ acima se dá através da solução de $\mathcal{H} \Psi=E \Psi$, que pode ser demonstrado equivalente ao problema de autovalores

$$
\sum_{J B} H_{I, J}^{A, B} c_{J}^{B}=E c_{I}^{A}
$$

onde os pares $I, A$ e $J, B$ representam cada qual uma excitação, de qualquer ordem, e

$$
H_{I, J}^{A, B}=\left\langle\Psi_{I}^{A}|\mathcal{H}| \Psi_{J}^{B}\right\rangle
$$

A solução de energia mais baixa representará o estado fundamental do sistema, ao passo que as demais soluções, com energias crescentes, representam os estados excitados. Assim, as diferentes configurações eletrônicas interagem entre si através do Hamiltoniano $\mathcal{H}$, aproximando-se dos valores exatos.

A expansão 3.18 é, em geral, truncada até uma determinada ordem de excitações; chamamos de CIS (CI-singles) aquelas que só incluem excitações de primeira ordem, CISD 
(CI-singles and doubles) aquelas que incluem excitações simples e duplas, etc. Neste trabalho vamos nos restringir ao CIS.

O problema de autovalores para CIS se reduz à forma geral abaixo, com $(i, j)$ restritos a estados ocupados e $(a, b)$ a estados desocupados:

$$
\left[\begin{array}{ccc}
H_{0,0}^{0,0} & H_{0, i}^{0, a} & H_{0, j}^{0, b} \\
H_{i, 0}^{a, 0} & H_{i, i}^{a, a} & H_{i, j}^{a, b} \\
H_{j, 0}^{b, 0} & H_{j, i}^{b, a} & H_{j, j}^{b, b}
\end{array}\right]\left[\begin{array}{c}
c_{0}^{0} \\
c_{i}^{a} \\
c_{j}^{b}
\end{array}\right]=E\left[\begin{array}{c}
c_{0}^{0} \\
c_{i}^{a} \\
c_{j}^{b}
\end{array}\right]
$$

O Hamiltoniano $\mathcal{H}$ só envolve operadores de uma e duas partículas, e como os orbitais $\psi_{i}$ são ortonormais, temos imediatamente que:

$$
\left\langle\Psi_{i}^{a}|\mathcal{H}| \Psi_{0}\right\rangle=\left\langle\psi_{a}|\mathcal{F}| \psi_{i}\right\rangle=\delta_{i a} \varepsilon_{i}
$$

(Teorema de Brillouin) ou seja, o Hamiltoniano $\mathcal{H}$ não acopla excitações simples diretamente ao estado fundamental: seriam para tal necessárias excitações duplas CISD. Nosso objetivo são os estados excitados (não descritos pela aproximação Hartree-Fock) obtidos pela resolução da equação

$$
\left[\begin{array}{ccc}
H_{0,0}^{0,0} & 0 & 0 \\
0 & H_{i, i}^{a, a} & H_{i, j}^{a, b} \\
0 & H_{j, i}^{b, a} & H_{j, j}^{b, b}
\end{array}\right]\left[\begin{array}{c}
c_{0}^{0} \\
c_{i}^{a} \\
c_{j}^{b}
\end{array}\right]=E\left[\begin{array}{c}
c_{0}^{0} \\
c_{i}^{a} \\
c_{j}^{b}
\end{array}\right]
$$

que acopla diferentes excitações simples. A solução deste problema de autovalores nos fornece um conjunto de funções de onda CIS $\Psi_{m}$, uma combinação linear de estados eletrônicos $\Psi_{i}^{a}$ através de coeficientes $c_{i}^{a}(m)$, e a sua respectiva energia $E_{m}$.

Para obter o espectro óptico, estamos interessados nas transições do estado fundamental para um estado excitado, ou seja, nas diferenças $E_{\text {trans }}=E_{m}-E_{0}$. Além disso, para obter o espectro de absorção devemos calcular também a chamada força de oscilador de cada transição

$$
f_{0 m}=\frac{2}{3} \frac{m_{e}}{\hbar^{2}}\left(E_{m}-E_{0}\right)\left|\left\langle\Psi_{m}\left|\sum_{\mu}^{N} \boldsymbol{r}^{\mu}\right| \Psi_{0}\right\rangle\right|^{2}
$$

associada ao momento de dipolo de transição entre os estados inicial e final.

Para cada transição ótica definimos aqui também as densidades de probabilidade do 
elétron e do buraco, escritas como[주]:

$$
\begin{aligned}
& \rho_{h}^{m}(\boldsymbol{r})=\sum_{i a}\left|c_{i}^{a}(m) \psi_{i}(\boldsymbol{r})\right|^{2} \\
& \rho_{e}^{m}(\boldsymbol{r})=\sum_{i a}\left|c_{i}^{a}(m) \psi_{a}(\boldsymbol{r})\right|^{2}
\end{aligned}
$$

Estas densidades de probabilidade nos permitem em princípio obter o caráter de transferência de carga presente em uma excitação, e serão utilizadas também para a visualização espacial dos excitons no capítulo dos resultados.

\subsubsection{A Parametrização MSINDO}

Conforme dito na seção [2:2] sobre métodos semi-empíricos, assim como para o HartreeFock, também existem parametrizações para o CIS. Neste trabalho escolhemos o método MSINDO, em virtude de alguns detalhes específicos de sua implementação, que nos permitem estudar sistemas periódicos e tratar grandes matrizes de estados, descritos abaixo.

Iniciando ainda pelas aproximações para o cálculo de Hartree-Fock, de forma a melhorar a factibilidade de cálculo são adotadas parametrizações semi-empíricas para as integrais do termo de Fock [87, 88], e também o uso do caroço congelado para reduzir o número de elétrons para o mínimo (no caso do Titânio, por exemplo, apenas os orbitais ocupados 3d e 4s são calculados explicitamente)

O Modelo de Aglomerado Cíclico, ou Cyclic Cluster Model[8.9, 90, 91, 92] é a proposta presente no código MSINDO para tratar sistemas periódicos. É inicialmente criado um "super aglomerado (cluster)" através de repetição da célula unitária original, de forma a manter uma boa descrição das interações de longo alcance, já que não serão incluídos pontos k no cálculo.

Outras aproximações para a simulação de sistemas periódicos a partir de aglomerados finitos utilizam o conceito de pseudo-átomos [93, 94] que agem como saturadores na "superfície" do cluster, para impedir a presença de orbitais "flutuantes" (dangling bonds) ou ligações quebradas que perturbam toda a estrutura eletrônica do sistema. No formalismo do cluster cíclico, nas extremidades do sistema são incluídas duplicatas dos átomos correspondentes da extremidade oposta, de forma que mesmo os átomos que formariam a superfície do sistema estão "cercados de átomos", criando assim um sistema cíclico. 
Por exemplo, em um sistema $1 \mathrm{D}$ composto pelos átomos $\mathrm{A}_{1}$ e $\mathrm{B}_{1}$ da figura [.], primeiramente construímos o super cluster repetindo estes átomos (átomos $\mathrm{A}_{2}, \mathrm{~B}_{2}, \mathrm{~A}_{3}$ e $\mathrm{B}_{3}$ ), com um parâmetro de rede efetivo $a$, que constitui o "super cluster".

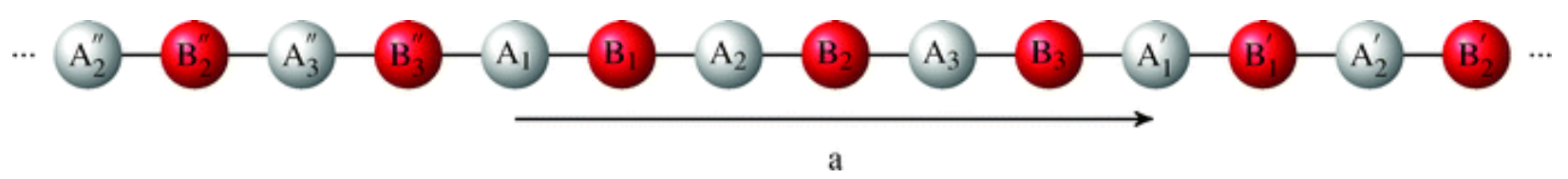

Figura 3.1: Esquema 1D para o Modelo de Aglomerado Cíclico (CCM). Retirado de[92].

A partir do super cluster, são introduzidas cópias dos átomos nas extremidades, através de translações do parâmetro de rede (na figura, translações positivas são demonstradas com aspas simples e as negativas com aspas duplas).

Para cada átomo do cluster é criado também um raio de interação, correspondente à metade desse parâmetro de rede. Desta forma, o átomo $A_{1}$ por exemplo interagiria com os átomos $\mathrm{B}_{2}$ ", $\mathrm{A}_{3}$ ", $\mathrm{B}_{3}$ ", $\mathrm{B}_{1}, \mathrm{~A}_{2}$ e $\mathrm{B}_{2}$. Além disso, de forma a evitar momentos de dipolo espúrios, a interação com os átomos da borda deste raio de interação (que são equivalentes entre si) é reduzida por um peso apropriado (no caso 1D, por exemplo, o peso seria um fator $0.5)$.

Em um cálculo CIS as matrizes a serem diagonalizadas crescem rapidamente com o número de funções-base. No código MSINDO foi escolhido o método de Diagonalização de Davidson, eficiente para matrizes esparsas grandes; este é um método iterativo, que substitui a diagonalização de uma matriz grande de uma só vez por uma sequência de diagonalizações de matrizes menores.

Primeiramente é escolhido um conjunto de $L$ funções base ortonormais, de forma que os autovalores exatos do Hamiltoniano CIS $\left|\Psi^{k}\right\rangle$ sejam expandidos através dos coeficientes $\alpha_{i}^{k}$ :

$$
\left|\Psi^{k}\right\rangle=\sum_{i}^{L} \alpha_{i}^{k}\left|\phi_{i}\right\rangle
$$

e assim construímos uma nova matriz do Hamiltoniano CIS, de dimensão $L \times L$ :

$$
H_{i j}=\left\langle\phi_{i}|\mathcal{H}| \phi_{j}\right\rangle=\left\langle\phi_{i} \mid \varphi_{j}\right\rangle
$$

Se definirmos os autovalores desta matriz de $\lambda^{k}$ e seus autovetores de $\left|c^{k}\right\rangle$, podemos 
também definir os vetores de correção

$$
\left|\Psi^{k}\right\rangle-\left|c^{k}\right\rangle=\left|\delta^{k}\right\rangle
$$

que está diretamente relacionado ao vetor resíduo $\left|r^{k}\right\rangle$ :

$$
\left(\mathcal{H}-\lambda^{k}\right)\left|\delta^{k}\right\rangle=-\left(\mathcal{H}-\lambda^{k}\right)\left|\delta^{k}\right\rangle=\left|r^{k}\right\rangle
$$

Os resíduos podem ser calculados utilizando as equações $\mathbf{3 . 2 7}$ e 3.28 :

$$
\left|r^{k}\right\rangle=\sum_{i}^{L} \alpha_{i}^{k}\left(\lambda\left|\phi_{i}\right\rangle-\left|\varphi_{i}\right\rangle\right)
$$

Como a matriz do CIS é esparsa, e dominada pelos elementos da diagonal, podemos inverter a equação 3.30 para obter os vetores $\left|\delta^{k}\right\rangle$ a partir dos resíduos:

$$
\left|\delta^{k}\right\rangle \approx\left(\boldsymbol{D}-\lambda^{k} \mathbf{1}\right)^{-1}\left|r^{k}\right\rangle
$$

onde $\boldsymbol{D}$ é uma matriz diagonal, que é aproximada pelas diferenças das energias orbitais dos estados de um elétron.

Utilizando os vetores de base existentes $\left|\phi_{i}\right\rangle$ e os novos vetores de correção $\left|\delta^{k}\right\rangle$, uma nova base é formada, através de uma ortogonalização de Gram-Schmidt. Utilizando esta nova base o cálculo é refeito, até que os resíduos caiam abaixo de um valor de convergência pré-determinado.

\subsection{Excitações de Uma Partícula: Aproximação GW}

Nas metodologias de campo médio (DFT ou Hartree-Fock) obter o real valor para as energias de excitações de uma partícula (adição de um elétron ou de um buraco) é um desafio; apesar dos teoremas de Koopmans e Janak nos garantirem alguma relação entre as energias de níveis de uma partícula ocupados e a energia necessária para retirar aquele elétron, nem sempre eles representam valores precisos, já que desprezamos toda a energia de relaxação eletrônica. Para os níveis não ocupados, nem estas relações podemos fazer, e o uso das energias de uma partícula de estados virtuais como energias de adição de um elétron, 
como se pode prever, não apresenta bons resultados.

Um caminho para obter estas energias vem da aplicação da Teoria de Perturbação de Muitos Corpos ([95, 96], entre outros) através do uso de funções de Green. Neste formalismo o sistema original de partículas fortemente interagentes é representado por quase-partículas fracamente interagentes. Estas quase-partículas, como será melhor explicado abaixo, representam elétrons (e "buracos") que descrevem o conjunto de partículas do sistema original interagindo através de uma blindagem (screened interaction). Sendo um método perturbativo, é possível construir uma série convergente de termos e truncá-la no valor realizável.

Partimos da função de Green de uma partícula, definida como:

$$
i G(1,2)=\left\langle N\left|\mathcal{T}\left[\hat{\psi}(1) \hat{\psi}^{\dagger}(2)\right]\right| N\right\rangle
$$

onde $|N\rangle$ é o estado fundamental de um sistema de $\mathrm{N}$ elétrons, $\hat{\psi}(1)$ é o operador de campo na representação de Heisenberg que destrói um elétron em $1=\left(x_{1}, t_{1}\right)$ e $\hat{\psi}^{\dagger}(2)$ aquele que cria um elétron em $2=\left(x_{2}, t_{2}\right)$; aqui $\mathcal{T}$ é o operador de ordem temporal, definido como:

$$
\mathcal{T}\left[\hat{\psi}(1) \hat{\psi}^{\dagger}(2)\right]=\left\{\begin{array}{rll}
\hat{\psi}(1) \hat{\psi}^{\dagger}(2) & \text { se } & t_{1}>t_{2} \\
-\hat{\psi}^{\dagger}(2) \hat{\psi}(1) & \text { se } & t_{2}>t_{1}
\end{array}\right.
$$

A interpretação física da função de Green diz respeito, para $t_{1}>t_{2}$, à amplitude de probabilidade de que um elétron criado em $x_{2}, t_{2}$ se propague até $x_{1}, t_{1}$; para $t_{2}>t_{1}$ temos a amplitude de probabilidade de, em $t_{2}$, encontrarmos um "buraco" em $x_{2}$, se retiramos um elétron de $x_{1}$ em $t_{1}$.

O interessante da função de Green é que podemos utilizá-la para encontrar todas as propriedades do sistema dependendes de uma partícula. De fato, se $\mathcal{J}$ é um operador de uma partícula:

$$
\begin{aligned}
\mathcal{J} & =\int \hat{\psi}^{\dagger}(1) J(1,2) \hat{\psi}(2) \delta\left(t_{2}-t_{1}\right) \mathrm{d} 1 \mathrm{~d} 2 \\
\langle N|\mathcal{J}| N\rangle & =\int J(1,2) \delta\left(t_{2}-t_{1}\right)\left\langle N\left|\hat{\psi}^{\dagger}(1) \hat{\psi}(2)\right| N\right\rangle \mathrm{d} 1 \mathrm{~d} 2 \\
& =-i \int \delta\left(t_{2}-t_{1}^{+}\right) J(1,2) G(2,1) \mathrm{d} 1 \mathrm{~d} 2
\end{aligned}
$$

onde $t_{1}^{+}=t_{1}+\delta, \delta>0$. 
Em particular, a densidade $n\left(x_{1}, t_{1}\right)$ pode ser escrita como:

$$
n(1)=-i \hbar G\left(1,1^{+}\right)
$$

Para construirmos a equação que dá a dinâmica da função de Green, partimos da dinâmica do operador de campo

$$
i \hbar \frac{\partial \hat{\psi}(1)}{\partial t}=[\hat{\psi}(1), \mathcal{H}]
$$

onde escrevemos o Hamiltoniano na notação de segunda quantização

$$
\mathcal{H}=\int \hat{\psi}^{\dagger}(1) h_{0}(1) \hat{\psi}(1) \mathrm{d} 1+\frac{1}{2} \iint \hat{\psi}^{\dagger}(1) \hat{\psi}^{\dagger}(2) v\left(\boldsymbol{r}_{1}, \boldsymbol{r}_{2}\right) \hat{\psi}(2) \hat{\psi}(1) \delta\left(t_{1}-t_{2}\right) \mathrm{d} 1 \mathrm{~d} 2
$$

e agrupamos no termo $h_{0}$ os termos de uma partícula, sendo $v$ a interação entre duas partículas.

Utilizando a definição da função de Green, e as equações acima, podemos chegar a

$$
\left[i \hbar \frac{\partial}{\partial t_{1}}-h_{0}(1)\right] G(1,2)=\delta(1-2)-i \hbar \int v\left(\boldsymbol{r}_{1}, \boldsymbol{r}_{3}\right) G_{2}\left(1,3,3^{+}, 2\right) \delta\left(t_{1}-t_{3}\right) \mathrm{d} 3
$$

sendo $3^{+}=\left(\boldsymbol{r}_{3}, t_{3}^{+}\right)$, e é trazida já a função de Green de duas partículas

$$
G_{2}(1,2,3,4)=(-i)^{2}\left\langle N\left|\mathcal{T}\left[\hat{\psi}(1) \hat{\psi}(2) \hat{\psi}^{\dagger}(3) \hat{\psi}^{\dagger}(4)\right]\right| N\right\rangle
$$

Do mesmo modo que para obter a função de Green de uma partícula dependemos da função de Green de duas partículas, quando tentamos obter explicitamente $G_{2}$ obtemos uma dependência de funções de Green de ordens maiores. Neste ponto, reescrevemos a função de Green de duas partículas como o produto de funções de Green de uma partícula, com a adição de um termo $\Lambda$ :

$$
G_{2}\left(1,3,3^{+}, 2\right)=G(1,2) G\left(3,3^{+}\right)+\Lambda
$$


Utilizando esta expansão para o último termo de 3.40 obtemos

$$
\begin{array}{r}
-i \hbar \int v\left(\boldsymbol{r}_{1}, \boldsymbol{r}_{3}\right) G_{2}\left(1,3,3^{+}, 2\right) \delta\left(t_{1}-t_{3}\right) \mathrm{d} 3= \\
-i \hbar \int v\left(\boldsymbol{r}_{1}, \boldsymbol{r}_{3}\right) G(1,2) G\left(3,3^{+}\right) \delta\left(t_{1}-t_{3}\right) \mathrm{d} 3-i \hbar \int v\left(\boldsymbol{r}_{1}, \boldsymbol{r}_{3}\right) \Lambda \delta\left(t_{1}-t_{3}\right) \mathrm{d} 3
\end{array}
$$

cujo primeiro termo está relacionado, utilizando a equação 3.37 , com um operador de Hartree $V_{H}$ aplicado à função de Green $G(1,2)$ :

$$
\begin{aligned}
-i \hbar \int v\left(\boldsymbol{r}_{1}, \boldsymbol{r}_{3}\right) G(1,2) G\left(3,3^{+}\right) \delta\left(t_{3}-t_{1}\right) \mathrm{d} 3 & =\int v\left(\boldsymbol{r}_{1}, \boldsymbol{r}_{3}\right) G(1,2) n(3) \delta\left(t_{3}-t_{1}\right) \mathrm{d} 3 \\
& =V_{H}(1) G(1,2)
\end{aligned}
$$

Já o segundo termo, que contém as demais interações de duas partículas, é em geral escrito em termos do operador de auto-energia $\Sigma$ (do inglês self-energy):

$$
\Sigma(1,3) G(3,2)=-i \hbar v\left(\boldsymbol{r}_{1}, \boldsymbol{r}_{3}\right) \Lambda \delta\left(t_{1}-t_{3}\right)
$$

Reescrevendo a equação [3.40, podemos passar o termo de Hartree para o primeiro lado, e com $H_{0}=h_{0}+V_{H}$ chegamos a:

$$
\left[i \hbar \frac{\partial}{\partial t_{1}}-H_{0}(1)\right] G(1,2)-\int \Sigma(1,3) G(3,2) \mathrm{d} 3=\delta(1-2)
$$

No caso mais simplificado $\Sigma=0$, equivalente ao problema de Hartree $(\Lambda=0)$, a equação acima passa a ser:

$$
\left[i \hbar \frac{\partial}{\partial t_{1}}-H_{0}(1)\right] G_{0}(1,2)=\delta(1-2)
$$

Multiplicando agora à esquerda a equação $\sqrt{3.46}$ por $G_{0}$ e a equação 3.47 por $G$, e integrando-as, chegamos à equação de Dyson

$$
G(1,2)=G_{0}(1,2)+\iint G_{0}(1,3) \Sigma(3,4) G(4,2) \mathrm{d} 3 \mathrm{~d} 4
$$

em que novamente temos presente $\Sigma$.

Esta é uma equação integral, que pode ser resolvida iterativamente, ou seja, no passo $i$ resolvemos para $G_{i}(1,2)$ em termos de $G_{i-1}(1,2)$. Para tal devemos especificar a forma de 
$\Sigma$. Como exemplo, se utilizarmos $\Sigma(1,2)=i \hbar v\left(1^{+}, 2\right) G(1,2)$, este termo fica equivalente ao termo de troca e recaímos na aproximação de Hartree-Fock.

As equações de Hedin [97] representam um sistema cíclico de equações, a priori exatas, para definir $\Sigma$. Na sua derivação utiliza-se um processo adiabático, introduzindo-se um potencial externo $U(1)$ ao Hamiltoniano $H(1)$ que depois será levado a zero. Emprega-se aqui também a representação de interação (Interaction Picture), em que o potencial $U$ é tido como uma perturbação de $H$.

Nesta dedução, apenas de forma a facilitar a visualização dos resultados, não serão escritas as integrais, que devem ser realizadas sobre os índices diferentes de 1,2,3. Todas as derivadas parciais devem, também, ser tomadas no valor $U=0$.

Define-se como função resposta $R$ a reação da densidade eletrônica do sistema a mudanças no potencial externo

$$
R(1,2)=\frac{\partial n(1)}{\partial U(2)}
$$

Podemos definir assim um novo potencial "efetivo" que leva em conta também a interação coulombiana causada pelas cargas induzidas

$$
U_{e}(1)=U(1)+v(1,4) R(4,2) U(2)
$$

relacionado a $U(1)$ pela inversa da função dielétrica

$$
\varepsilon^{-1}(1,2)=\frac{\partial U_{e}(1)}{\partial U(2)}=\delta(1,2)+v(1,4) R(4,2)
$$

(o lado direito vem da definição de $U_{e}$ ). Define-se também a função de polarização

$$
P(1,2)=\frac{\partial n(1)}{\partial U_{e}(2)}
$$

e usando as regras de derivação funcional, podemos reescrever a função dielétrica direta- 
mente:

$$
\begin{aligned}
\varepsilon^{-1}(1,2) & =\delta(1,2)+v(1,4)\left(\frac{\partial n(4)}{\partial U_{e}(5)} \frac{\partial U_{e}(5)}{\partial U(2)}\right) \\
& =\delta(1,2)+v(1,4) P(4,5) \varepsilon^{-1}(5,2) \\
\Rightarrow \quad \delta(1,2) & =[\delta(1,5)-v(1,4) P(4,5)] \varepsilon^{-1}(5,2) \\
\Rightarrow \quad \varepsilon(1,2) & =\delta(1,2)-v(1,4) P(4,2)
\end{aligned}
$$

Chega-se agora ao potencial coulombiano blindado

$$
W(1,2)=\varepsilon^{-1}(1,4) v(4,2)
$$

que com a expressão para $\varepsilon^{-1}$ acima nos dá:

$$
\begin{aligned}
W(1,2) & =v(1,2)+v(1,4) P(4,5) \varepsilon^{-1}(5,6) v(6,2) \\
& =v(1,2)+v(1,4) P(4,5) W(5,2)
\end{aligned}
$$

Pode ser demonstrado que, na representação de interação, a derivada do valor médio do operador ordem temporal de operadores $\mathcal{O}_{i}$ em relação ao potencial perturbador $U$ é dada por

$$
\frac{\partial\left\langle N\left|\mathcal{T}\left[\mathcal{O}_{1}\left(t_{1}\right) \mathcal{O}_{2}\left(t_{2}\right)\right]\right| N\right\rangle}{\partial U(3)}=-\frac{i}{\hbar}\left\langle N\left|\mathcal{T}\left[\left(\psi^{\dagger}(3) \psi\left(3^{+}\right)-\left\langle\psi^{\dagger}(3) \psi\left(3^{+}\right)\right\rangle\right) \mathcal{O}_{1}\left(t_{1}\right) \mathcal{O}_{2}\left(t_{2}\right)\right]\right| N\right\rangle
$$

Aplicando esta regra de derivação funcional à $G(1,2)$ (equação 3.3.3), obtém-se

$$
\hbar \frac{\partial G(1,2)}{\partial U(3)}=G(1,2) G\left(3,3^{+}\right)-G\left(1,3,3^{+}, 2\right)
$$

que nos fornece uma definição para $\Sigma$ :

$$
\begin{aligned}
\Sigma(1,4) G(4,2) & =i \hbar v(1,4) \frac{\partial G(1,2)}{\partial U(4)} \\
\Sigma(1,2) & =i \hbar v(1,4) \frac{\partial G(1,5)}{\partial U(4)} G^{-1}(5,2)
\end{aligned}
$$


Utilizando a identidade matemática

$$
0=\frac{\partial\left[A(1,4) A^{-1}(4,2)\right]}{\partial B(3)}=\frac{\partial A(1,4)}{\partial B(3)} A^{-1}(4,2)+A(1,4) \frac{\partial A^{-1}(4,2)}{\partial B(3)}
$$

com $A=G, B=U$ podemos reescrever $\Sigma$ como:

$$
\Sigma(1,2)=-i \hbar v(1,4) G(1,5) \frac{\partial G^{-1}(5,2)}{\partial U(4)}
$$

Finalmente é definida a função vértice:

$$
\Gamma(1,2 ; 3)=-\frac{\partial G^{-1}(1,2)}{\partial U_{e}(3)}=-\frac{\partial G^{-1}(1,2)}{\partial U(4)} \frac{\partial U(4)}{\partial U_{e}(3)}=-\frac{\partial G^{-1}(1,2)}{\partial U(4)} \varepsilon(4,3)
$$

e podemos escrever a auto-energia como:

$$
\Sigma(1,2)=i \hbar v(1,4) G(1,5) \Gamma(5,2 ; 6) \varepsilon^{-1}(6,4)=i \hbar W(1,6) G(1,5) \Gamma(5,2 ; 6)
$$

Neste ponto já temos 3 das 5 equações de Hedin, a saber a equação de Dyson para $G$ (eq. [.48), a equação para $W$ (eq. [3.5.5) e aquela para $\Sigma$ (eq. [.6.3). Resta-nos escrever $\Gamma$ e $P$ removendo a dependência com $U$.

Para ambas utilizamos a seguinte identidade, diretamente da equação [3.60]:

$$
\frac{\partial G(1,2)}{\partial U_{e}(3)}=-G(1,4) \frac{\partial G^{-1}(4,5)}{\partial U_{e}(3)} G(5,2)=G(1,4) \Gamma(4,5 ; 3) G(5,2)
$$

Utilizando a definição de $n(1)$ em termos da função de Green e a identidade acima, podemos reescrever a função de polarização como:

$$
P(1,2)=\frac{\partial n(1)}{\partial U_{e}(2)}=-i \hbar \frac{\partial G(1,1)}{\partial U_{e}(2)}=-i \hbar G(1,4) \Gamma(4,5 ; 2) G(5,1)
$$

Para a última equação, utilizamos $G^{-1}$ que podemos obter da equação da dinâmica de $G$ (3.46); com

$$
S(1)=\left(i \frac{\partial}{\partial t_{1}}-H_{0}(1)\right)
$$


vem

$$
\begin{aligned}
& S(1) G(1,2)-\Sigma(1,4) G(4,2)=\delta(1,2) \\
\Rightarrow \quad & (S(1)-\Sigma(1,3)) G(3,2)=\delta(1,2) \\
\Rightarrow & G^{-1}(1,2)=S(1)-\Sigma(1,2)
\end{aligned}
$$

Assim,

$$
\begin{aligned}
\Gamma(1,2 ; 3) & =-\frac{\partial G^{-1}(1,2)}{\partial U_{e}(3)}=-\frac{\partial S(1)}{\partial U(3)} \delta(1,2)+\frac{\partial \Sigma(1,2)}{\partial U_{e}(3)} \\
& =\delta(1,2) \delta(1,3)+\frac{\partial \Sigma(1,2)}{\partial G(4,5)} \frac{\partial G(4,5)}{\partial U_{e}(3)} \\
& =\delta(1,2) \delta(1,3)-\frac{\partial \Sigma(1,2)}{\partial G(4,5)} G(4,6) \Gamma(6,7 ; 3) G(7,5)
\end{aligned}
$$

Temos agora o problema da função vértice, que como vemos é uma função recorrente. A aproximação normalmente utilizada é escrever

$$
\Gamma(1,2 ; 3)=\delta(1,2) \delta(1,3)
$$

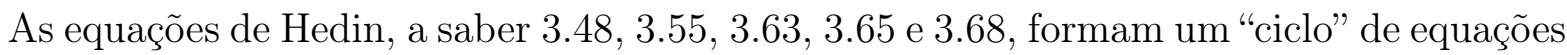
inter-dependentes. Por não existir um princípio variacional relacionado a estes valores, estas equações não podem ser resolvidas de forma auto-consistente. O que pode ser feito, porém, é uma solução iterativa: Faz-se uma aproximação inicial, e resolvendo as equações na ordem, chegamos a um novo valor para a variável inicial, dando continuidade ao ciclo.

Por exemplo, iniciando com a aproximação $\Sigma=0$, e utilizando a aproximação [.69] obtemos:

$$
\begin{aligned}
G(1,2) & =G_{0}(1,2) \\
\Gamma(1,2 ; 3) & =\delta(1,2) \delta(1,3) \\
P(1,2) & =-i \hbar G_{0}(1,2) G_{0}(2,1) \\
W(1,2) & =v(1,2)+v(1,4) P(4,5) W(5,2) \\
\Sigma(1,2) & =i \hbar G_{0}(1,2) W(1,2)
\end{aligned}
$$


Em virtude da forma de $\Sigma$ na última equação do ciclo, surgiu o nome da aproximação como "one-shot GW" e ultimamente chamada explicitamente $G_{0} W_{0}$. Utilizando este novo $\Sigma$ poderíamos reiniciar o ciclo, obtendo novos valores para $G, \Gamma, P, W$ e finalmente outro $\Sigma$; entretanto o que se verifica é que um ciclo já apresenta ótimas correções, e é o que se faz na prática.

Neste primeiro grau de aproximação, as funções de onda de uma partícula DFT são mantidas para representar as quase-partículas obtidas, e apenas as energias são corrigidas. Comparando a equação 3.46] com a equação de Kohn-Sham [2.54, podemos escrever a correção em cada nível de energia como

$$
\epsilon_{i}^{\mathrm{GW}}-\epsilon_{i}^{\mathrm{KS}}=\left\langle\psi_{i}\left|\Sigma\left(\epsilon_{i}^{\mathrm{GW}}\right)-V_{\mathrm{xc}}^{\mathrm{KS}}\right| \psi_{i}\right\rangle
$$

onde $V_{\mathrm{xc}}^{\mathrm{KS}}$ é o potencial de troca e correlação de Kohn-Sham.

No código computacional Yambo[98], utilizado neste trabalho, a auto-energia é expandida em torno da energia de uma partícula de Kohn-Sham:

$$
\Sigma\left(\epsilon_{i}^{\mathrm{GW}}\right) \approx \Sigma\left(\epsilon_{i}^{\mathrm{KS}}\right)+\left.\frac{\partial \Sigma}{\partial \epsilon}\right|_{\epsilon=\epsilon_{i}^{\mathrm{KS}}}\left(\epsilon_{i}^{\mathrm{GW}}-\epsilon_{i}^{\mathrm{KS}}\right)+\cdots
$$

Substituindo esta expansão na equação anterior, reordenando os termos, e definindo o fator de renormalização

$$
Z_{i}=\left(1-\left.\frac{\partial \Sigma}{\partial \epsilon}\right|_{\epsilon=\epsilon_{i}^{\mathrm{KS}}}\right)^{-1}
$$

chegamos finalmente a fórmula utilizada para as energias de quase-partícula

$$
\epsilon_{i}^{\mathrm{GW}}-\epsilon_{i}^{\mathrm{KS}}=Z_{i}\left\langle\psi_{i}\left|\Sigma\left(\epsilon_{i}^{\mathrm{KS}}\right)-V_{\mathrm{xc}}^{\mathrm{KS}}\right| \psi_{i}\right\rangle
$$

Uma outra possibilidade (implementada no código computacional SaX [9,9], utilizado no início deste trabalho) é calcular as energias GW diretamente, através de

$$
\epsilon_{i}^{\mathrm{GW}}=\left\langle\psi_{i}\left|H_{0}+\Sigma\left(\epsilon_{i}^{\mathrm{GW}}\right)\right| \psi_{i}\right\rangle
$$





\section{Capítulo 4}

\section{Resultados}

Neste capítulo reunimos nossos resultados, obtidos com as diferentes metodologias descritas até aqui, para os sistemas isolados de $\mathrm{TiO}_{2}$ (cristal e fatias) e molécula de ácido retinóico, e para a montagem quimissorvida retinóico/fatia de $\mathrm{TiO}_{2}$ anatase (101).

Serão também discutidos resultados para outros sistemas, que foram adotados como referência no estudo das metodologias: sistema cristalino de $\mathrm{SiO}_{2}$ em estrutura $\alpha$-quartzo, molécula de tiofeno, e montagem fisissorvida tiofeno/fatia de $\mathrm{TiO}_{2}$ anatase (101).

\subsection{Propriedades Estruturais}

\subsubsection{Sistemas isolados}

Iniciamos o estudo do dióxido de titânio pelo cristal na fase anatase. Esta análise foi realizada por DFT, utilizando o funcional LDA-PZ. Durante a otimização de geometria foram otimizadas não só as posições atômicas como também a célula unitária, ou seja, os vetores de rede do cristal. Os vetores de rede assim obtidos são $A=B=3,7463 \AA \mathrm{e}$ $C=9,4436 \AA$, ligeiramente menores que os valores experimentais[100] $A=B=3,785(1) \AA$ e $C=9,514(6) \AA$. Essa diferença é esperada para o método LDA que superestima as forças de ligação do material. Na figura $4 . \mathbb{D}$ está esquematizada a célula unitária convencional do cristal.

A partir da estrutura do cristal obtivemos a estrutura geométrica da superfície, através de um corte na direção 101, mais relevante para nanoestruturas. Nesta metodologia de sistemas periódicos, as superfícies são representadas através do modelo de fatia (slab), cortando o 


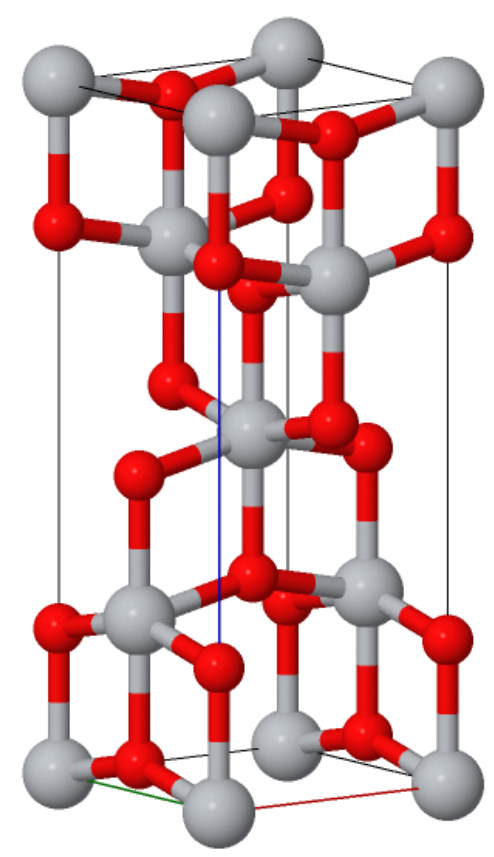

Figura 4.1: Estrutura do cristal de dióxido de titânio, fase anatase.

cristal na direção da superfície a ser estudada com uma espessura escolhida. Os vetores de rede nas direções paralelas à superfície tem direções determinadas a partir dos vetores de rede do cristal, e dimensões ditadas pela escolha do modelo (molécula na superfície) que iremos estudar. Na direção perpendicular à superfície (direção z), utilizamos valores que nos garantam separação entre uma fatia e sua vizinha, com distância de vácuo suficiente para que ambas não interajam. Além disso, estudamos as propriedades de fatias com diferentes espessuras, que batizamos pelo número de camadas atômicas do óxido, variando de 3 a 7 camadas (espessuras de 1 a 2,5nm). Isto nos permite investigar o efeito da espessura da fatia na estrutura eletrônica (será discutido com detalhes na seção 4.2 ), o que pode trazer informações importantes para o campo da nanociência.

Passando ao estudo do ácido retinóico, iniciamos por uma comparação entre as estruturas obtidas através de diferentes metodologias (tabela K.], de acordo com a numeração dos átomos da Figura 4.3). Por existirem resultados experimentais do retinal (equivalente aldeídico do ácido retinóico), este também foi simulado.

Enquanto os cálculos MP2 (através do código Gaussian [58] com uma base $6-31 G$ ) e AM1 (utilizando o pacote Materials Studio [103]) se fizeram para uma molécula isolada 


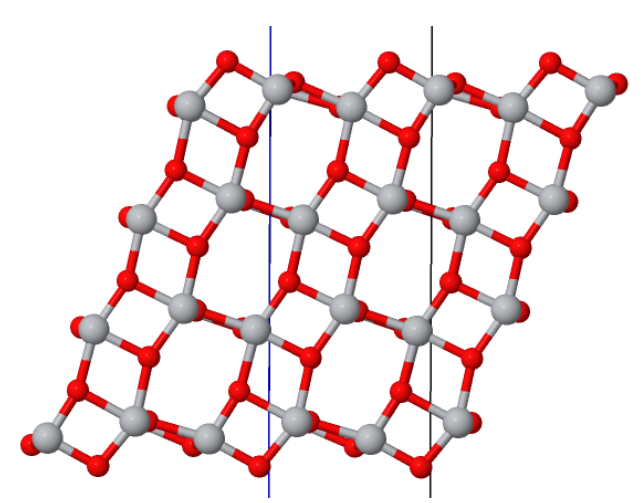

(a) Lateral

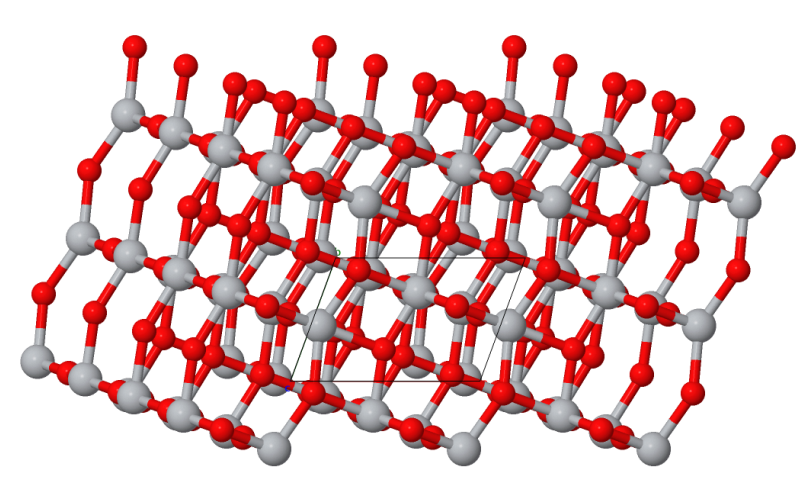

(b) Superior

Figura 4.2: Estrutura de uma fatia referente à superfície (101) do $\mathrm{TiO}_{2}$ anatase, nas visões Lateral e Superior.

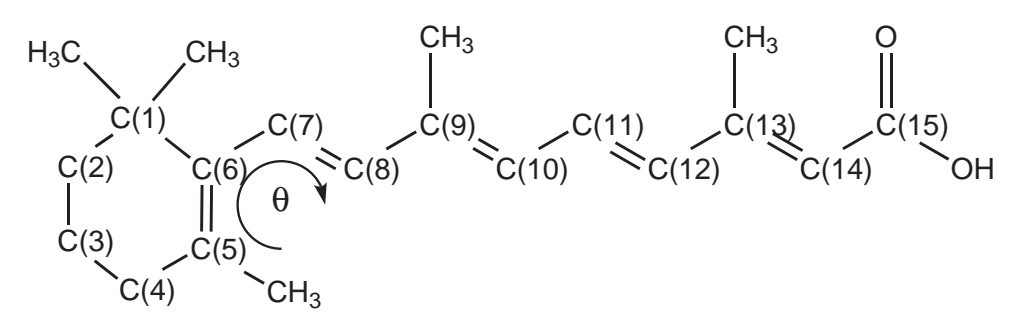

Figura 4.3: Estrutura do ácido retinóico

no vácuo, o cálculo DFT foi feito com o código Quantum ESPRESSO[6:3], específico para sistemas periódicos, e portanto foi adotado o modelo de super-célula, ou seja, a escolha de uma célula unitária suficientemente grande para que não exista interação entre moléculas.

Podemos verificar uma boa concordância dos resultados obtidos para a estrutura geométrica através dos diversos métodos (tabela 4.1 ). Mesmo quando comparamos os dois sistemas (ácido retinóico e retinal) vemos uma coerência grande entre os valores encontrados, indicando que a cadeia praticamente não se modifica com a substituição $\mathrm{OH} \rightarrow \mathrm{H}$.

A única propriedade que difere de forma marcante entre os cálculos realizados por métodos diferentes é o valor do ângulo $\theta$ entre o anel e a cadeia, indicado na Figura 4.3. Os resultados DFT fornecem um ângulo menor que nos demais cálculos $\left(36^{\circ}\right.$ contra $\left.51^{\circ}\right)$ : não temos um valor experimental para comparação, desta forma em cálculos futuros indicaremos qual a estrutura utilizada em cada caso. 
Tabela 4.1: Distâncias de ligação (em Å) e Ângulo de torção $\theta$ entre cadeia e anel (em graus), para o ácido retinóico de acordo com semi-empírico AM1, ab-initio MP2 e DFT LDA-PZ; e para o retinal, AM1, DFT-LDA (da referência [101]), e experimental [1102]. Nas linhas sombreadas destacamos a região conjugada da molécula.

\begin{tabular}{c|ccc|ccc}
\hline & \multicolumn{3}{|c|}{ Ácido Retinóico } & \multicolumn{3}{c}{ Retinal } \\
\hline Ligação & AM1 & MP2 & DFT & AM1 & DFT[10]] & Exp \\
\hline C1-C2 & 1,532 & 1,532 & 1,519 & 1,532 & - & - \\
C6-C1 & 1,511 & 1,51 & 1,52 & 1,511 & - & - \\
C2-C3 & 1,51 & 1,51 & 1,50 & 1,51 & - & - \\
C3-C4 & 1,512 & 1,512 & 1,50 & 1,512 & - & - \\
C4-C5 & 1,49 & 1,49 & 1,485 & 1,49 & - & - \\
C5=C6 & 1,351 & 1,35 & 1,352 & 1,35 & 1,37 & 1,329 \\
C6-C7 & 1,461 & 1,46 & 1,439 & 1,461 & 1,451 & 1,483 \\
C7=C8 & 1,343 & 1,343 & 1,348 & 1,343 & 1,366 & 1,317 \\
C8-C9 & 1,456 & 1,457 & 1,424 & 1,457 & 1,441 & 1,469 \\
C9=C10 & 1,353 & 1,353 & 1,362 & 1,353 & 1,381 & 1,346 \\
C10-C11 & 1,443 & 1,442 & 1,407 & 1,443 & 1,422 & 1,444 \\
C11=C12 & 1,347 & 1,347 & 1,353 & 1,347 & 1,372 & 1,339 \\
C12-C13 & 1,458 & 1,458 & 1,424 & 1,457 & 1,437 & 1,455 \\
C13=C14 & 1,352 & 1,352 & 1,356 & 1,352 & 1,379 & 1,346 \\
C14-C15 & 1,457 & 1,457 & 1,44 & 1,46 & 1,44 & 1,458 \\
C15=O & 1,238 & 1,238 & 1,218 & 1,235 & 1,255 & 1,2 \\
C15-OH & 1,37 & 1,37 & 1,354 & - & - & - \\
\hline Ângulo $\theta$ & 51,2 & 51,2 & 36,3 & 51,7 & - & - \\
\hline
\end{tabular}

Entretanto, podemos notar uma diferença sutil entre os resultados MP2 e DFT para o ácido retinóico: examinando as distâncias entre os átomos de carbono da coluna dorsal conjugada, $\mathrm{C}_{5}$ a $\mathrm{C}_{14}$ (destacados na tabela $4 . \mathrm{C}$ ), vemos que a geometria MP2 traz uma dimerização (conjugação) mais forte, com as ligações duplas ligeiramente mais curtas, e as ligações simples pouco mais longas que os resultados DFT. É interessante notar também a absoluta coerência entre os resultados semi-empíricos AM1 e ab-initio MP2.

Já o tiofeno, que tem uma estrutura mais simples, teve sua geometria estudada apenas através do DFT LDA-PZ. 


\subsubsection{Montagem Superfície-Ácido Retinóico}

Iniciamos o estudo das montagens com a deposição do ácido fórmico, o mais curto dos ácidos carboxílicos, de forma a entender como se dá a ligação ácido-superfície. Vittadini e colaboradores[104] em seu artigo definem os possíveis modos de quimissorção do ácido fórmico sobre a superfície (101) (fig. 4.4), e baseando-nos em seus resultados escolhemos 图 as interações "MHa" (Monodentada através do grupo CO) e "BB(H)" (Bidentada de ponte), que são as ligações moleculares e dissociativas (respectivamente) mais estáveis.
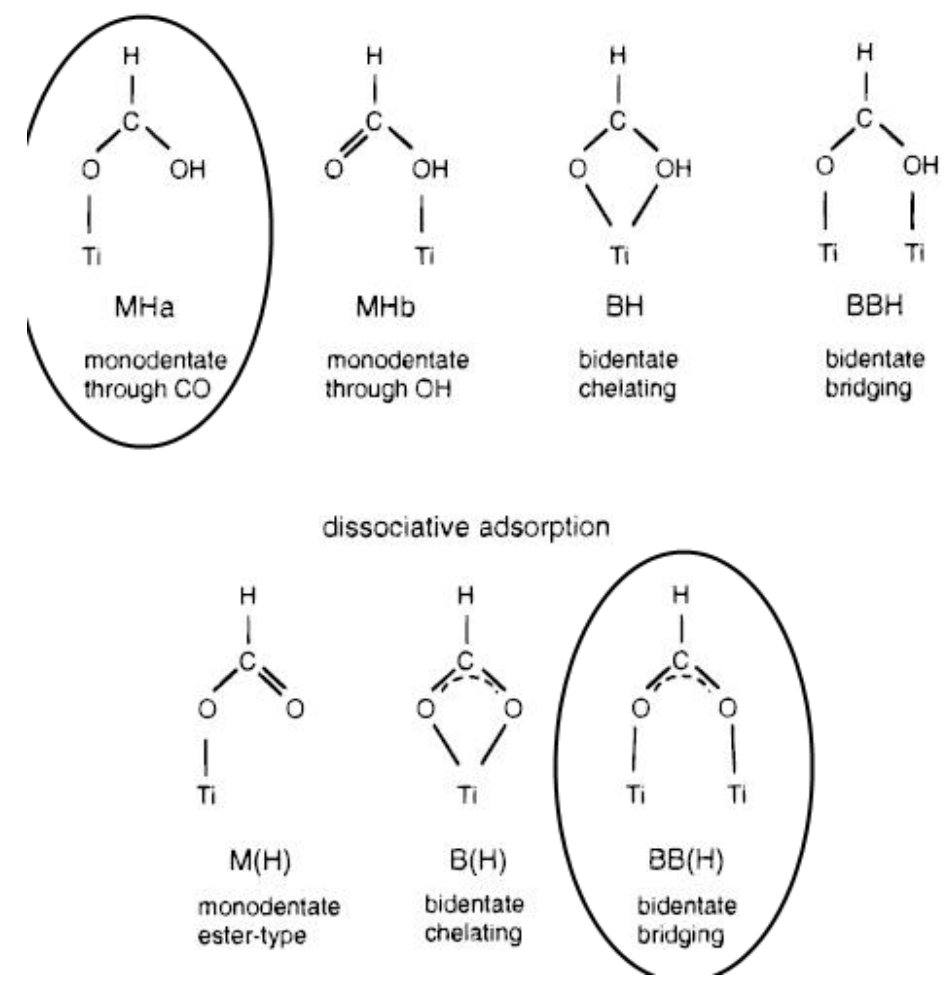

Figura 4.4: Possíveis formas de ligação entre o ácido fórmico e a superfície (101) da anatase. Em destaque estão as formas escolhidas por nós. Retirado de [104].

O relaxamento da estrutura foi mais uma vez realizado com o método DFT LDA-PZ, e obtivemos as estruturas representadas nas figuras 4.5 e 4.67, onde incluímos as energias de ligação. As energias são calculadas como a diferença entre a soma de energia dos sistemas isolados e a situação final.

*Este trabalho foi realizado em colaboração com o pesquisador Arrigo Calzolari, do CNR, Itália 


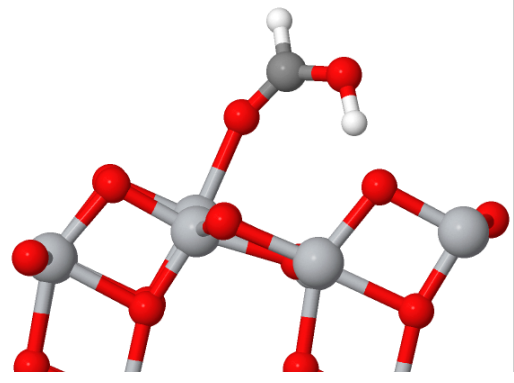

(a) Lateral

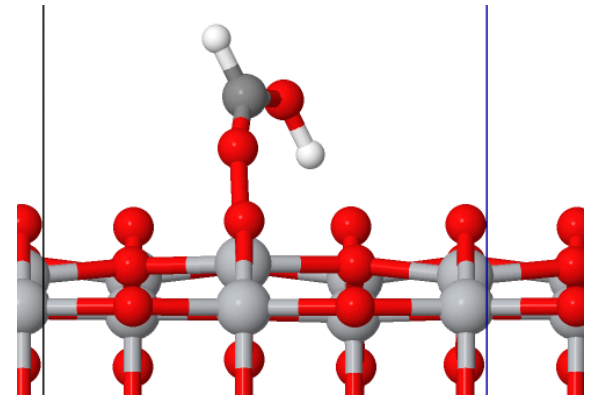

(b) Frontal

Figura 4.5: Estrutura da montagem MHa do Ácido-fórmico em superfície (101) da anatase. Energia de ligação $1,20 \mathrm{eV}$.

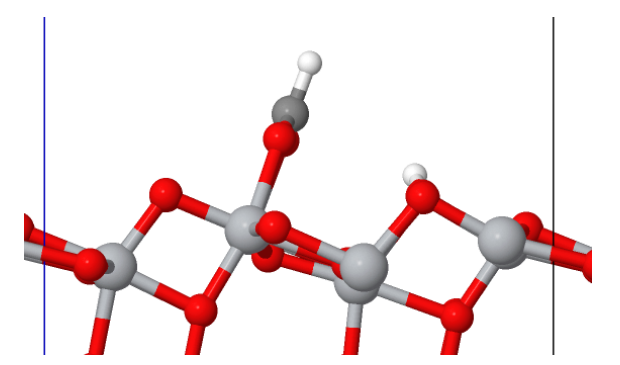

(a) Lateral

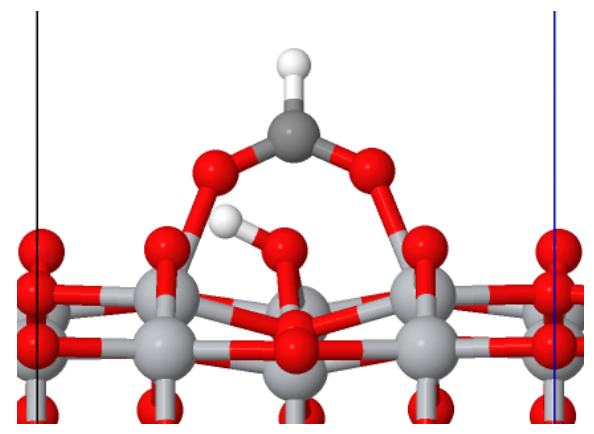

(b) Frontal

Figura 4.6: Estruturas da montagem $\mathrm{BB}(\mathrm{H})$ do Ácido-fórmico em superfície (101) da anatase. Energia de ligação $1,17 \mathrm{eV}$.

Vemos que a diferença para esta molécula curta entre energias de ligação nas duas configurações é muito pequena (1,20eV na estrutura monodentada e $1,17 \mathrm{eV}$ para a bidentada), menor que a nossa precisão de cálculo, e portanto neste nível não podemos definir qual a estrutura mais estável. É importante notar que a ligação Bidentada de Ponte é dissociativa, com a liberação de um átomo de hidrogênio. Como não pretendemos estudar sistemas carregados, e em nossa simulação não está presente o solvente (que em um sistema real poderia capturar este hidrogênio), ele deve ser ligado em algum outro ponto do sistema. Nesta análise energética seguimos a idéia de Vittadini, e escolhemos religar o hidrogênio na própria superfície. Este hidrogênio, porém, cria estados no meio do gap, e não nos é claro de que forma seria absorvido em realidade. Desta forma, para os cálculos de estrutura eletrônica, nos focamos na ligação Monodentada, sendo o estudo da Bidentada interessante 
para análises futuras.

O ácido retinóico não somente é mais longo que o ácido fórmico, como também ocupa mais espaço lateralmente, devido ao seu anel. Desta forma, utilizamos uma célula unitária maior na lateral, de dimensões $10.82 \times 14.98 \times 60 \AA^{3}$. Este sistema representa uma alta densidade de deposição do ácido sobre a superfície, pode ser considerado como uma monocamada extremamente ordenada. Sem dúvida é um modelo idealizado, mas que pode nos dar indicações muito relevantes para os processos de nosso interesse, como será visto adiante quanto a propriedades óticas. Apesar da alta densidade a menor distância anel-anel entre cadeias é já de $5 \AA$, a distância entre as cadeias conjugadas é de $11 \AA$ na direção de empilhamento $\pi$, e de $7 \AA$ na direção perpendicular, quando para haver interação em empilhamento $\pi$ seriam necessárias distâncias menores que $4 \AA$.

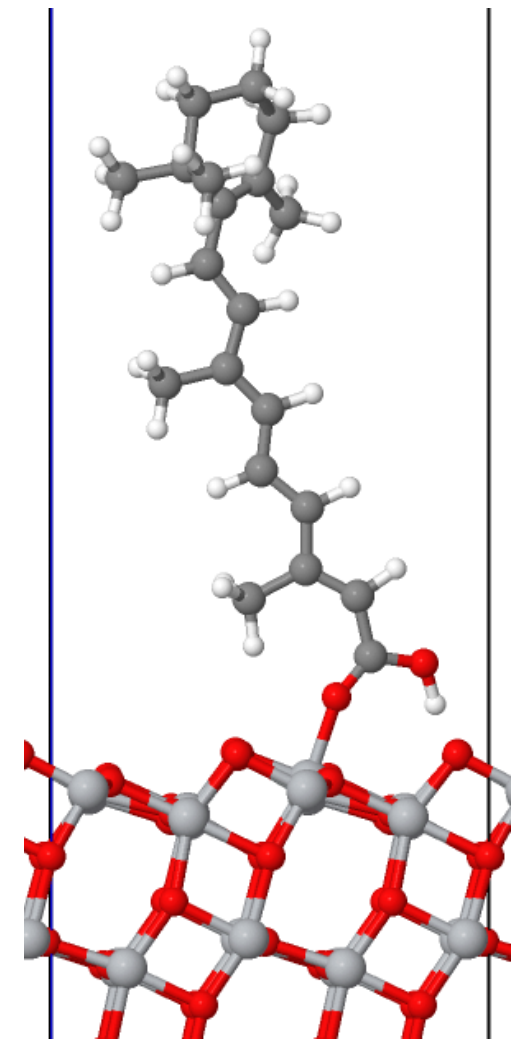

(a) Lateral

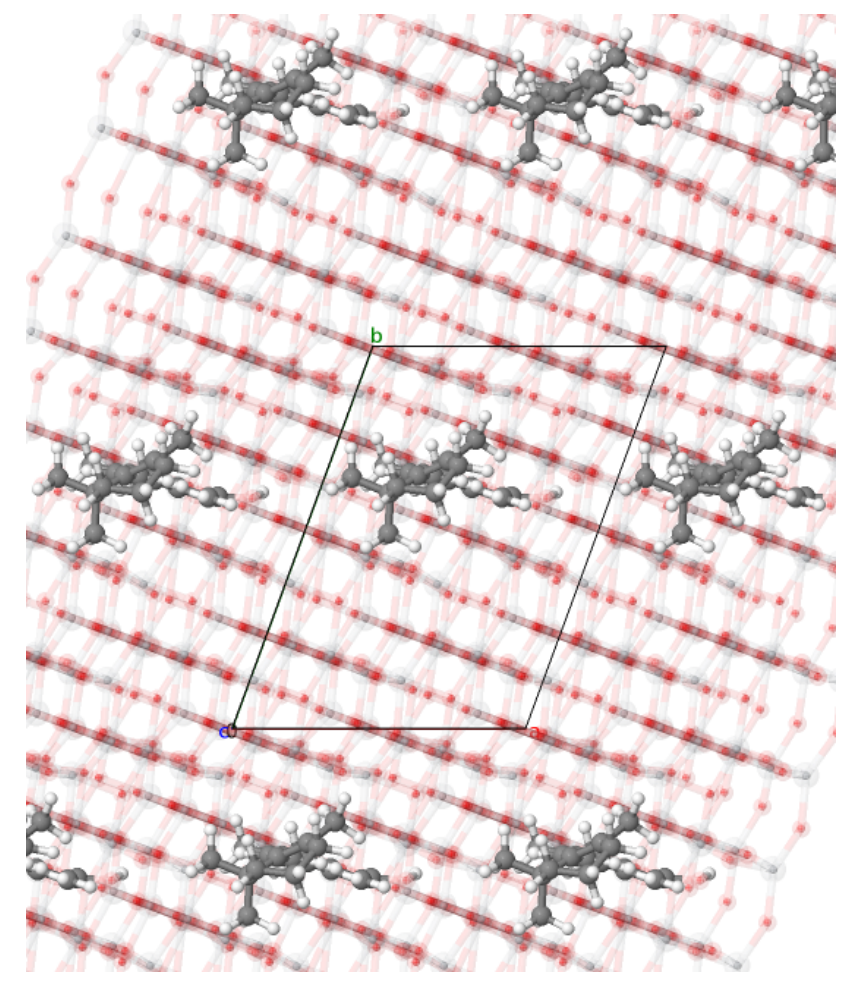

(b) Superior

Figura 4.7: Estrutura da montagem de ácido retinóico sobre superfície (101) da anatase, obtida com cálculo DFT LDA-PZ, em vistas lateral e superior. 


\subsection{Propriedades Eletrônicas: Nanoestruturas e o efeito de confinamento}

Em um poço de potencial infinito, a separação entre os níveis energéticos cresce com a diminuição da largura do poço, e cresce também a energia do mais baixo nível permitido; de forma equivalente, ao confinar os elétrons em um sistema de dimensões nanoscópicas temos o aumento da separação entre os níveis, e consequentemente do gap de energia, o chamado efeito de confinamento.

Não é claro, porém, para que tipo de nanoestruturas este efeito deve ocorrer. Uma análise teórica feita por Bruus[1(15] para aglomerados indica uma dependência do gap com o inverso do quadrado do raio do aglomerado. Baierle et al., através de cálculos ZINDO para aglomerados de silício, e Chiodo et al., através de cálculo GW para pequenos aglomerados de $\mathrm{TiO}_{2}$ (até $\mathrm{Ti}_{10} \mathrm{O}_{20}$ ) verificaram também a ocorrência do alargamento do gap, assim como outros trabalhos para nanofios de $\mathrm{TiO}_{2}$ utilizando DFT LDA/PZ[106, 107]).

Aqui analisamos o efeito de confinamento em apenas uma dimensão, ou seja, em sistemas bidimensionais; criamos fatias com diferentes números de camadas, e analisamos em primeiro lugar qual a diferença nas propriedades eletrônicas comparadas ao cristal, e ainda se existe variação do gap de energia com a espessura (tabela 4.2).

Tabela 4.2: Valores (em eV) para o gap de energia de $\mathrm{TiO}_{2}$ na fase anatase, para fatias cortadas na direção (101) com diferentes números de camadas (N) e espessuras (L, em nm). Os valores calculados com LDA-PZ correspondem à diferença de energia entre fundo da banda de condução (conduction band minimum, CBM) e topo da banda de valência (valence band top, VBT), e os valores GW já correspondem ao gap elétrico. Para comparação o valor para o gap ótico experimental do cristal também é fornecido

\begin{tabular}{c|c|c|c|c|c|c} 
Sistema: N (L) & $3(1,05)$ & $4(1,40)$ & $5(1,75)$ & $6(2,10)$ & $7(2,45)$ & cristal \\
\hline VBT-CBM (LDA-PZ) & 2,48 & 2,29 & 2,20 & 2,14 & 2,11 & 2,07 \\
gap elétrico (GW) & 5,69 & 5,37 & 5,18 & 5,07 & 5,02 & 3,68 \\
\hline Experimental (ótico) & & & & & & 3,3
\end{tabular}

Para a metodologia GW foi utilizado o código computacional Yambo[98 $]^{\mathbb{1}}$, tendo como ponto de partida cálculos LDA do código Quantum ESPRESSO[6:3]. Verificamos uma forte dependência do gap com a espessura da fatia, indicando a existência do confinamento. De fato, mesmo utilizando 7 camadas (a maior fatia simulada aqui, e já de largura 2,45nm) o

\footnotetext{
†Trabalho em colaboração com Daniele Varsano, desenvolvedor do código Yambo
} 


\subsection{Propriedades Eletrônicas: Problemas no Tratamento DFT para Sistemas Híbridos}

gap ainda fica bem maior que o valor obtido para o sistema cristalino. Comparativamente, no resultado da metodologia DFT LDA/PZ o gap da fatia de 7 camadas já é praticamente igual ao do sistema cristalino, e a sua dependência com o número de camadas é mais fraca. Conforme mencionado acima, esta metodologia já foi utilizada na literatura[106, [07] para tratar o efeito de confinamento de clusteres e nanofios, resultando em efeitos maiores devido à menor dimensionalidade destes sistemas, e já recuperando o valor do cristal com um pequeno aumento do tamanho do sistema. Vemos também que este é um efeito principalmente devido à correlação, já que a simples inclusão da troca exata não introduz o efeito de confinamento, conforme mostrado na tabela 4.3 . Já temos com $\sim 1 / 4$ de inclusão de troca exata um valor razoável para o gap do cristal, mas o efeito de confinamento absolutamente não é visto sequer para esta camada tão estreita. Este resultado está de acordo com o trabalho de Palummo et al.[108], para nanofolhas de $\mathrm{TiO}_{2}$, que obtém uma grande correção $\mathrm{GW}$, mas pequena alteração no resultado DFTh.

Tabela 4.3: Valores (em eV) para o gap de energia de fatia de dióxido de titânio anatase (101) com 4 camadas, comparado ao valor para o sistema cristalino para diferentes funcionais.

\begin{tabular}{c|c|c|c|c} 
Funcional & LDA-PZ & HSE & B3LYP & PBE0 \\
\hline fatia & 2,29 & 4,13 & 4,24 & 4,75 \\
cristal & 2,07 & 3,9 & 4,2 & 4,7
\end{tabular}

Assim percebe-se a diferença de alcance entre as interações de muitos corpos (GW) e as utilizadas com campo médio (DFT e troca-exata). Salientamos aqui que esta diferença deve ser clara para futuros estudos, tanto de forma a entender o porquê de resultados GW apresentarem gaps superiores aos experimentais (já que superfícies experimentais, mesmo as mais finas, têm no mínimo 10nm), quanto para entender porque cálculos que simulam "superfícies" no nível DFT, com uma espessura de fatia muito pequena, já se aproximam de resultados para o cristal.

\subsection{Propriedades Eletrônicas: Problemas no Tratamento DFT para Sistemas Híbridos}

Conforme visto até aqui, já para tratar nanoestruturas os funcionais DFT apresentam problemas. Veremos agora que, além disso, existem problemas ao adotar essa metodologia 
para o estudo de um sistema híbridos orgânico/óxido; testamos assim a validade de funcionais DFT em sistemas de óxidos e orgânicos isolados: a metodologia ideal deve apresentar bons resultados simultaneamente para ambos os tipos de sistemas.

Além do funcional PZ (LDA), foram também testados os funcionais PBE (GGA), os funcionais híbridos PBE0, B3LYP, HSE e o-PBEh, e também o funcional PZ corrigido através do $L D A-1 / 2$. Outras comparações semelhantes existem na literatura, mas focadas em apenas um tipo específico de material[10.9, 110, 11]]. Para melhor basear nossos resultados, além do $\mathrm{TiO}_{2}$ anatase, testamos também $\mathrm{SiO}_{2} \alpha$-quartzo e no caso de moléculas isoladas adotamos a molécula de tiofeno T1. Todos estes resultados foram comparados aos resultados GW, que por ser o método mais preciso foi adotado como padrão.

Os cálculos com funcionais sem troca-exata foram feitos com 100Ry de cutoff para as ondas planas, enquanto para aqueles com termo de troca-exata chegamos a 70Ry. Sistemas moleculares (finitos, portanto sem interação para formação de bandas) foram estudados em super-células no ponto $\Gamma$. Para os sistemas cristalinos utilizamos malha de $4 \times 4 \times 4$ para $\mathrm{TiO}_{2}$ anatase e $4 \times 2 \times 4$ para $\mathrm{SiO}_{2} \alpha$-quartzo, para a densidade eletrônica; devido ao custo computacional o termo de troca exata foi calculado em uma malha com metade do número de pontos $k$ em cada direção.

Além disso, para todos os cálculos foram utilizados pseudopotenciais gerados utilizando

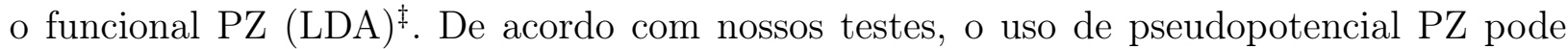
trazer erros de no máximo $0.1 \mathrm{eV}$ para os níveis de energia, e $0.05 \mathrm{eV}$ para gaps, valores estes inferiores às diferenças em estudo.

Nossos resultados estão resumidos na tabela 4.4, e concordam com resultados da literatura para $\mathrm{TiO}_{2}$ [10.9, 11:3] e Tiofeno[114]. Podemos ver que, descontados os problemas relativos a efeitos de confinamento, utilizar o método LDA-1/2 ou os funcionais híbridos HSE, PBE0 e B3LYP pode ser uma boa opção para os óxidos, pois os resultados se aproximam dos resultados GW. Para os sistemas orgânicos, porém, estas metodologias subestimam fortemente a energia da primeira transição elétrica, também chamada de gap HOMO-LUMO, ficando muito abaixo dos valores GW. Já o funcional o-PBEh se aproxima bastante dos resultados GW para as moléculas, entretanto fornece gaps de energia excessivamente grandes

\footnotetext{
${ }^{\ddagger}$ É comum, entre os usuários do código Quantum ESPRESSO, o uso de pseudopotenciais criados a partir de um funcional diferente do que será utilizado no cálculo quando se utiliza troca exata, devido à impossibilidade de se criar um pseudopotencial com um funcional híbrido com o programa ld1.x, que acompanha o código.
} 
Tabela 4.4: Valores de energia $(\mathrm{em} \mathrm{eV})$ para o gap elétrico direto d e indireto i para os sistemas cristalinos $\mathrm{TiO}_{2}$ Anatase e $\mathrm{SiO}_{2} \alpha$-quartzo, e para o gap HOMO-LUMO das moléculas de Tiofeno e Ácido Retinóico.

\begin{tabular}{cc|c|c|c|c|c|c|c|c} 
& & LDA & PBE & LDA-1/2 & HSE & B3LYP & PBE0 & o-PBEh & GW \\
\hline \multirow{2}{*}{$\mathrm{TiO}_{2}$} & d & 2,75 & 2,61 & 4,12 & 4,40 & 4,69 & 5,11 & 10,67 & $\mathbf{4 , 1 9}$ \\
& $\mathrm{i}$ & 2,22 & 2,15 & 3,70 & 3,91 & 4,20 & 4,63 & 10,09 & $\mathbf{3 , 6 8}$ \\
\hline \multirow{2}{*}{$\mathrm{SiO}_{2}$} & $\mathrm{~d}$ & 5,99 & 6,46 & 8,47 & 8,25 & 8,61 & 9,01 & 14,78 & $\mathbf{9 , 3}[\Pi \mathbf{1 1}]$ \\
& $\mathrm{i}$ & 5,96 & 6,43 & 8,44 & 8,21 & 8,58 & 8,97 & 14,73 & \\
\hline \multicolumn{2}{r|}{ Tiofeno } & 4,24 & 4,21 & 4,74 & 5,32 & 5,66 & 6,07 & 8,88 & $\mathbf{7 , 9 2}$ \\
\hline \multicolumn{2}{|c|}{ Ácido retinóico } & 1,44 & 1,45 & 1,50 & 2,10 & 2,48 & 2,74 & 6,12 & $\mathbf{5 , 6 1}$
\end{tabular}

para os óxidos.

Desta forma, verificamos que nenhuma metodologia ab-initio baseada na DFT, consegue fornecer resultados acurados para ambos os tipos de sistema simultaneamente, e assim nenhuma destas metodologias é aplicável por si só para o sistema híbrido orgânico/óxido. Métodos de campo médio como norma não são aplicáveis ao cálculo de excitações elétricas ou óticas. Uma maneira corrente de tratar este problema, para corrigir o valor do gap, é aplicar uma mesma correção $a d-h o c$ a todos os estados virtuais do sistema, um deslocamento energético independente da simetria do estado (ponto k) conhecido como rigid shift [15, ए6, Ш7]. Para o estudo de apenas um tipo de sistema, por exemplo o óxido, poderíamos utilizar este método, adotando como deslocamento a diferença entre o gap DFT e GW. Entretanto para um sistema híbrido o erro no resultado vai em direção opostas para um e outro material, o que dificulta ou impede o uso de um deslocamento rígido.

\footnotetext{
${ }^{\dagger}$ Foi mantido o ordenamento de orbitais do DFT
} 


\subsection{Propriedades Eletrônicas e Óticas}

Conforme discutido no capítulo de metodologias, a obtenção das propriedades óticas de um material necessita de uma abordagem diversa que a utilizada para a obtenção de sua estrutura eletrônica. Os métodos adequados para este tipo de problema são a BSE e o CIS. A solução da BSE, porém, depende de um cálculo prévio de estrutura eletrônica; ora, o cálculo GW é impraticável para o sistema híbrido completo, e a DFT não é aplicável para sistemas híbridos.

Com a exceção dos sistemas moleculares pequenos, a aplicação do CIS ab initio também apresenta um alto custo computacional, e assim neste trabalho utilizamos implementações semi-empíricas ZINDO e MSINDO, cujos resultados são descritos a seguir.

\subsubsection{Moléculas}

Iniciamos aqui com o Tiofeno. Um primeiro fato curioso muito específico a esta molécula está relacionado ao ordenamento de seus níveis virtuais. Cálculos de campo médio, seja DFT seja HF/MSINDO, apontam como LUMO um orbital $\pi$, mas ao aplicar as correções de orbital virtual sobre HF, ou GW sobre DFT, verificamos que um outro estado, de simetria $\sigma$, assume a menor energia excitada. Apenas em um outro artigo[18] encontramos referência a este fato; demais artigos que tratam o tiofeno utilizam sempre o gap $\pi-\pi^{*}$.

Utilizando o método CIS/MSINDO obtivemos o valor para o gap ótico, ou seja a energia da primeira transição ótica de $5,35 \mathrm{eV}$, muito próximo de seu valor experimental de $5,37 \mathrm{eV}$ [119], ainda melhor que o obtido através do mais utilizado ZINDO (4,52eV). Na figura 4.8 mostramos o espectro de absorção obtido, assim como a DOCIS (Density of CI states), em que podemos ver não só as transições permitidas mas também aquelas proibidas (força de oscilador zero). Já na figura 4. प. apresentamos a representação espacial de sua primeira transição ótica, que é constituída principalmente da transição eletrônica $\mathrm{HOMO} \rightarrow \mathrm{LUMO}$, mesmo que tenha sido, nas funções de onda determinantais, invertida a ordem energética de $\mathrm{LUMO} \leftrightarrow \mathrm{LUMO}+1$.

Para o ácido retinóico, o gap ótico experimental é 3,42eV[120]. Aqui, além do estudo com ZINDO e MSINDO, também foi feito o cálculo CIS ab-initio, através do código Gaussian $03[58]$ com uma base $6-31+\mathrm{G}(\mathrm{d})$.

Utilizando a geometria que resultou de cálculo DFT LDA/PZ, obtemos com a metodolo- 


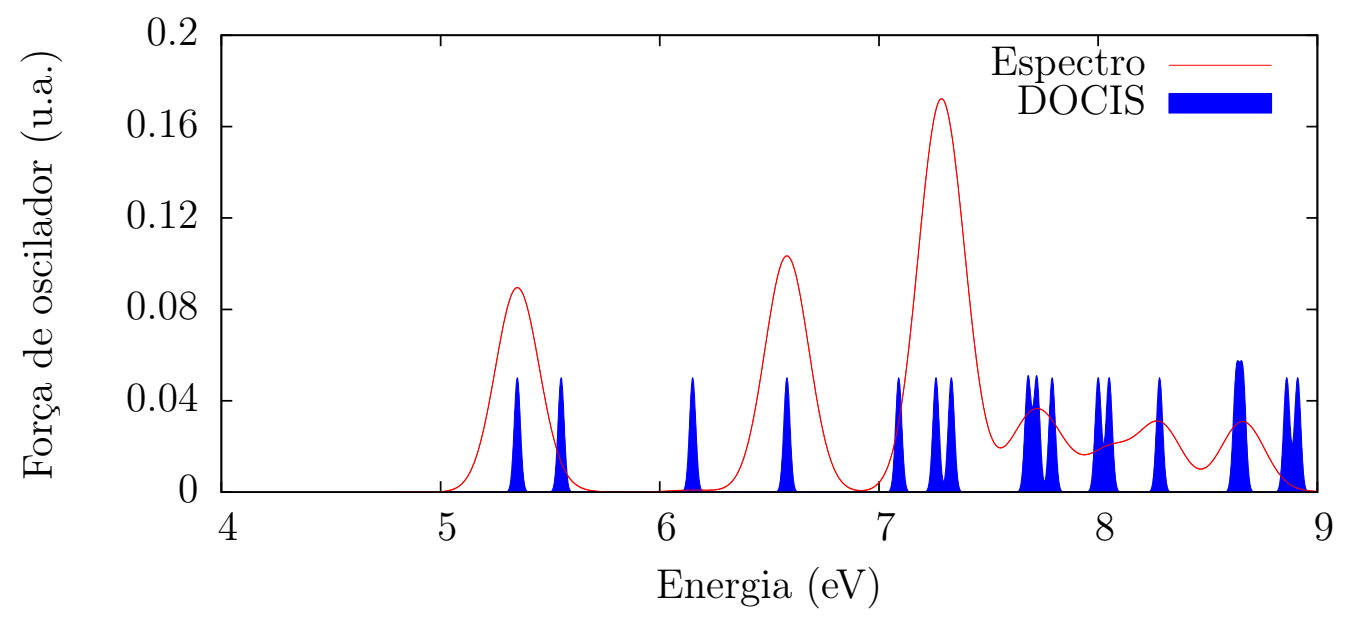

Figura 4.8: Espectro ótico do Tiofeno, e a Density of CI states (DOCIS), obtidos em cálculo CIS/MSINDO.

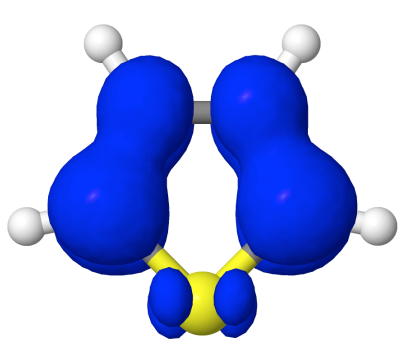

(a) Buraco

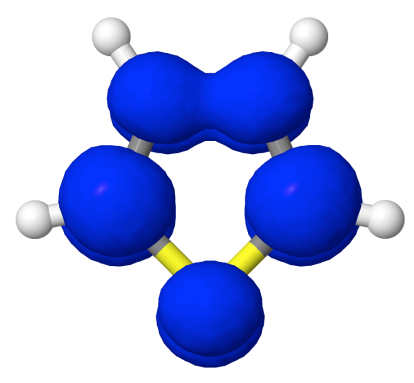

(b) Elétron

Figura 4.9: Representação espacial da primeira transição ótica do Tiofeno, obtida em cálculo CIS/MSINDO: há grande semelhança com os orbitais de campo médio HOMO (buraco) e LUMO (elétron), dada a composição CI da transição.

gia CIS ab initio um gap ótico de $3,97 \mathrm{eV}$, ao passo que utilizando a estrutura obtida via MP2 este valor se reduz para 3,41eV. Esta tendência repetiu-se com a metodologia CIS/MSINDO, que nos deu valores para o gap ótico de $3,76 \mathrm{eV}$ para a geometria DFT e $3,29 \mathrm{eV}$ para a geometria MP2 (3,19eV com o método ZINDO). No gráfico 4.10 comparamos o espectro total calculado para a mesma estrutura DFT com ambas as metodologias.

Esta diferença entre os gaps das duas geometrias poderia estar ligada ao ângulo $\theta$ entre anel e cadeia, a diferença mais marcante entre elas. Realizamos um teste com o MSINDO, utilizando a geometria DFT mas girando o anel "à mão", de forma a aumentar o ângulo para o mesmo valor daquele na geometria MP2, e mantendo todos os demais átomos fixos (geometria "DFTmod"). Esta alteração acarretou em uma mudança no gap ótico de apenas $0,01 \mathrm{eV}$, 


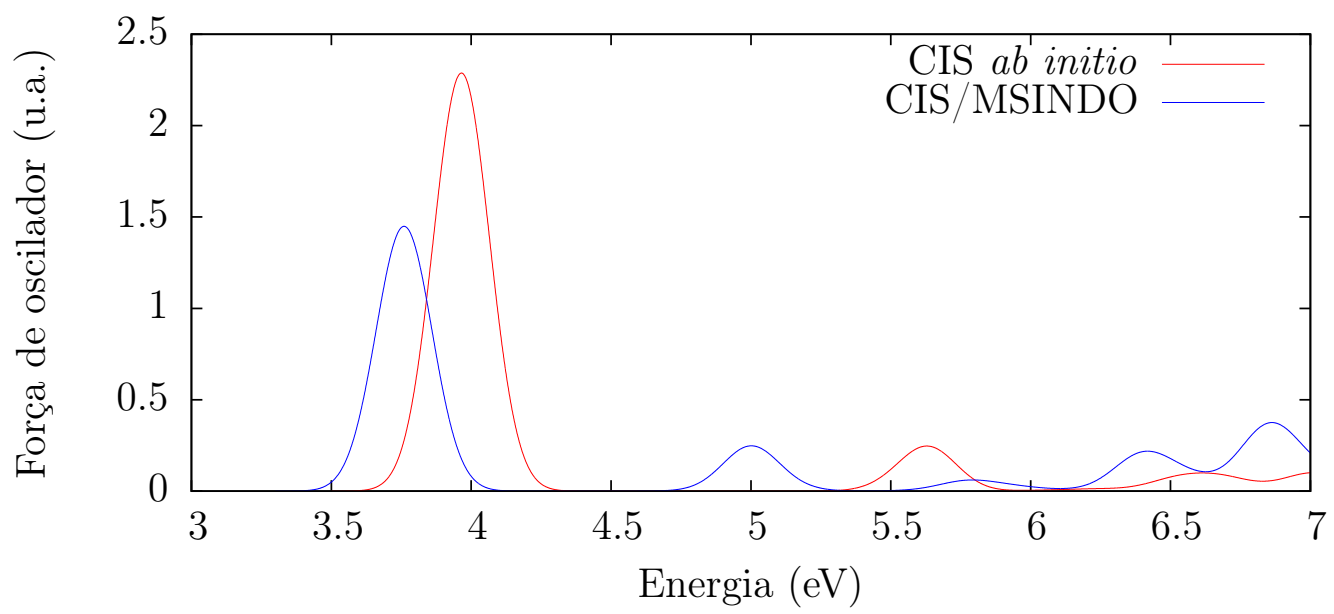

Figura 4.10: Espectro de absorção ótica do ácido retinóico na estrutura "DFT" calculado através de metodologias CIS ab initio e semi-empírico MSINDO.

indicando que a principal diferença entre as geometrias é realmente o grau de conjugação da cadeia, e não o ângulo cadeia-anel. No gráfico 4.1 comparamos o espectro de absorção calculado com o CIS/MSINDO para as três geometrias. De fato, em todos os casos, a primeira transição ótica (representada abaixo na figura 4.T2) é caracterizada por mais de $60 \%$ da transição eletrônica $\mathrm{HOMO} \rightarrow \mathrm{LUMO}$, que praticamente não tem localização no anel e está quase totalmente distribuida na coluna dorsal conjugada. 


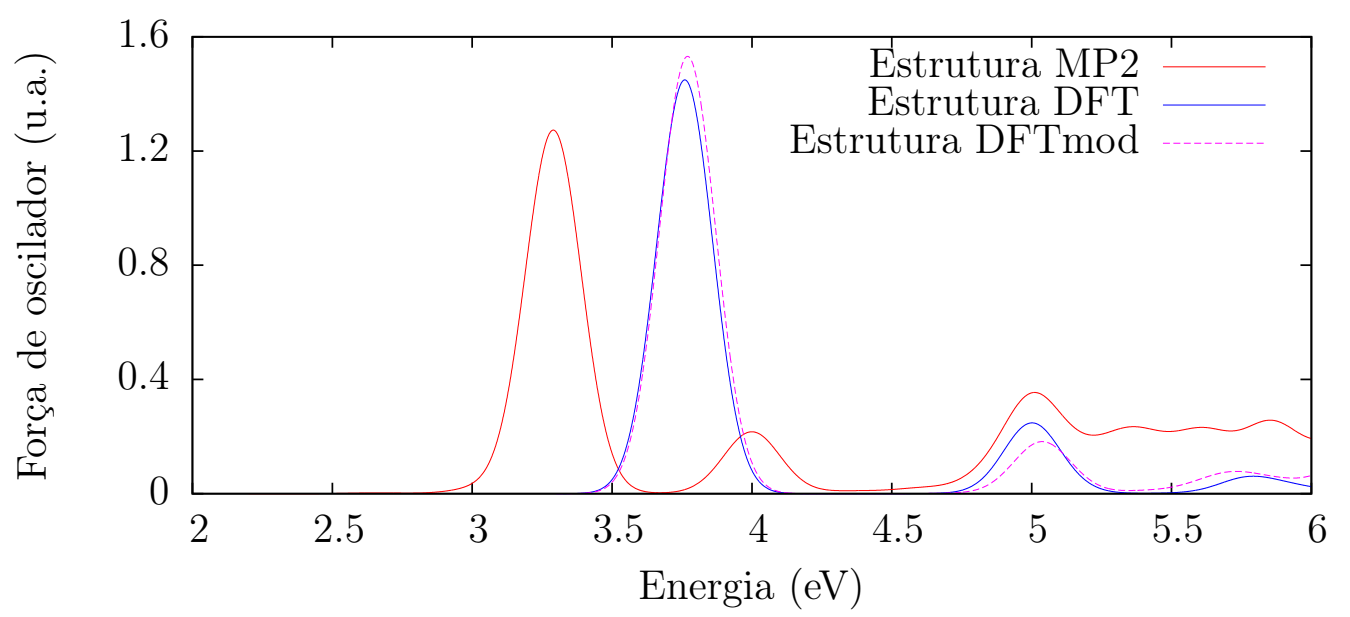

Figura 4.11: Espectro de absorção ótica do ácido retinóico nas diferentes geometrias, calculado através de metodologia CIS/MSINDO.

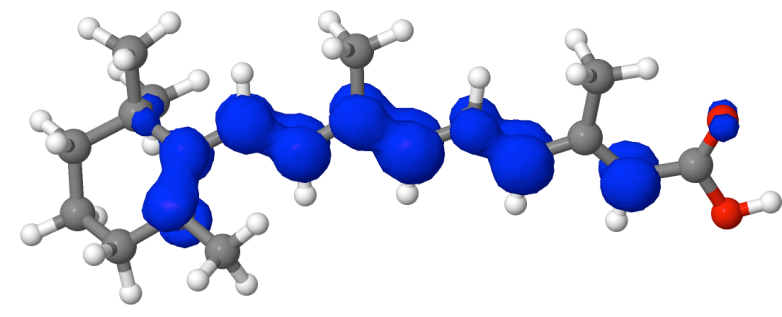

(a) Buraco

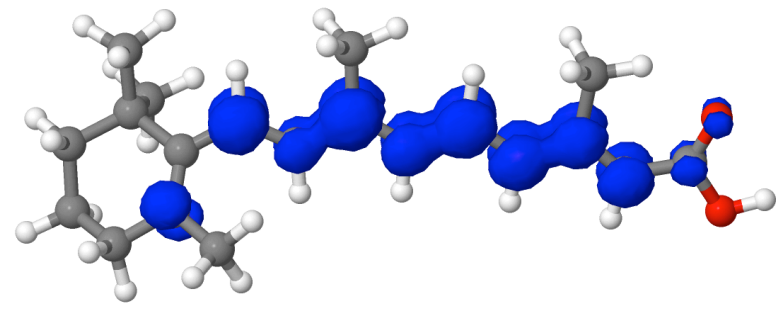

(b) Elétron

Figura 4.12: Representação espacial da primeira transição ótica do ácido retinóico, obtida em cálculo CIS/MSINDO com a geometria DFT. 


\subsection{2 $\quad \mathrm{TiO}_{2}$}

Conforme já discutido, o código MSINDO apresenta a possibilidade do estudo de propriedades óticas de um sistema periódico através do procedimento CIS utilizando para tal o modelo de cluster cíclico. Para estudar o cristal de $\mathrm{TiO}_{2}$ utilizamos uma super célula 4x4x2 em relação à célula convencional, em um total de 384 átomos. Obtivemos para a primeira excitação permitida uma energia de $3,33 \mathrm{eV}$, em ótimo acordo com os valores experimentais de $3,3 \mathrm{eV}$ para o gap ótico[[21], e 3,7eV para a energia do primeiro pico de absorção[[13, Ш22]. A representação espacial desta excitação em termos das densidades (elétron e buraco), definidas da mesma forma que para os sistemas finitos (figura 4.13), mostra em primeiro lugar a completa deslocalização, sobre todo o volume, seja do elétron seja do buraco; além disso vemos uma modulação periódica, ressaltando o caráter cristalino do material.

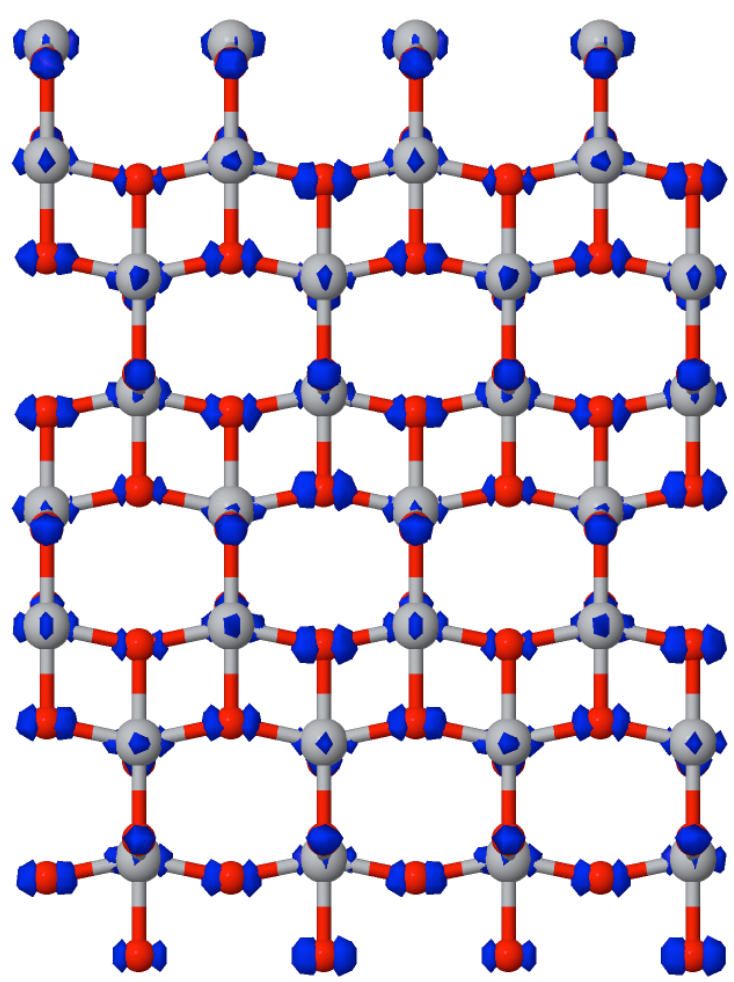

(a) Buraco

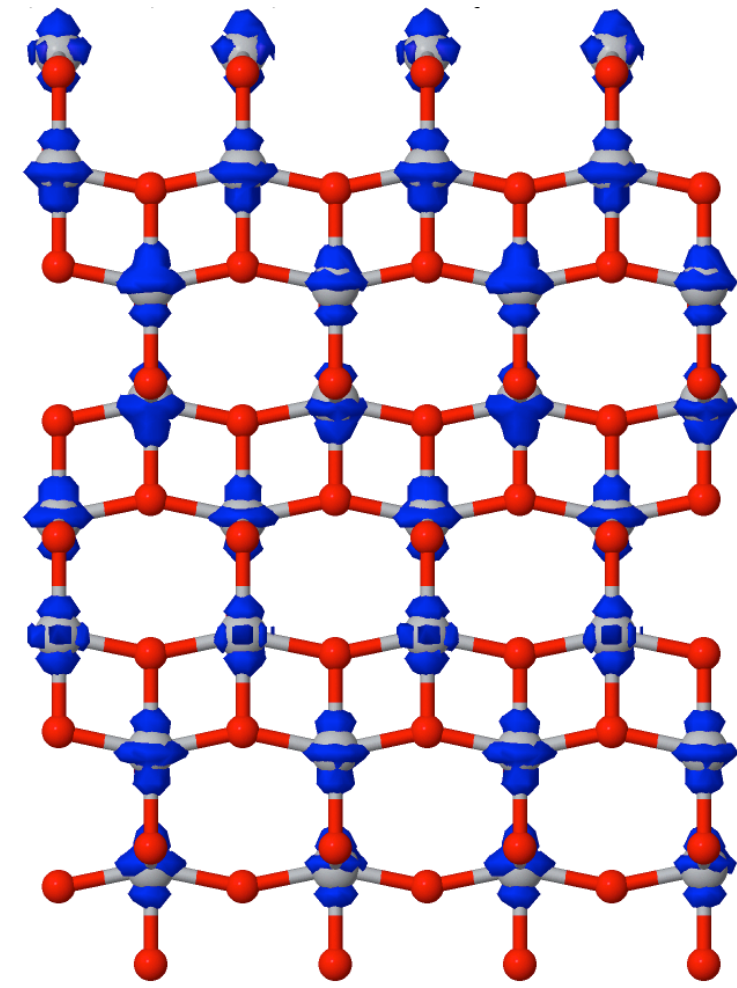

(b) Elétron

Figura 4.13: Representação espacial da primeira transição ótica permitida do cristal de $\mathrm{TiO}_{2}$ anatase, obtida em cálculo CIS/MSINDO. 


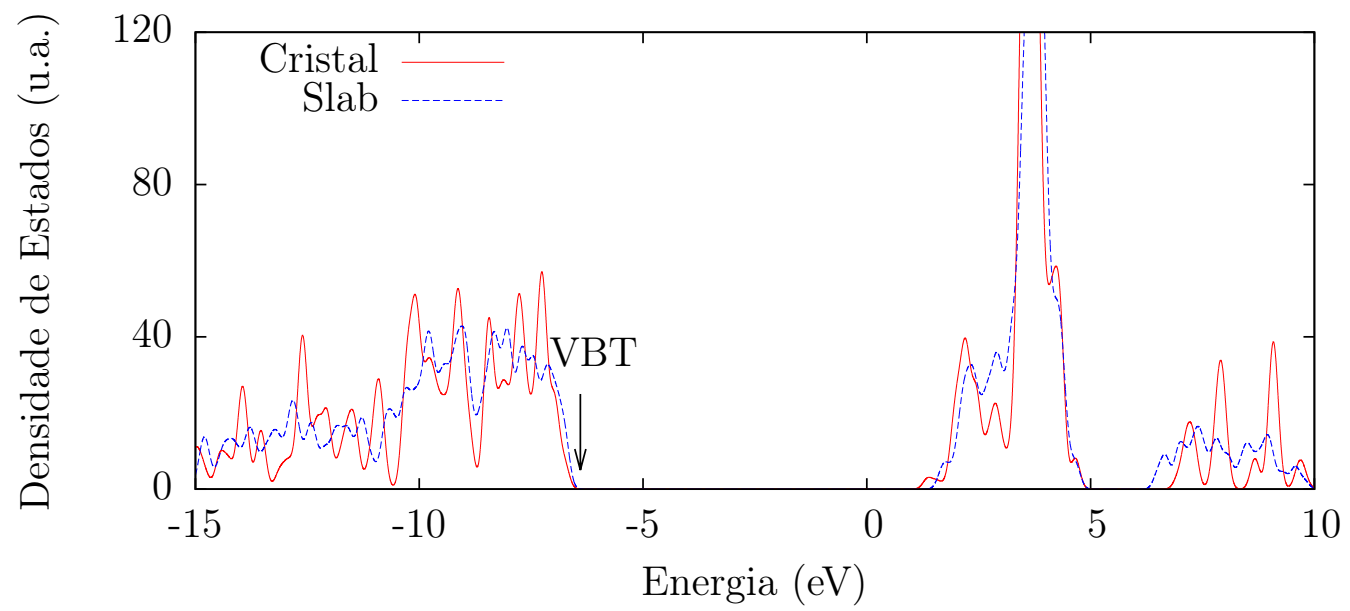

Figura 4.14: Densidades de Estados de campo médio para $\mathrm{TiO}_{2}$ anatase, cristal e fatia de 4 camadas (101), obtidas em cálculo HF/MSINDO.

Para estudar o efeito de confinamento no modelo de fatia, escolhemos o sistema de 4 camadas, com dimensão lateral de 2x2 em relação ao utilizado no DFT, em um total de 192 átomos. Olhando primeiramente para o resultado Hartree-Fock (que precede o cálculo CIS), percebemos que, no nível de campo médio, novamente não é visto o efeito de confinamento, conforme esperado. O gap elétrico obtido para a fatia é $6,08 \mathrm{eV}$, pouco maior que o gap do cristal de 5,97eV. Na figura 4.14 estão representadas as densidades de estados HF obtidas, para o cristal e para a fatia, e vemos praticamente sobreposição completa.

Se no nível Hartree-Fock os resultados são semelhantes, no cálculo CIS surgem diferenças relevantes (Figura 4.5). A excitação com maior força de oscilador está ainda em 3,3eV, mas excitações a energias distintamente menores também são permitidas.

Algumas destas excitações (energias entre 3 e 3,2eV) estavam presentes já no caso cristalino, com força de oscilador zero; aqui, devido à quebra de simetria na direção $z$, elas assumem força de oscilador não nula. Além disso, outras excitações a energias ainda mais baixas surgiram: estas excitações estão relacionadas a estados de superfície, não existentes no caso cristalino, conforme pode ser visto na figura 4.J6, ao passo que as excitações a energias maiores se concentram no interior da fatia (figura 4.17).

Este resultado é importantíssimo, pois representa outra forma do efeito de confinamento, mas agora aplicado ao problema excitônico: quanto mais concentrado ficar o par elétronburaco maior será a atração entre eles, e assim o gap ótico diminui (ao contrário do gap 


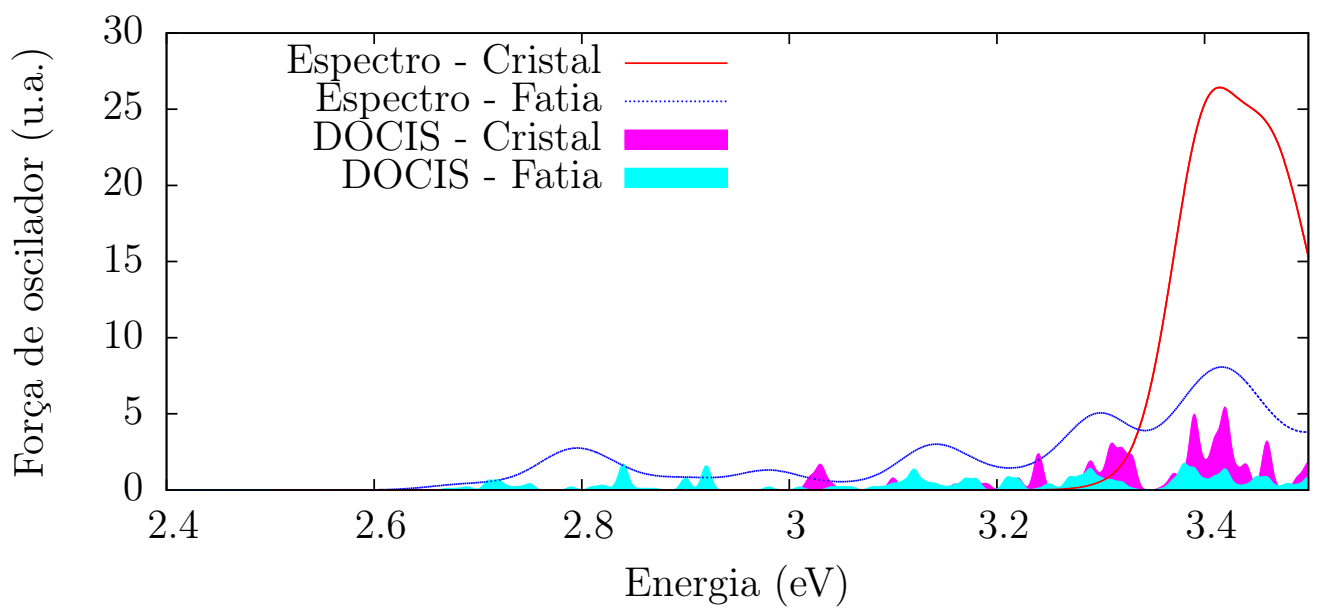

Figura 4.15: Espectro de absorção ótica do $\mathrm{TiO}_{2}$ anatase cristalino e fatia de 4 camadas (101), e respectivas DOCIS, calculados através de metodologia CIS/MSINDO.

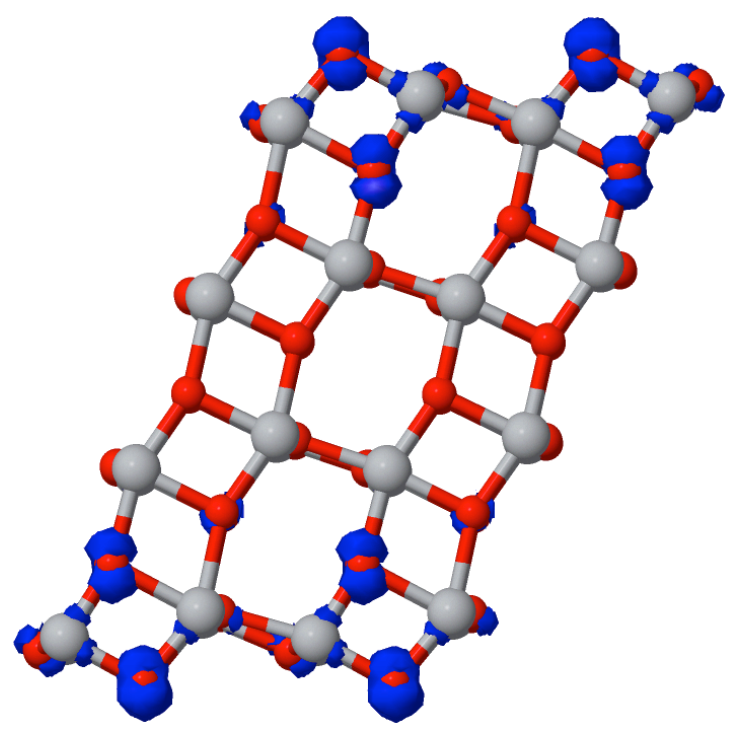

(a) Buraco

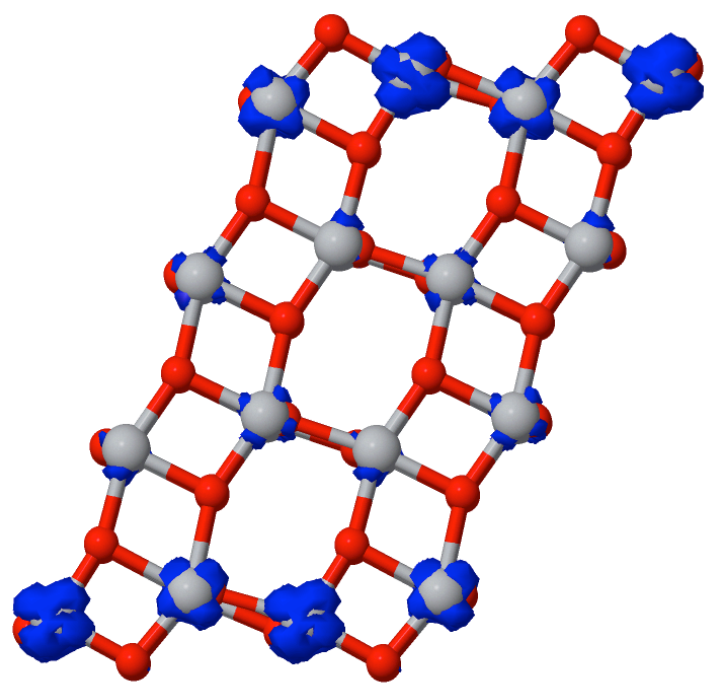

(b) Elétron

Figura 4.16: Representação espacial de uma das transições óticas que compõe o pico de $2,79 \mathrm{eV}$ da fatia de 4 camadas (101) de $\mathrm{TiO}_{2}$ anatase, obtida em cálculo CIS/MSINDO. 


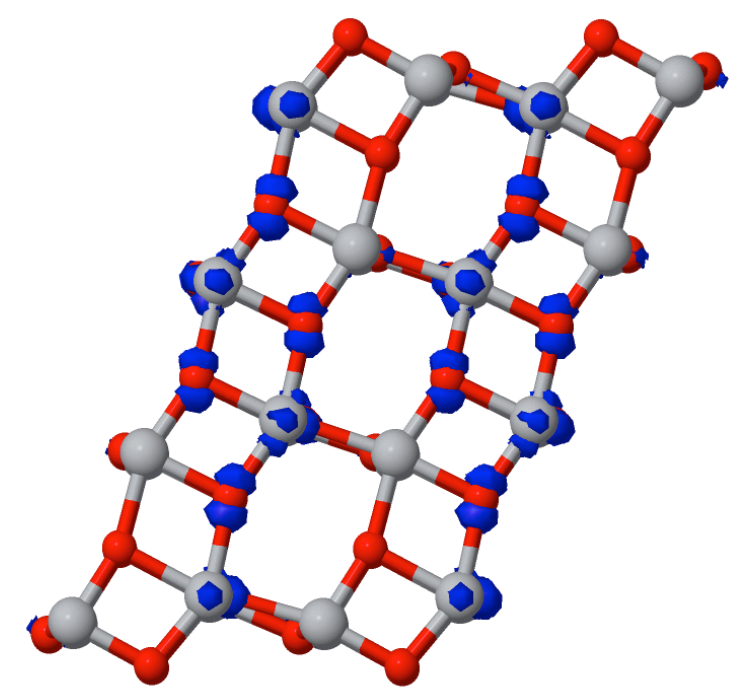

(a) Buraco

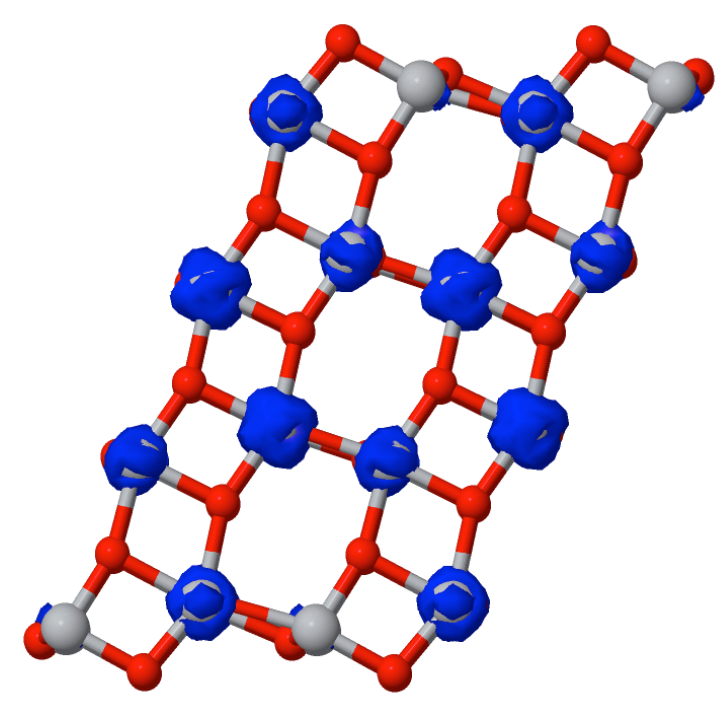

(b) Elétron

Figura 4.17: Representação espacial da transição ótica de maior força de oscilador do pico de 3,30eV da fatia de 4 camadas (101) de $\mathrm{TiO}_{2}$ anatase, obtida em cálculo CIS/MSINDO.

elétrico, que aumenta). Esta é uma característica conhecida de longa data, e comumente batizada de energia de ligação excitônica (exciton binding energy). Em sistemas cristalinos extensos é normalmente de dezenas de meV, enquanto em sistemas moleculares ou poliméricos, altamente localizados, chega à ordem de $\mathrm{eV}$ como vemos aqui. Esse efeito já havia sido visto nos cálculos GW para nanofolhas de $\mathrm{TiO}_{2}$ de Palummo et al.[108] e para a superfície 001, também de $\mathrm{TiO}_{2}$, por Giorgi et al.[[123]; em ambos os casos, não só se vê um red-shift do espectro, como o surgimento de outros picos menos intensos em energias mais baixas, também caracterizados por estados de superfície. Recentemente, Liu et al.[124] também encontraram, experimentalmente, picos de absorção para estruturas de $\mathrm{TiO}_{2}$ a energias menores que o gap ótico do cristal; algumas foram atribuídas a defeitos e vacâncias de oxigênio, mas uma banda entre 2,8 a 3,1eV apresentou forte caráter de estado superficial.

Todos estes resultados de literatura demonstram a confiabilidade de nossos cálculos, e a relevância de estados de superfície. Assim, ao considerarmos as montagens devemos ter presente a existência destes estados. 


\subsubsection{Tiofeno sobre $\mathrm{TiO}_{2}$}

Conforme já descrito nas seções anteriores, o sistema retinóico/ $\mathrm{TiO}_{2}$ é bastante complexo e assim, antes de abordá-lo quanto a propriedades óticas, aplicamos o mesmo procedimento a um outro sistema que já vinha sendo estudado em nosso grupo[125] e para o qual temos resultados ab-initio para comparação. Trata-se da molécula de tiofeno sobre a superfície de $\mathrm{TiO}_{2}$, um sistema mais simples, com menor dimensão lateral da célula para cálculo, apenas 69 átomos no total, e no qual o tiofeno está fisissorvido na superfície (ao contrário do retinóico, que se liga quimicamente à superfície), conforme pode ser visto na figura 4.18 .

Analisando primeiramente o alinhamento de níveis eletrônicos de campo médio, na tabela 4.5 apresentamos a comparação de resultados obtidos para tiofeno isolado, fatia de $\mathrm{TiO}_{2}$ anatase, e sistema fisissorvido de tiofeno sobre a superfície, obtidos através das metodologias DFT LDA/PZ, GW e HF/MSINDO. Neste caso, como adotamos uma geometria diferente daquela utilizada no resto do trabalho, para poder ser comparada com os resultados previamente obtidos de GW, já para a fatia limpo as propriedades eletrônicas e óticas diferem daquelas obtidas anteriormente. Além disso, ao adotarmos o modelo de cluster cíclico, devemos sempre utilizar uma supercélula grande o suficiente para atingir convergência

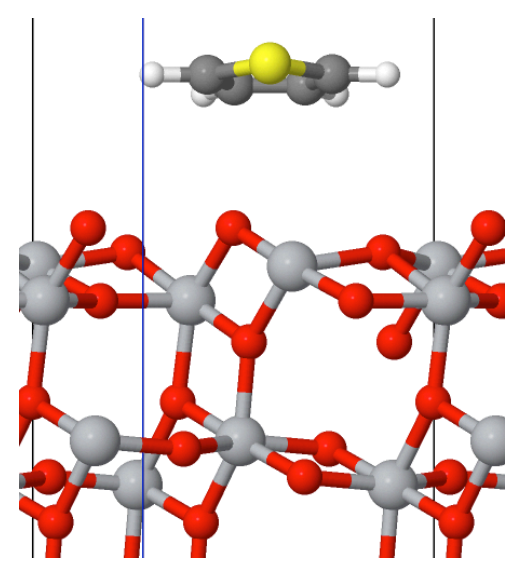

(a) Lateral

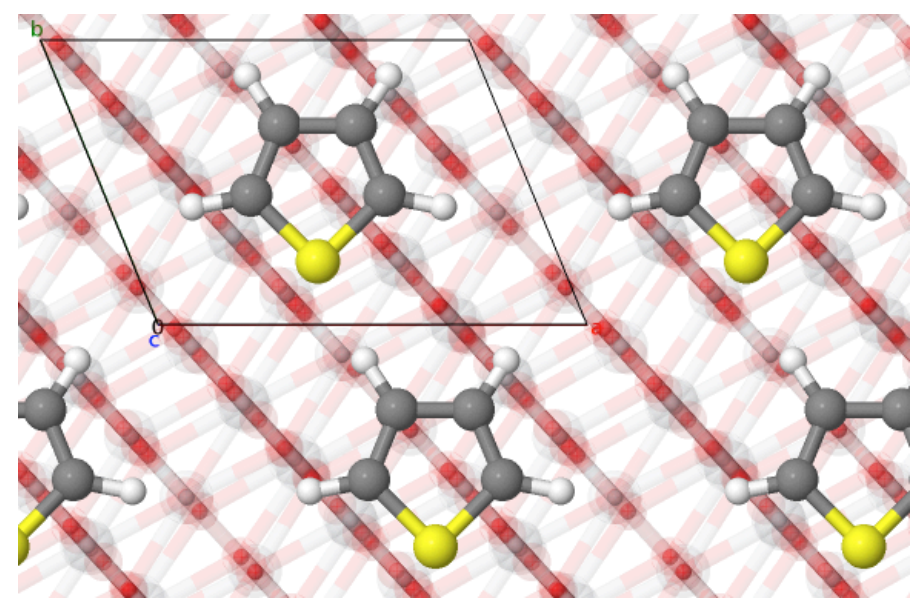

(b) Superior

Figura 4.18: Estrutura do sistema Tiofeno fisissorvido sobre fatia de 4 camadas (101) de $\mathrm{TiO}_{2}$, com visão lateral e superior[s.

\footnotetext{
${ }^{\S}$ A geometria havia sido obtida previamente através de otimização de geometria com DFT GGA/PBE
} 
de resultados para as transições óticas [92], como fizemos até aqui. Neste caso, ainda para manter contato com nosso cálculo anterior, a célula é menor e traz efeitos sobre o gap ótico que comentaremos à frente.

Para o alinhamento entre as metodologias DFT e MSINDO levamos primeiramente o topo da banda de valência ( Valence Band Top, VBT) da fatia isolada para 0,0eV; em seguida alinhamos com o sistema híbrido $\mathrm{T} 1 / \mathrm{TiO}_{2}$ a partir de estados profundos do óxido em comum ao sistema isolado (apenas para a DFT, para HF/MSINDO este alinhamento já surgiu naturalmente do cálculo); e por fim foi alinhado o espectro do tiofeno a partir do sistema híbrido, utilizando o primeiro nível eletrônico da molécula como referência. Os níveis GW foram alinhados baseados na correção aos níveis DFT correspondentes.

Tabela 4.5: Níveis de energia para sistema de Tiofeno isolado (T1), fatia de 4 camadas (101) de $\mathrm{TiO}_{2}$ anatase $\left(\mathrm{TiO}_{2}\right)$ e Tiofeno fisissorvido sobre a fatia $\left(\mathrm{T} 1 / \mathrm{TIO}_{2}\right)$ para as diferentes metodologias.

\begin{tabular}{l|ccc|ccc|ccc} 
& \multicolumn{3}{|c|}{$\mathrm{LDA} / \mathrm{PZ}$} & \multicolumn{3}{c|}{$\mathrm{GW}$} & \multicolumn{3}{c}{$\mathrm{HF} / \mathrm{MSINDO}$} \\
\hline \multirow{2}{*}{ LUMO } & $\mathrm{T} 1$ & $\mathrm{TiO}_{2}$ & $\mathrm{~T} 1 / \mathrm{TiO}_{2}$ & $\mathrm{~T} 1$ & $\mathrm{TiO}_{2}$ & $\mathrm{~T} 1 / \mathrm{TiO}_{2}$ & $\mathrm{~T} 1$ & $\mathrm{TiO}_{2}$ & $\mathrm{~T}_{1} / \mathrm{TiO}_{2}$ \\
$\mathrm{CBM}$ & 5,45 & - & 5,47 & 7,57 & - & 7,59 & 13,96 & - & 13,96 \\
\hline $\mathrm{HOMO}$ & - & 2,41 & 2,41 & - & 4,81 & 4,72 & - & 8,25 & 8,26 \\
$\Delta$ & 1,38 & - & 1,43 & $-0,76$ & - & 0,30 & 1,18 & - & 1,25 \\
HOMO-1 & 0,61 & - & 0,62 & 0,78 & - & 0,82 & 1,00 & - & 0,95 \\
VBT & 0,77 & - & 0,81 & $-1,54$ & - & $-0,52$ & 0,18 & - & 0,30 \\
\hline HOMO-LUMO & - & 0,00 & 0,00 & - & $-0,36$ & $-0,32$ & - & 0.00 & 0,00 \\
VBT-CBM &,- 07 & - & 4,04 & 8,33 & - & 7,29 & 12,78 & - & 12,71 \\
gap Efetivo & - & 2,41 & 2,41 & - & 5,17 & 5,04 & - & 8,25 & 8,26 \\
& - & 0,98 & - & - & 4,42 & - & - & 7,01
\end{tabular}

Comparando os resultados DFT LDA/PZ, GW/LDA e HF/MSINDO, verificamos uma forte tendência crescente para os gaps de energia, que já era esperada para estas 3 metodologias: gaps DFT muito pequenos, e gaps Hartree-Fock muito grandes, quando adotamos o GW como referência. Outra diferença marcante entre os resultados LDA/PZ e GW/LDA diz respeito aos níveis HOMO-1 e HOMO da molécula, localizados no meio do gap para $\mathrm{LDA} / \mathrm{PZ}$, e trazidos para energias mais próximas ao topo da banda de valência pelas correções GW/LDA. Podemos perceber que a diferença de energia entre HOMO-1 e VBT torna-se menor no MSINDO, apesar de não ocorrer a inversão vista no GW. Uma comparação entre a densidade de estados projetada na superfície, e a DOS total da fatia limpa (figura 4.19 ) 


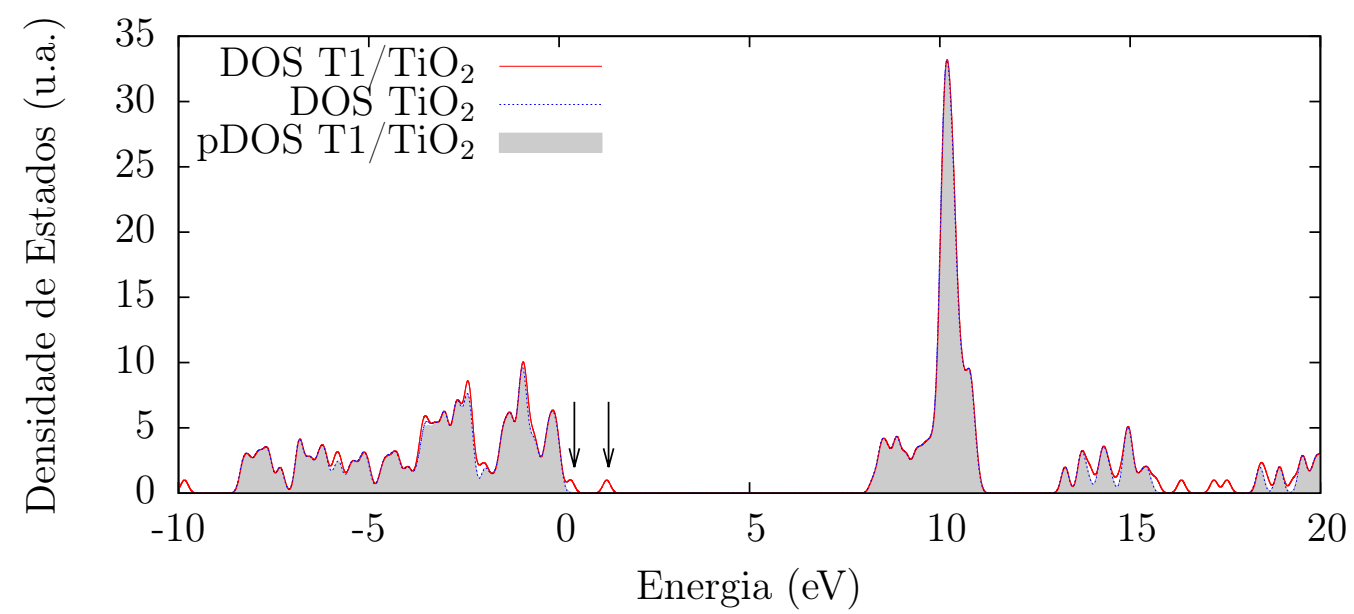

Figura 4.19: DOS do sistema híbrido $\mathrm{T} 1 / \mathrm{TiO}_{2}$ total e projetada sobre a superfície, e DOS da fatia isolada, calculados através de metodologia HF/MSINDO. Vemos dois estados ocupados da molécula no gap da fatia, sendo o HOMO-1 quase coincidente com o VBT (assinalados na figura).

mostra que o tiofeno afeta muito pouco os níveis eletrônicos da superfície, deixando clara a fraca interação existente entre os sistemas.

Da mesma forma, à primeira vista o espectro de absorção do sistema híbrido e da fatia isolado são muito próximos (figura 4.201). Devido ao tamanho mais reduzido da célula adotada, foi possível obter o espectro até energias mais altas. Por outro lado, conforme comentado, estamos ainda longe da convergência, o que provoca a redução do valor do gap ótico, ao compararmos com os resultados da figura 4.15. Este problema não afeta entretanto a discussão a seguir.

Em uma análise mais profunda dos estados excitados, vemos a existência de excitons de transferência de carga entre os sistemas: de fato, na excitação a 5,16eV, energia esta muito próxima à primeira transição ótica da molécula (HOMO-LUMO, já discutida na seção 4.4.D, figura (4.9), vemos a delocalização do exciton sobre o complexo molécula-óxido, com participação mais forte do HOMO (molécula) no buraco, e do óxido no elétron (figura 4.20 ). Muito interessante, já a energias mais baixas esta transferência de carga ocorre, ainda que menos intensa; o pico a 2,21eV (figura 4.22) mostra uma clara transferência eletrônica entre molécula e óxido, resultante do alinhamento energético entre o nível HOMO-1 da molécula e o VBT da fatia. 


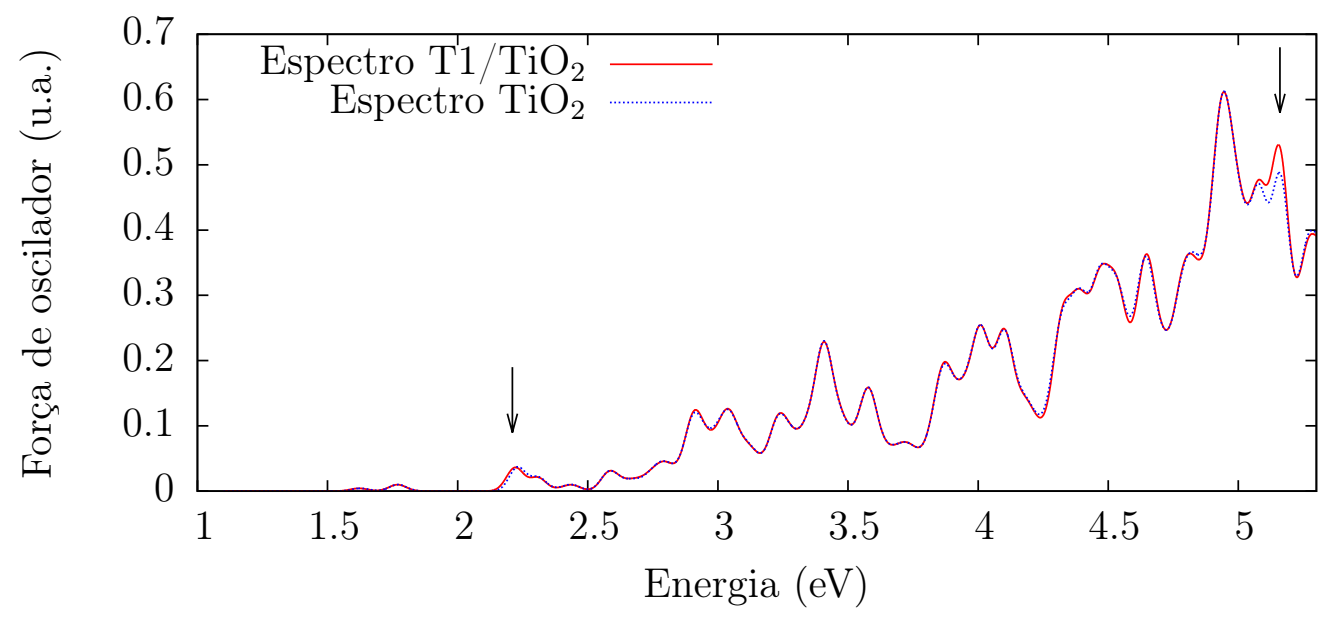

Figura 4.20: Espectro de absorção ótica do sistema híbrido $\mathrm{T} 1 / \mathrm{TiO}_{2}$ e da fatia isolada, calculados através de metodologia CIS/MSINDO. Sinalizadas as transições representadas nas figuras 4.20 e 4.22 .
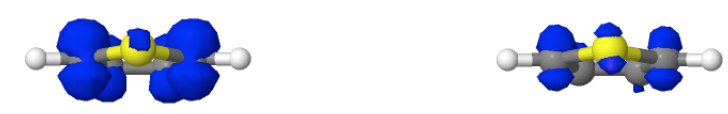

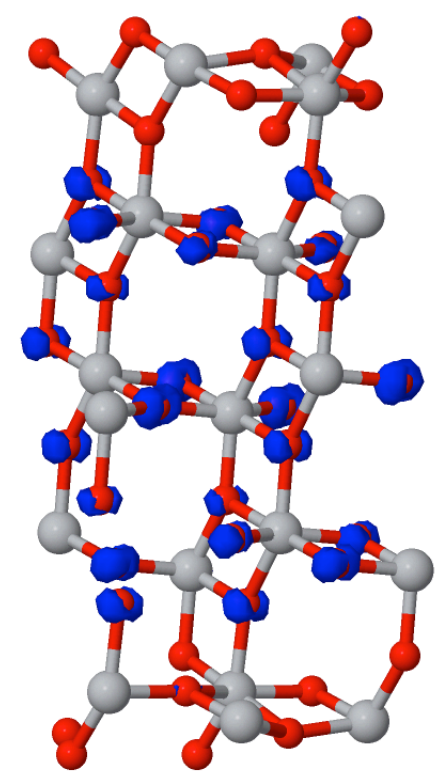

(a) Buraco

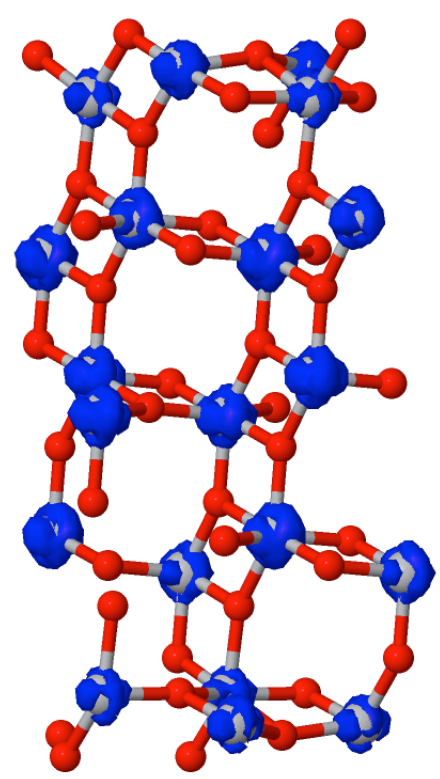

(b) Elétron

Figura 4.21: Representação espacial de uma das transições óticas que compõem o pico a $5,16 \mathrm{eV}$ do sistema híbrido $\mathrm{T} 1 / \mathrm{TiO}_{2}$, obtida em cálculo CIS/MSINDO. 


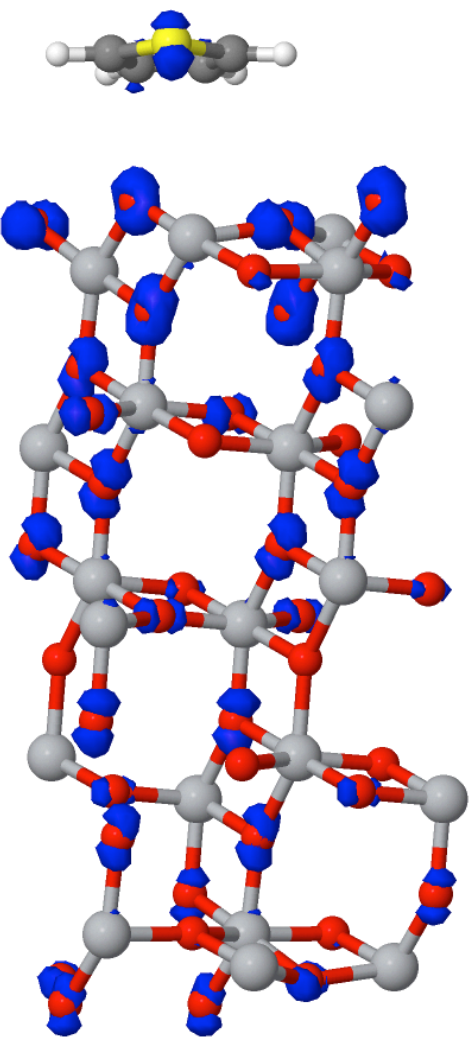

(a) Buraco
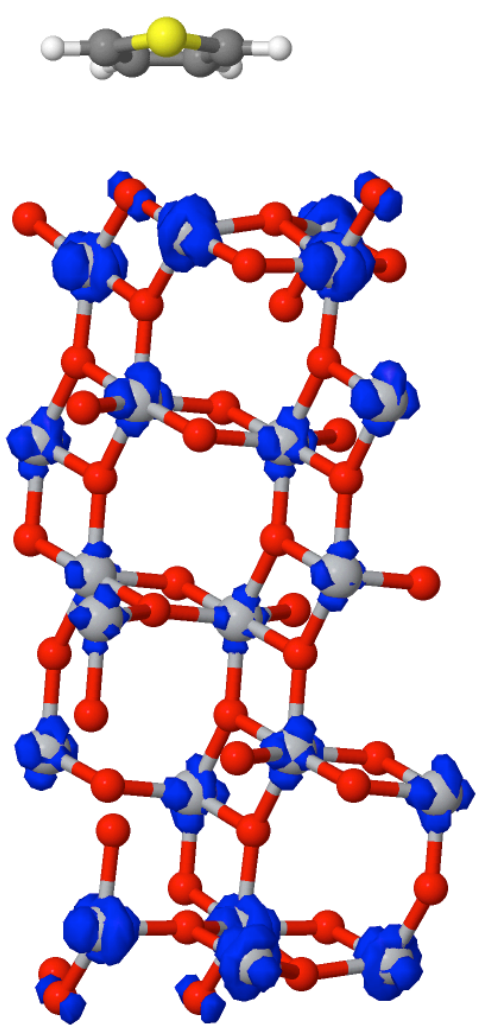

(b) Elétron

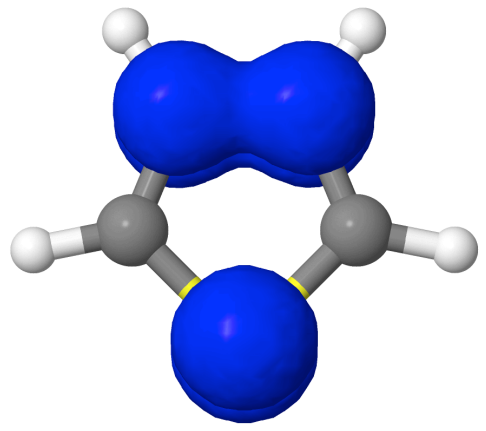

(c) HOMO-1

Figura 4.22: Representação espacial de uma das transições óticas que compõem o pico a $2,21 \mathrm{eV}$ do sistema híbrido $\mathrm{T} 1 / \mathrm{TiO}_{2}$, obtida em cálculo CIS/MSINDO, e orbital HOMO-1 do tiofeno isolado. 


\subsection{4 Ácido Retinóico sobre $\mathrm{TiO}_{2}$}

O sistema de Ácido Retinóico sobre $\mathrm{TiO}_{2}$ é completamente diferente do sistema $\mathrm{T} 1 / \mathrm{TiO}_{2}$ visto acima, pois aqui temos uma ligação química entre os dois sistemas, que ocasiona mudanças grandes tanto nas propriedades eletrônicas quanto óticas em relação aos sistemas isolados. Como mencionamos anteriormente, temos uma certa proximidade entre uma molécula e suas vizinhas nesta nossa modelagem. Para nos certificar que não há interação entre uma molécula e a sua repetição (na modelagem do cluster cíclico), realizamos os cálculos CIS/MSINDO também para a mono-camada isolada de ácido retinóico, utilizando a mesma estrutura e periodicidade do sistema híbrido de ácido retinóico sobre óxido de titânio, mas sem a fatia semicondutora. Verificamos que tal interação é muito pequena, e a mudança tanto eletrônica quanto ótica no sistema é mínima.

Iniciando pela densidade de estados do sistema híbrido (figura 4.23), podemos ver o alargamento das bandas, em especial da banda de estados desocupados, apesar do pico principal ter mantido sua posição. Com este alargamento temos também o fechamento parcial do gap de energia. Além disso, verificamos também que o primeiro estado desocupado com contribuição da molécula (LUMO) muda de caráter: no sistema híbrido temos um estado $\sigma$ localizado no anel, enquanto o LUMO da cadeia isolada, como mostrado anteriormente, é um estado $\pi$ deslocalizado ao longo da cadeia (este estado no complexo ainda é visto, mas se torna o $\mathrm{LUMO}+3)$.

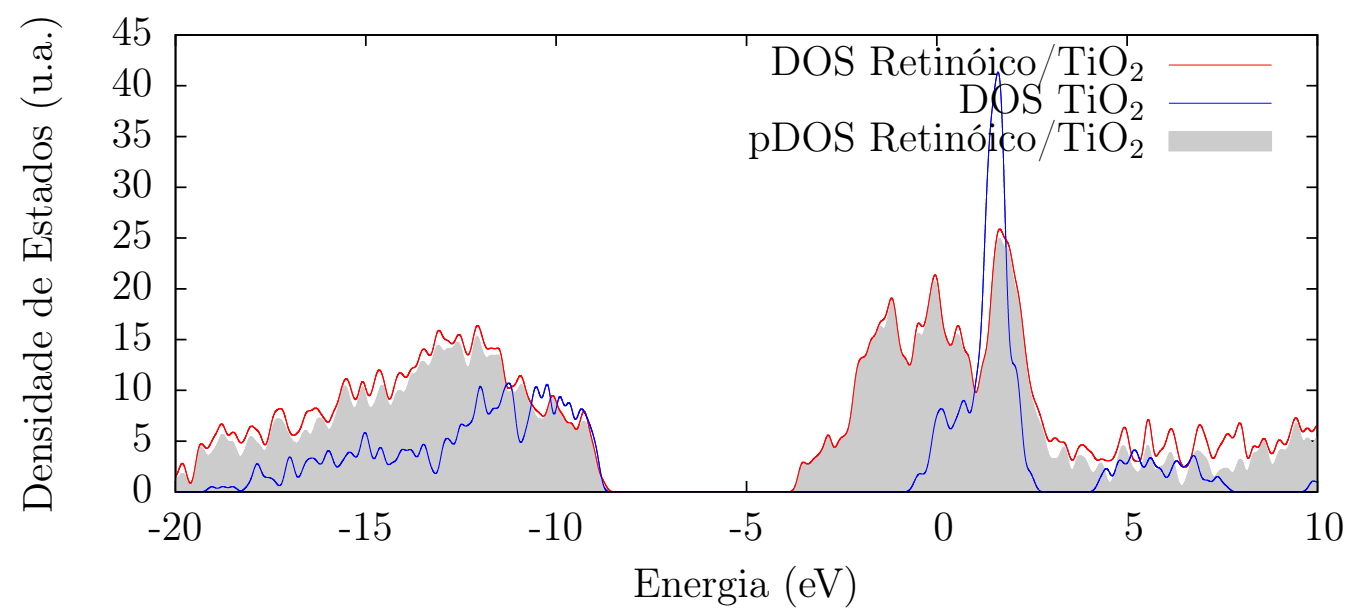

Figura 4.23: Densidade de Estados do sistema híbrido de ácido retinóico ligado ao $\mathrm{TiO}_{2}$, total e projetada sobre a superfície, e Densidade de Estados total da fatia isolada, calculados através de metodologia HF/MSINDO. 


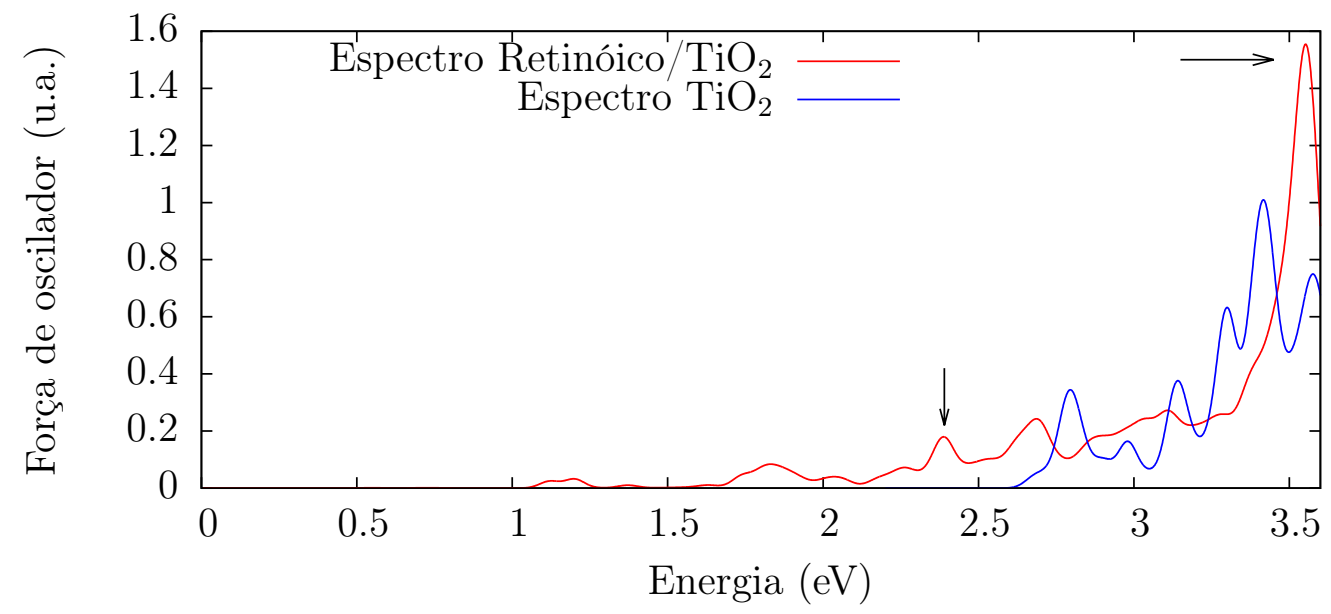

Figura 4.24: Espectro de absorção ótica do sistema híbrido de ácido retinóico ligado ao $\mathrm{TiO}_{2}$ e da fatia isolada, calculados através de metodologia CIS/MSINDO.

A análise das propriedades óticas deste sistema também demonstra que sistemas ligados quimicamente sofrem maiores modificações. Vemos que o sistema híbrido passa a absorver luz a energias menores que o gap ótico da fatia isolada, absorvendo em praticamente toda a região do visível, tornando o sistema "preto". É de fato um resultado inesperado e muito interessante: estas transições a energias mais baixas, apesar de surgirem devido à adição da molécula, não envolvem a molécula diretamente; como pode ser visto na figura 4.25 elas são relacionadas a estados que chegam à superfície oposta à de inserção, ou seja, os excitons da superfície funcionalizada são extremamente perturbados.

Não necessariamente toda a energia luminosa absorvida poderia ser disponibilizada para conversão elétrica, podendo se tornar simplesmente calor. Algumas destas transições, porém, representam claramente transferência de carga da molécula para o óxido, como pode ser visto na figura 4.26 para uma das transições que compõem o pico de 3,6eV; vê-se o buraco localizado inteiramente na molécula, e o elétron, apesar de ainda se localizar majoritariamente na molécula, passa também ao óxido.

Sumarizando, vemos que no complexo fisissorvido a nanoestrutura permanece com suas características principais - absorção apenas no UV, excitons de superfície - e assim também são mantidas as estruturas da molécula. Adicionalmente, vemos o processo de transferência de carga molécula $\rightarrow$ óxido. Já no complexo quimissorvido, em particular neste caso retinóico-óxido em que a ligação envolve a cadeia conjugada, as características de ambos os componentes são bastante afetadas. Temos agora um alcance de absorção UV-Vis chegando 
ao vermelho, e os processos de transferência de carga existem, são vários, e mais dispersos que no caso anterior.

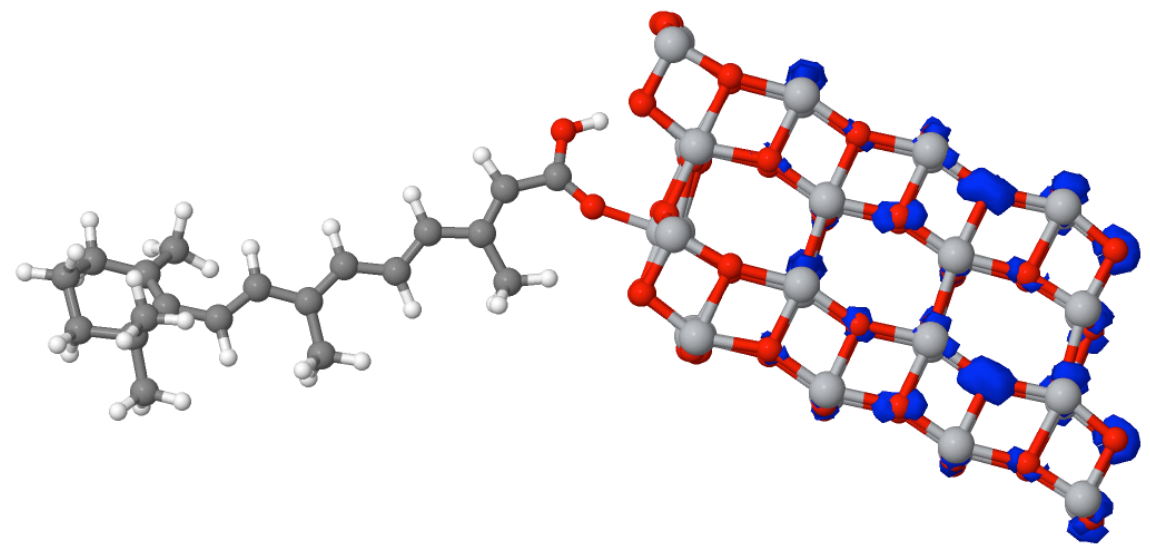

(a) Buraco

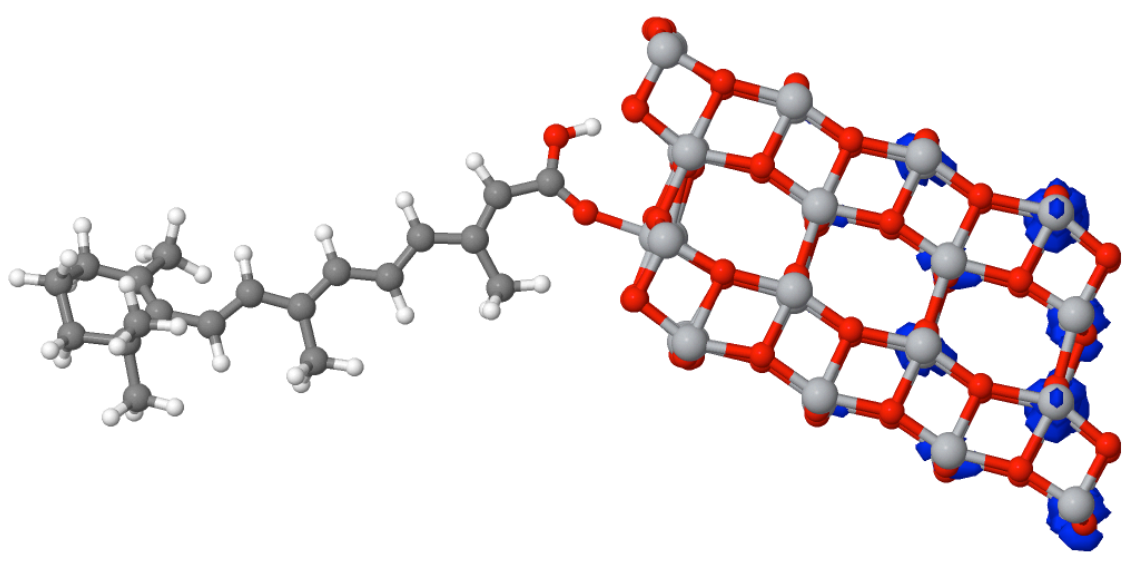

(b) Elétron

Figura 4.25: Representação espacial de uma das transições óticas do pico de 2,39eV do sistema híbrido de ácido retinóico ligado ao $\mathrm{TiO}_{2}$, obtida em cálculo CIS/MSINDO. 


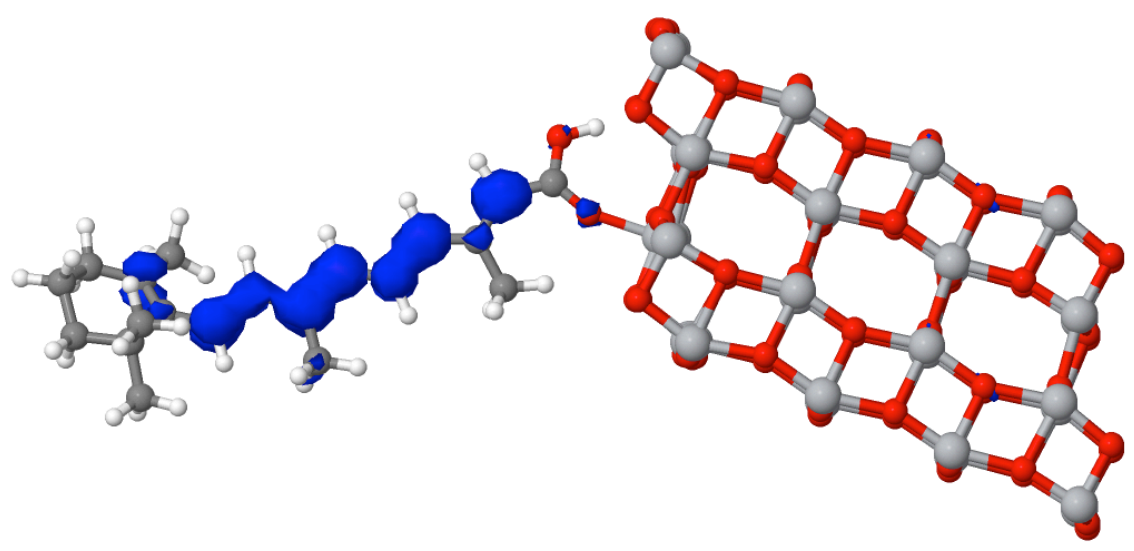

(a) Buraco

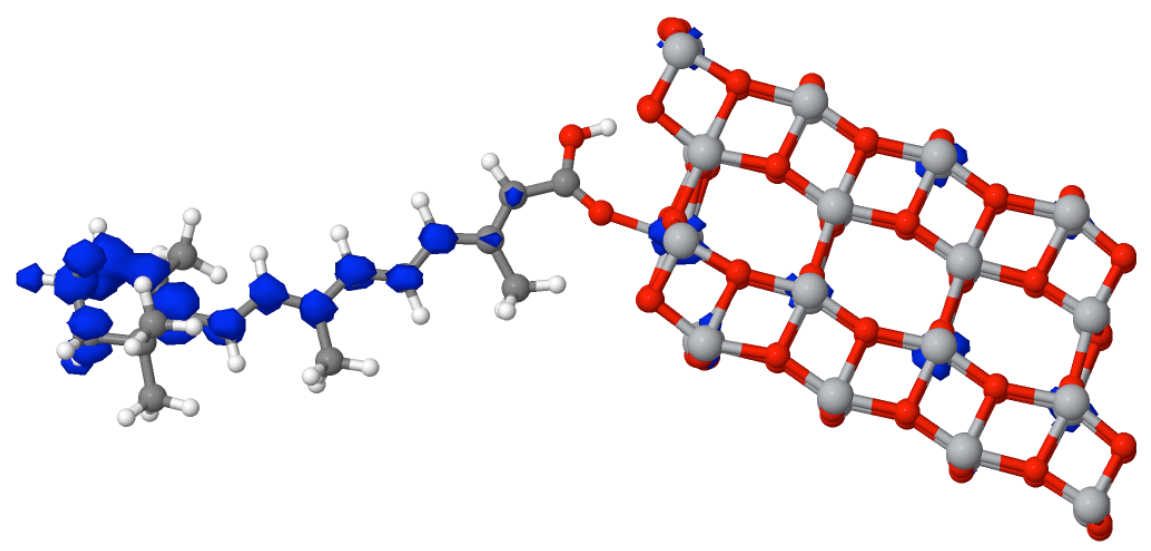

(b) Elétron

Figura 4.26: Representação espacial de uma das transições óticas do pico de 3,59eV do sistema híbrido de ácido retinóico ligado ao $\mathrm{TiO}_{2}$, obtida em cálculo CIS/MSINDO. 


\section{Capítulo 5}

\section{Conclusões}

A Teoria do Funcional da Densidade no conjunto de metodologias de campo médio representou um grande avanço no estudo de propriedades eletrônicas, pois em sua simplicidade consegue descrever surpreendentemente bem determinadas propriedades do estado fundamental de uma ampla gama de materiais. Entre estas temos geometria, estrutura de bandas, energias totais (para cálculo de energias de adsorção ou ligação, por exemplo) e magnetização. Ela sabidamente apresenta certas deficiências, como a descrição do potencial de ionização, e certamente não descreve, por princípio, estados excitados e portanto não é adequada para obtenção do gap de energia. Diversas melhorias foram propostas, como o uso de funcionais generalizados que tornou-se comum.

Verificamos, porém, que para algumas destas deficiências devemos ir além do campo médio. No estudo de nanoestruturas, por exemplo, a DFT não descreve adequadamente o efeito de confinamento. Este fato pode, eventualmente, até ser visto como uma vantagem, já que para a descrição de propriedades macroscópicas seria suficiente um sistema modelo de menores dimensões: por exemplo, para simulação de quimissorção em superfícies de filmes finos ou substratos macroscópicos. Quando se quer estudar justamente um sistema nanoscópico, porém, corre-se o risco de perder parte da descrição, que de acordo com nossos resultados não pode ser obtida com as modificações existentes para a DFT.

Outro caso em que as modificações existentes para a DFT não se mostraram capazes de produzir bons resultados é o estudo de sistemas híbridos orgânico/óxido. Embora a descrição precisa para os sistemas individuais seja possível, utilizando metodologias diversas, não encontramos um método único que fosse capaz de descrever ambos os sistemas ao mesmo 
tempo, para que pudesse em seguida ser utilizado com confiança no sistema híbrido.

Já a metodologia MSINDO mostrou-se eficaz no estudo de ambos os problemas. Por ser uma metodologia semi-empírica e parametrizada, um melhor acordo com resultados experimentais já era esperado. Ela mostrou-se adequada às nossas necessidades ao descrever o efeito de confinamento na fatia (com o interessante resultado de as primeiras excitações se localizarem na superfície), e ao resultar em energias para as excitações óticas dos sistemas isolados próximas aos valores experimentais, indicando que sua aplicação para os sistemas orgânico/óxido seria possível.

Concluímos portanto que, através da metodologia MSINDO CIS, é possível realizar um estudo mais detalhado dos processos de transferência de carga em sistemas mistos orgânico/óxido.

$\mathrm{O}$ estudo do sistema de molécula de tiofeno depositada sobre $\mathrm{TiO}_{2}$ resultou em uma densidade de estados e espectro de absorção muito semelhantes aos da fatia de $\mathrm{TiO}_{2}$ limpa. Para o uso em célula solar é necessária a injeção de elétrons no óxido durante a absorção de luz, e de fato conseguimos verificar que o alinhamento entre o VBT do óxido e do HOMO-1 da molécula ocasiona uma transferência de carga no sistema logo nos primeiros picos de absorção, além de outra clara transferência de carga relacionada à excitação exclusiva da molécula. Ora, é extremamente interessante notar a presença dessa excitação com transferência de carga, envolvendo o estado HOMO-1 da molécula, ocorrendo na energia do gap do óxido.

O sistema de ácido retinóico sobre $\mathrm{TiO}_{2}$, por sua vez, apresentou propriedades completamente diferentes daquelas dos sistemas isolados. Devido à ligação química direta covalente dos átomos de superfície do óxido à estrutura conjugada da molécula, verificamos que a montagem passa a absorver luz a energias menores que as energias em que absorvem individualmente ambos os sistemas isolados, em praticamente todo o espectro visível. Em energias próximas à da excitação da molécula isolada foi obtido um forte pico de absorção, que está relacionado à transferência de carga molécula $\rightarrow$ óxido.

Finalmente, vemos que o estudo combinado, utilizando diferentes técnicas e metodologias, nos permite uma visão mais ampla e detalhada dos processos relevantes que ocorrem em células solares híbridas orgânico/inorgânico, representando um importante passo para o desenvolvimento de materiais para fotocolheita. 


\section{Referências Bibliográficas}

[1] ANEEL, "Matriz de energia elétrica." http://archive.is/8r8Fg, 2013. Online, arquivado em $21 / 01 / 2013$.

[2] REN21, "Renewables 2012 global status report."

http://wWw.map.ren21.net/GSR/GSR2012.pdf, 2012. Online, consultado em $21 / 01 / 2013$.

[3] M. Green, "Photovoltaics: technology overview," Energy Policy 28 (2000) 989-998.

[4] M. Yamaguchi, "Present status and prospects of photovoltaic technologies in Japan," Renewable and Sustainable Energy Reviews 5 (2001) 113-135.

[5] J. M. Kroon, N. J. Bakker, H. J. P. Smit, P. Liska, K. R. Thampi, P. Wang, S. M. Zakeeruddin, M. Grätzel, A. Hinsch, S. Hore, U. Würfel, R. Sastrawan, J. R. Durrant, E. Palomares, H. Pettersson, T. Gruszecki, J. Walter, K. Skupien, e G. E. Tulloch, "Nanocrystalline dye-sensitized solar cells having maximum performance," Progress in Photovoltaics: Research and Applications 15 (2007) 1-18.

[6] R. E. World, "Solar junction does it again, sets new cpv efficiency record." http://archive.is/c6APW, 2012. Online, arquivado em 22/01/2013.

[7] N. Espinosa, M. Hösel, D. Angmo, e F. C. Krebs, "Solar cells with one-day energy payback for the factories of the future," Energy $\&$ Environmental Science 5 (2012), no. 1,5117 .

[8] M. Grätzel, "Photoelectrochemical cells.," Nature 414 (2001) 338-44.

[9] G. Phani, G. Tulloch, D. Vittorio, e I. Skryabin, "Titania solar cells: new photovoltaic technology," Renewable Energy 22 (2001) 303-309. 
[10] M. Grätzel, "Solar energy conversion by dye-sensitized photovoltaic cells.," Inorganic chemistry 44 (2005) 6841-51.

[11] M. Sahyun e N. Serpone, "Photophysics of all-trans-retinoic acid (ATRA) chemisorbed to nanoparticulate $\mathrm{TiO}_{2}$ : Evidence for $\mathrm{TiO}_{2}{ }^{*}$ to ATRA energy transfer and reverse electron transfer sensitisation," Journal of Photochemistry and Photobiology A: Chemistry 115 (1998) 231-238.

[12] F. G. Gao, A. J. Bard, e L. D. Kispert, "Photocurrent generated on a carotenoid-sensitized $\mathrm{TiO}_{2}$ nanocrystalline mesoporous electrode," Journal of Photochemistry and Photobiology A: Chemistry 130 (2000) 49-56.

[13] J. Pan, G. Benkö, Y. Xu, T. Pascher, L. Sun, V. Sundström, e T. Polívka, "Photoinduced Electron Transfer between a Carotenoid and $\mathrm{TiO}_{2}$ Nanoparticle," Journal of the American Chemical Society 124 (2002) 13949-13957.

[14] Y.-X. Weng, L. Li, Y. Liu, L. Wang, G.-Z. Yang, e J.-Q. Sheng, "Interfacial charge recombination via the triplet state? Mimicry of photoprotection in the photosynthetic process with a dye-sensitized $\mathrm{TiO}_{2}$ solar cell reaction," Chemical Physics Letters 355 (2002) 294-300.

[15] L. Zhang, J. Yang, L. Wang, G.-Z. Yang, e Y.-X. Weng, "Direct Observation of Interfacial Charge Recombination to the Excited-Triplet State in All-trans-Retinoic Acid Sensitized $\mathrm{TiO}_{2}$ Nanoparticles by Femtosecond Time-Resolved Difference Absorption Spectroscopy," The Journal of Physical Chemistry B 107 (2003) 13688-13697.

[16] A. Petrella, P. D. Cozzoli, M. L. Curri, M. Striccoli, P. Cosma, e A. Agostiano, "Photoelectrochemical study on photosynthetic pigments-sensitized nanocrystalline ZnO films.," Bioelectrochemistry 63 (2004) 99-102.

[17] "Wikipedia - titanium dioxide." http://en.wikipedia.org/wiki/Titanium_dioxide. Visualizado em 15/02/2013.

[18] A. S. Barnard e P. Zapol, "Effects of particle morphology and surface hydrogenation on the phase stability of $\mathrm{TiO}_{2}, "$ Physical Review B 70 (2004) 1-13. 
[19] F. D. Brandão, M. V. B. Pinheiro, G. M. Ribeiro, G. Medeiros-Ribeiro, e K. Krambrock, "Identification of two light-induced charge states of the oxygen vacancy in single-crystalline rutile $\mathrm{TiO}_{2}$," Physical Review B $8 \mathbf{0 0}$ (2009) 235204.

[20] A. Vittadini, M. Casarin, e A. Selloni, "Chemistry of and on $\mathrm{TiO}_{2}$-anatase surfaces by DFT calculations: a partial review," Theoretical Chemistry Accounts 117 (2006) 663-671.

[21] U. Diebold, "The surface science of titanium dioxide," Surface Science Reports 48 (2003) 53-229.

[22] Q. Xiang, K. Lv, e J. Yu, "Pivotal role of fluorine in enhanced photocatalytic activity of anatase $\mathrm{TiO}_{2}$ nanosheets with dominant (001) facets for the photocatalytic degradation of acetone in air," Applied Catalysis B: Environmental 96 (2010) $557-564$.

[23] T. Polívka e V. Sundström, "Ultrafast dynamics of carotenoid excited states-from solution to natural and artificial systems.," Chemical reviews 104 (2004) 2021-71.

[24] R. Argazzi, N. Y. Murakami Iha, H. Zabri, F. Odobel, e C. A. Bignozzi, "Design of molecular dyes for application in photoelectrochemical and electrochromic devices based on nanocrystalline metal oxide semiconductors," Coordination Chemistry Reviews 248 (2004) 1299-1316.

[25] J. Linnanto e J. Korppi-Tommola, "Quantum chemical simulation of excited states of chlorophylls, bacteriochlorophylls and their complexes.," Physical Chemistry Chemical Physics : PCCP 8 (2006) 663-87.

[26] A. Dreuw, "Influence of geometry relaxation on the energies of the S1 and S2 states of violaxanthin, zeaxanthin, and lutein.," The journal of physical chemistry. A $\mathbf{1 1 0}$ (2006) 4592-9.

[27] T. Yakhanthip, S. Jungsuttiwong, S. Namuangruk, N. Kungwan, V. Promarak, T. Sudyoadsuk, e P. Kochpradist, "Theoretical investigation of novel carbazole-fluorene based D- $\pi$-A conjugated organic dyes as dye-sensitizer in dye-sensitized solar cells (DSCs).," Journal of computational chemistry 32 (2011) $1568-76$. 
[28] B. Durbeej e L. A. Eriksson, "Protein-bound chromophores astaxanthin and phytochromobilin: excited state quantum chemical studies.," Physical chemistry chemical physics : PCCP 8 (2006) 4053-71.

[29] H. M. Vaswani, C.-P. Hsu, M. Head-Gordon, e G. R. Fleming, "Quantum Chemical Evidence for an Intramolecular Charge-Transfer State in the Carotenoid Peridinin of Peridinin-Chlorophyll-Protein," The Journal of Physical Chemistry B 107 (2003) $7940-7946$.

[30] P. Tarakeshwar, D. Finkelstein-Shapiro, T. Rajh, e V. Mujica, "Quantum confinement effects on the surface enhanced Raman spectra of hybrid systems molecule- $\mathrm{TiO}_{2}$ nanoparticles," International Journal of Quantum Chemistry 111 (2011) 1659-1670.

[31] N. Marom, J. Moussa, X. Ren, A. Tkatchenko, e J. Chelikowsky, "Electronic structure of dye-sensitized $\mathrm{TiO}_{2}$ clusters from many-body perturbation theory," Physical Review B 84 (2011) 1-15.

[32] M. Vega-Arroyo, P. R. LeBreton, T. Rajh, P. Zapol, e L. A. Curtiss, "Density functional study of the $\mathrm{TiO}_{2}$-dopamine complex," Chemical Physics Letters 406 (2005) 306-311.

[33] T. Homann, T. Bredow, e K. Jug, "Adsorption of small molecules on the anatase(100) surface," Surface Science 555 (2004) 135-144.

[34] H. S. Wahab, T. Bredow, e S. M. Aliwi, "MSINDO quantum chemical modeling study of water molecule adsorption at nano-sized anatase $\mathrm{TiO}_{2}$ surfaces," Chemical Physics 354 (2008) 50-57.

[35] B. S. Ong, Y. Wu, P. Liu, e S. Gardner, "Structurally Ordered Polythiophene Nanoparticles for High-Performance Organic Thin-Film Transistors," Advanced Materials 17 (2005) 1141-1144.

[36] D. R. Hartree, "The Wave Mechanics of an Atom with a Non-Coulomb Central Field. Part I. Theory and Methods," Mathematical Proceedings of the Cambridge Philosophical Society 24 (2008) 89. 
[37] V. Fock, "Näherungsmethode zur Losung des quantenmechanischen Mehrkörperprobleme," Z. Phys 61 (1930) 126-148.

[38] T. Koopmans, "Über die Zuordnung von Wellenfunktionen und Eigenwerten zu den Einzelnen Elektronen Eines Atoms," Physica 1 (1934) 104-113.

[39] L. H. Thomas, "The calculation of atomic fields," Mathematical Proceedings of the Cambridge Philosophical Society 23 (1927) 542.

[40] E. Fermi, "Statistical method to determine some properties of atoms," Rend. Accad. Naz. Lincei 6 (1927) 602-607.

[41] J. Slater, "A Simplification of the Hartree-Fock Method," Physical Review 81 (1951) 385-390.

[42] P. Hohenberg e W. Kohn, "Inhomogeneous Electron Gas," Physical Review 136 (1964) B864-B871.

[43] W. Kohn e L. J. Sham, "Self-Consistent Equations Including Exchange and Correlation Effects," Physical Review 140 (1965) 1133-1138.

[44] J. P. Perdew e A. Zunger, "Self-interaction correction to density-functional approximations for many-electron systems," Physical Review B 23 (1981) 5048-5079.

[45] D. M. Ceperley e B. J. Alder, "Ground State of the Electron Gas by a Stochastic Method," Physical Review Letters 45 (1980) 566-569.

[46] J. P. Perdew, K. A. Jackson, M. R. Pederson, D. J. Singh, e C. Fiolhais, "Atoms, molecules, solids, and surfaces: Applications of the generalized gradient approximation for exchange and correlation," Physical Review B 46 (1992) 6671-6687.

[47] J. P. Perdew, K. Burke, e M. Ernzerhof, "Generalized Gradient Approximation Made Simple," Physical Review Letters 77 (1996) 3865-3868.

[48] J. Janak, "Proof that $\partial \mathrm{E} / \partial \mathrm{n}_{i}=\epsilon$ in density-functional theory," Physical Review B 18 (1978) 7165-7168. 
[49] A. Görling, "Density-functional theory for excited states," Physical Review A $\mathbf{5 4}$ (1996) 3912-3915.

[50] J. P. Perdew, R. G. Parr, M. Levy, e J. L. Balduz, "Density-Functional Theory for Fractional Particle Number: Derivative Discontinuities of the Energy," Physical Review Letters 49 (1982) 1691-1694.

[51] S. Kümmel e L. Kronik, "Orbital-dependent density functionals: Theory and applications," Reviews of Modern Physics 80 (2008) 3-60.

[52] A. D. Becke, "A new mixing of Hartree-Fock and local density-functional theories," The Journal of Chemical Physics 98 (1993) 1372.

[53] J. P. Perdew, M. Ernzerhof, e K. Burke, "Rationale for mixing exact exchange with density functional approximations," The Journal of Chemical Physics 105 (1996) 9982 .

[54] V. Atalla, M. Yoon, F. Caruso, P. Rinke, e M. Scheffler A ser publicado.

[55] J. M. Pinheiro Jr, M. J. Caldas, P. Rinke, V. Blum, e M. Scheffler A ser publicado.

[56] J. Heyd, G. E. Scuseria, e M. Ernzerhof, "Hybrid functionals based on a screened Coulomb potential," The Journal of Chemical Physics 118 (2003) 8207.

[57] J. Heyd, G. E. Scuseria, e M. Ernzerhof, "Erratum: "Hybrid functionals based on a screened Coulomb potential" [J. Chem. Phys. 118, 8207 (2003)]," The Journal of Chemical Physics 124 (2006) 219906.

[58] M. J. Frisch, G. W. Trucks, H. B. Schlegel, et al., "Gaussian 03, Revision E.01." Gaussian, Inc., Wallingford, CT, 2004.

[59] I. Gadaczek, K. Krause, K. J. Hintze, e T. Bredow, "MSINDO-sCIS: A New Method for the Calculation of Excited States of Large Molecules," Journal of Chemical Theory and Computation 7 (2011) 3675-3685.

[60] J. M. Soler, E. Artacho, J. D. Gale, A. García, J. Junquera, P. Ordejón, e D. Sánchez-Portal, "The SIESTA method for ab initio order- N materials simulation," Journal of Physics: Condensed Matter 14 (2002) 2745-2779. 
[61] V. Blum, R. Gehrke, F. Hanke, P. Havu, V. Havu, X. Ren, K. Reuter, e M. Scheffler, "Ab initio molecular simulations with numeric atom-centered orbitals," Computer Physics Communications 180 (2009) 2175-2196.

[62] X. Gonze, B. Amadon, P.-M. Anglade, et al., "ABINIT: First-principles approach to material and nanosystem properties," Computer Physics Communications $\mathbf{1 8 0}$ (2009) 2582-2615.

[63] P. Giannozzi, S. Baroni, N. Bonini, et al., "QUANTUM ESPRESSO: a modular and open-source software project for quantum simulations of materials.," Journal of physics. Condensed matter : an Institute of Physics journal 21 (2009) 395502.

[64] C. Roothaan, "New Developments in Molecular Orbital Theory," Reviews of Modern Physics 23 (1951) 69-89.

[65] R. J. Baierle, Propriedades Estruturais e Óticas de Nanopartículas de Silício. Tese de doutorado, Universidade de São Paulo, 1997.

[66] M. Zerner, "Removal of core orbitals in 'valence orbital only' calculations," Molecular Physics 23 (1972) 963-978.

[67] R. Pariser e R. G. Parr, "A Semi-Empirical Theory of the Electronic Spectra and Electronic Structure of Complex Unsaturated Molecules. I.," The Journal of Chemical Physics 21 (1953) 466.

[68] J. A. Pople, D. P. Santry, e G. A. Segal, "Approximate Self-Consistent Molecular Orbital Theory. I. Invariant Procedures," The Journal of Chemical Physics 43 (1965) S129.

[69] J. A. Pople, "Approximate Self-Consistent Molecular-Orbital Theory. V. Intermediate Neglect of Differential Overlap," The Journal of Chemical Physics 47 (1967) 2026.

[70] T. Bredow e K. Jug, "Theory and range of modern semiempirical molecular orbital methods," Theoretical Chemistry Accounts 113 (2004) 1-14.

[71] M. J. S. Dewar e W. Thiel, "Ground states of molecules. 38. The MNDO method. Approximations and parameters," Journal of the American Chemical Society 99 (1977) 4899-4907. 
[72] M. J. S. Dewar, E. G. Zoebisch, E. F. Healy, e J. J. P. Stewart, "Development and use of quantum mechanical molecular models. 76. AM1: a new general purpose quantum mechanical molecular model," Journal of the American Chemical Society 107 (1985) 3902-3909.

[73] P. Coffey e K. Jug, "Semiempirical Molecular Orbital Calculations and Molecular Energies. A New Formula for the $\beta$ Parameter," Journal of the American Chemical Society 95 (1973) 7575-7580.

[74] D. N. Nanda e K. Jug, "SINDO1. A semiempirical SCF MO method for molecular binding energy and geometry I. Approximations and parametrization," Theoretica Chimica Acta 57 (1980) 95-106.

[75] J. Ridley e M. Zerner, "An intermediate neglect of differential overlap technique for spectroscopy: Pyrrole and the azines," Theoretica Chimica Acta 32 (1973) 111-134.

[76] P. E. Blöchl, "Projector augmented-wave method," Physical Review B 50 (1994) 17953-17979.

[77] T. Takeda e J. Kubler, "Linear augmented plane wave method for self-consistent calculations," Journal of Physics F: Metal Physics 9 (1979) 661-672.

[78] N. Troullier e J. L. Martins, "Efficient pseudopotentials for plane-wave calculations," Physical Review B 43 (1991) 1993-2006.

[79] A. Rappe, K. Rabe, E. Kaxiras, e J. Joannopoulos, "Optimized pseudopotentials," Physical Review B 41 (1990) 1227-1230.

[80] L. Kleinman e D. Bylander, "Efficacious Form for Model Pseudopotentials," Physical Review Letters 48 (1982) 1425-1428.

[81] P. E. Blöchl, "Generalized separable potentials for electronic-structure calculations," Physical Review B 41 (1990) 5414-5416.

[82] R. Feynman, "Forces in Molecules," Physical Review 56 (1939) 340-343.

[83] L. Ferreira, M. Marques, e L. K. Teles, "Approximation to density functional theory for the calculation of band gaps of semiconductors," Physical Review B 78 (2008) 125116. 
[84] C. Møller e M. S. Plesset, "Note on an Approximation Treatment for Many-Electron Systems," Physical Review 46 (1934) 618-622.

[85] J. Kohanoff, Electronic Structure Calculations for Solids and Molecules. Cambridge University Press, 2006.

[86] C. Cocchi, D. Prezzi, A. Ruini, M. J. Caldas, e E. Molinari, "Optical Properties and Charge-Transfer Excitations in Edge-Functionalized All-Graphene Nanojunctions," The Journal of Physical Chemistry Letters 2 (2011) 1315-1319.

[87] B. Ahlswede e K. Jug, "Consistent modifications of SINDO1: I. Approximations and parameters," Journal of Computational Chemistry 20 (1999) 563-571.

[88] T. Bredow, G. Geudtner, e K. Jug, "MSINDO parameterization for third-row transition metals," Journal of Computational Chemistry 22 (2001) 861-887.

[89] P. Deák, "Cyclic cluster models with quantum-chemical hamiltonians," Acta Physica Academiae Scientiarum Hungaricae 50 (1981) 247-262.

[90] P. Deák, "Choosing Models for Solids," physica status solidi (b) 217 (2000) 9-21.

[91] T. Bredow, G. Geudtner, e K. Jug, "Development of the cyclic cluster approach for ionic systems," Journal of Computational Chemistry 22 (2001) 89-101.

[92] I. Gadaczek, K. J. Hintze, e T. Bredow, "Periodic calculations of excited state properties for solids using a semiempirical approach.," Physical chemistry chemical physics : PCCP 14 (2012) 741-50.

[93] M. J. Caldas, J. R. Leite, e A. Fazzio, "Theoretical Study of the Si-A Centre," physica status solidi (b) 98 (1980) K109-K111.

[94] R. J. Baierle e M. J. Caldas, "Quantum-Chemistry study of semiconductor systems: The initial oxidation of the (111)Si-H surface," International Journal of Modern Physics B 13 (1999) 2733-2757.

[95] F. Aryasetiawan e O. Gunnarsson, "The GW method," Reports on Progress in Physics 61 (1998) 237-312. 
[96] C. Friedrich e A. Schindlmayr, Many-Body Perturbation Theory: The GW Approximation, vol. 31 of Computational Nanoscience: Do It Yourself!, pp. 335-355. NIC Series, 2006.

[97] L. Hedin e S. Lundqvist, "Effects of Electron-Electron and Electron-Phonon Interactions on the One-Electron States of Solids," Solid State Physics 23 (1970) $1-181$.

[98] A. Marini, C. Hogan, M. Grüning, e D. Varsano, "yambo: An ab initio tool for excited state calculations," Computer Physics Communications 180 (2009) 1392-1403.

[99] L. Martin-Samos e G. Bussi, "SaX: An open source package for electronic-structure and optical-properties calculations in the GW approximation," Computer Physics Communications 180 (2009), no. 8, 1416-1425.

[100] D. T. Cromer e K. Herrington, "The Structures of Anatase and Rutile," Journal of the American Chemical Society 77 (1955) 4708-4709.

[101] A. Bifone, H. J. de Groot, e F. Buda, "Ab initio molecular dynamics of retinals," Chemical Physics Letters 248 (1996) 165-172.

[102] T. Hamanaka, T. Mitsui, T. Ashida, e M. Kakudo, "The crystal structure of all-trans retinal," Acta Crystallographica Section B Structural Crystallography and Crystal Chemistry 28 (1972) 214-222.

[103] Accelrys, "Materials Studio, release 4.1," 2006.

[104] A. Vittadini, A. Selloni, F. P. Rotzinger, e M. Grätzel, "Formic Acid Adsorption on Dry and Hydrated $\mathrm{TiO}_{2}$ Anatase (101) Surfaces by DFT Calculations," The Journal of Physical Chemistry B 104 (2000) 1300-1306.

[105] L. Brus, "Electronic wave functions in semiconductor clusters: experiment and theory," The Journal of Physical Chemistry 90 (1986) 2555-2560.

[106] H. Peng e J. Li, "Quantum Confinement and Electronic Properties of Rutile $\mathrm{TiO}_{2}$ Nanowires," The Journal of Physical Chemistry C 112 (2008) 20241-20245. 
[107] A. Hmiel e Y. Xue, "Quantum confinement and surface relaxation effects in rutile $\mathrm{TiO}_{2}$ nanowires," Physical Review B 85 (2012) 235461.

[108] M. Palummo, G. Giorgi, L. Chiodo, A. Rubio, e K. Yamashita, "The nature of radiative transitions in $\mathrm{tio}_{2}$-based nanosheets," The Journal of Physical Chemistry C 116 (2012) 18495-18503.

[109] F. Labat, P. Baranek, C. Domain, C. Minot, e C. Adamo, "Density functional theory analysis of the structural and electronic properties of $\mathrm{TiO}_{2}$ rutile and anatase polytypes: performances of different exchange-correlation functionals.," The Journal of chemical physics 126 (2007) 154703.

[110] B. Lee, C.-K. Lee, C. S. Hwang, e S. Han, "Influence of exchange-correlation functionals on dielectric properties of rutile $\mathrm{TiO}_{2}, "$ Current Applied Physics 11 (2011) S293-S296.

[111] M. Jain, J. Chelikowsky, e S. Louie, "Reliability of Hybrid Functionals in Predicting Band Gaps," Physical Review Letters 107 (2011) 1-5.

[112] L. Martin-Samos, G. Bussi, A. Ruini, E. Molinari, e M. J. Caldas, " $\mathrm{SiO}_{2}$ in density functional theory and beyond," physica status solidi (b) 248 (2011) 1061-1066.

[113] L. Chiodo, J. M. García-Lastra, A. Iacomino, S. Ossicini, J. Zhao, H. Petek, e A. Rubio, "Self-energy and excitonic effects in the electronic and optical properties of $\mathrm{TiO}_{2}$ crystalline phases," Physical Review B 82 (2010) 1-12.

[114] X. Blase, C. Attaccalite, e V. Olevano, "First-principles GW calculations for fullerenes, porphyrins, phtalocyanine, and other molecules of interest for organic photovoltaic applications," Physical Review B 83 (2011) 115103.

[115] G. Baraff e M. Schlüter, "Migration of interstitials in silicon," Physical Review B 30 (1984) 3460-3469.

[116] A. Ruini, M. J. Caldas, G. Bussi, e E. Molinari, "Solid State Effects on Exciton States and Optical Properties of PPV," Physical Review Letters 88 (2002) 206403. 
[117] F. Flores, J. Ortega, e H. Vázquez, "Modelling energy level alignment at organic interfaces and density functional theory.," Physical chemistry chemical physics : PCCP 11 (2009) 8658-75.

[118] J. Wan, M. Hada, M. Ehara, e H. Nakatsuji, "Electronic excitation spectrum of thiophene studied by symmetry-adapted cluster configuration interaction method," The Journal of Chemical Physics 114 (2001) 842.

[119] J. L. Bredas, R. Silbey, D. S. Boudreaux, e R. R. Chance, "Chain-length dependence of electronic and electrochemical properties of conjugated systems: polyacetylene, polyphenylene, polythiophene, and polypyrrole," Journal of the American Chemical Society 105 (1983) 6555-6559.

[120] Y. Tsujiuchi, H. Masumoto, e T. Goto, "Visible Absorption Properties of Retinoic Acid Controlled on Hydrogenated Amorphous Silicon Thin Film," Japanese Journal of Applied Physics 47 (2008) 1211-1214.

[121] H. Tang, H. Berger, P. E. Schmid, e F. Lévy, "Photoluminescence in $\mathrm{TiO}_{2}$ anatase single crystals," Solid State Communications 87 (1993) 847-850.

[122] W. Kang e M. S. Hybertsen, "Quasiparticle and optical properties of rutile and anatase $\mathrm{TiO}_{2}, "$ Physical Review B $\mathbf{8 2}$ (2010) 085203.

[123] G. Giorgi, M. Palummo, L. Chiodo, e K. Yamashita, "Excitons at the (001) surface of anatase: Spatial behavior and optical signatures," Physical Review B 84 (2011) 2-5.

[124] B. Liu, L. Wen, e X. Zhao, "The photoluminescence spectroscopic study of anatase $\mathrm{TiO}_{2}$ prepared by magnetron sputtering," Materials Chemistry and Physics 106 (2007) 350-353.

[125] M. A. dos Santos, Estudo Atomistico da Formação de Interfaces Orgânico-Inorgânico: Tiofenos sobre Óxido de Titânio. Tese de doutorado, Universidade de São Paulo, 2007. 